\title{
Cross-Coupling Reactions of Alkenylsilanolates: Investigation of the Mechanism and Identification of Key Intermediates through Kinetic Analysis
}

\author{
Scott E. Denmark* and Ramzi F. Sweis \\ Roger Adams Laboratory, Department of Chemistry, University of Illinois, Urbana, Illinois, \\ 61801

\section{SUPPORTING INFORMATION}

\section{General Experimental}

All reactions were performed in oven $\left(180^{\circ} \mathrm{C}\right)$ and/or flame dried glassware under an atmosphere of dry argon. All reaction temperatures corresponded to internal temperatures unless otherwise noted. All kinetic runs were run at $23{ }^{\circ} \mathrm{C} \pm 1{ }^{\circ} \mathrm{C}$ (ambient temperature). All the solvents used were technical grade and distilled from the indicated drying agents: dichloromethane: $\mathrm{P}_{2} \mathrm{O}_{5}$; diethyl ether and tetrahydrofuran: $\mathrm{Na}$, benzophenone; pentane, hexane, dimethylformamide, and dimethoxyethane: $\mathrm{CaH}_{2}$; methanol: $\mathrm{Mg}(\mathrm{OMe})_{2}$; ethyl acetate: $\mathrm{K}_{2} \mathrm{CO}_{3}$. "Brine" refers to a saturated solution of $\mathrm{NaCl}$. Bulb-to-bulb distillations were performed on a Büchi GKR-50 Kugelrohr and boiling points (bp) correspond to the uncorrected recorded air bath temperatures (ABT).

${ }^{1} \mathrm{H}$ and ${ }^{13} \mathrm{C}$ NMR were recorded on a Varian Unity-500 $\left(500 \mathrm{MHz}{ }^{1} \mathrm{H}, 126 \mathrm{MHz}{ }^{13} \mathrm{C}\right)$ spectrometer in THF- $d_{8}$ using it as an internal reference $\left(1.73,3.58 \mathrm{ppm},{ }^{1} \mathrm{H} ; 25.4,67.6 \mathrm{ppm}\right.$, $\left.{ }^{13} \mathrm{C}\right)$. Chemical shifts are reported in $\operatorname{ppm}(\delta)$; multiplicities are indicated by $\mathrm{s}$ (singlet), $\mathrm{d}$ (doublet), q (quartet), qn (quintet), sext (sextet), m (multiplet), and br (broad). Coupling constants, $J$, are reported in Hertz $(\mathrm{Hz})$; integration is provided; and assignments are indicated.

Column chromatography was performed using 230-400 mesh silica gel purchased from EM Science or 230-400 mesh C18 Reverse Phase (RP) silica gel purchased from Fluka.

Analytical gas chromatography (GC) was performed using a Hewlett Packard 5890 Series II Gas Chromatograph fitted with a flame ionization detector. Injections were made on a Hewlett-Packard HP-5 (50 meter) capillary column. The injector temperature was $225^{\circ} \mathrm{C}$, the detector temperature was $300^{\circ} \mathrm{C}$, with a split ratio of 100:1. Retention times $\left(t_{R}\right)$ and integrated 
ratios were obtained using Agilent Chemstation Software. Sample injections were made using an HP 6890 Series Autosampler Injector. Kinetic analysis was made by plotting conversion over time. Conversion was calculated by the relative integrations of the signals from the product and an internal standard, biphenyl. The slope of obtained from the conversion vs. time plots was calculated as the initial rate.

Potassium hydride was provided from Aldrich as in immersion in oil. This was washed with hexane 3-5 times to remove the mineral oil. The oil and solvent-free $\mathrm{KH}$ was stored under nitrogen.

\section{Literature Preparations}

$(E)$-Dimethyl-(1-heptenyl)silanol $(E)-\mathbf{1},{ }^{1} \quad(E \quad)$-2-(1-heptenyl)thiophene ${ }^{1} \quad$ and bis(dibenzylideneacetone)palladium $(0)^{2}$ were prepared by literature methods.

\section{Kinetics Experiments}

Each entry in the kinetics portion of the Table of Contents refers to a set of six (6) pages describing triplicate runs of the same experiment. Each individual run is entered on two (2) pages, the first describes the procedure in detail along with the data fit, and the second is a tabular listing of the raw data. 
Preparation of a Solution of $\mathrm{K}^{+}(E)-1^{-}$in DME.

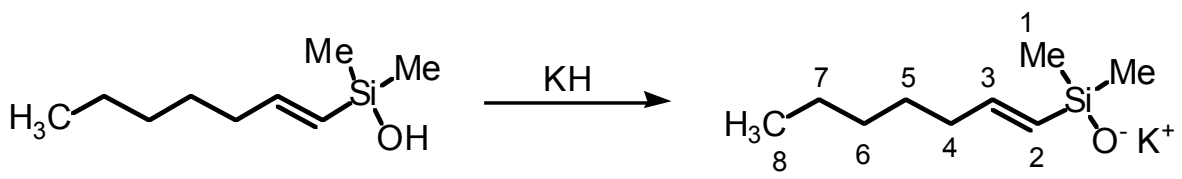

To a suspension of potassium hydride (1.16 g, $29.0 \mathrm{mmol}, 2.00$ equiv) in THF (15 mL) was added silanol $(E)-1(2.50 \mathrm{~g}, 14.5 \mathrm{mmol})$ dropwise over $15 \mathrm{~min}$. The resultant mixture was stirred for 20 min further, and then added via syringe into 2 vials previously purged with argon. The vials were then centrifuged for 10 minutes, and the supernatant was removed via syringe, with care taken not to disturb the excess $\mathrm{KH}$ and $\mathrm{KOH}$ precipitate at the bottom of the vials. The supernatant was then placed in a pre-weighed argon-purged 1-neck round-bottom flask containing a magnetic stir bar. The solution was then stirred under vacuum to slowly remove all the solvent. After $\sim 30 \mathrm{~min}$, all the solvent was removed leaving an off-white pasty solid residue (2.94 g, 96\%) which was analyzed by ${ }^{1} \mathrm{H}$ NMR and determined to be $\mathrm{K}^{+}(E)-\mathbf{1}^{-}$. To this solid was then immediately added $28 \mathrm{~mL}$ of DME and the solution was stirred for $\sim 10$ minutes until all the solid dissolved. The resultant $0.5 \mathrm{M}$ solution was transferred via cannula into a Schlenk bottle and was stored at $-20{ }^{\circ} \mathrm{C}$ when not in use. The exact concentration of the silanolate was checked via a titration method described in the next procedure.

\section{Data for $\mathrm{K}^{+}(E)-\mathbf{1}^{-}$:}

${ }^{1}$ H NMR: $(500 \mathrm{MHz}, \mathrm{THF})$

$5.89(\mathrm{dt}, J=18.2,6.3, \mathrm{HC}(3), 1 \mathrm{H}) ; 5.63(\mathrm{~d}, J=18.2,1.5, \mathrm{HC}(2), 1 \mathrm{H}) ; 2.05$ (qd, $J=6.3$, $1.5, \mathrm{HC}(4), 2 \mathrm{H}) ; 1.33(\mathrm{~m}, \mathrm{HC}(5), \mathrm{HC}(6)$ and $\mathrm{HC}(7), 6 \mathrm{H}) ; 0.90(\mathrm{t}, J=6.9, \mathrm{HC}(8), 3 \mathrm{H})$; -0.13 (s, HC(1), $3 \mathrm{H})$.

${ }^{13}$ C NMR: (126 MHz, THF)

142.8 (C(3)), $56.0(\mathrm{C}(2)), 37.6(\mathrm{C}(4)), 32.4(\mathrm{C}(5)), 29.7(\mathrm{C}(6)), 23.3(\mathrm{C}(7)), 14.4(\mathrm{C}(8))$, $3.8(\mathrm{C}(1))$. 


\section{Method for Titration of $\mathrm{K}^{+}(E)-1^{-}$Solution}

To $0.2 \mathrm{~mL}$ of glacial acetic acid was added $100 \square \mathrm{L}$ of the silanolate solution and $5.0 \mathrm{mg}$ of biphenyl. Solid potassium acetate was immediately formed. This was then filtered through a silica gel-packed pipette with $2 \mathrm{~mL}$ of diethyl ether. The resultant eluent was then injected into the GC. This process was repeated three times. The amount of $(E)-\mathbf{1}$ formed was calculated by the relative peak area integrations of the internal standard, biphenyl $(\mathbf{A})$, and $(E)-\mathbf{1}$ corrected according to the response factor (calculated below).

$\mathrm{t} R(E)-1: \quad 4.82 \mathrm{~min}$.

$\mathrm{t}_{R}(\mathbf{A}): \quad 6.90 \mathrm{~min}$.

\begin{tabular}{cccc} 
area A & area $(E)-\mathbf{1}$ & mg A & calculated conc. of solution (M) \\
\hline 20285 & 19322 & 5.0 & 0.476 \\
20410 & 19253 & 5.0 & 0.471 \\
19437 & 18425 & 5.0 & 0.474
\end{tabular}

average $0.474 \mathrm{M}$

Determination of the correlation factor of $(E)-1$ and Biphenyl (A).

Stock solutions of containing a mixture of $(E)-\mathbf{1}$ and $\mathrm{A}$ in the proportions labeled in columns 1 and 2 were prepared by dilution with THF to $1.0 \mathrm{~mL}$. These samples were injected into the GC three times. The areas of each component are listed in columns 3 and 4 . The resultant mass response factor was calculated by the following equation:

Response factor $=(\operatorname{mg} \mathbf{1} *$ area $\mathbf{A}) /(\operatorname{area} \mathbf{1} * \operatorname{mg~\mathbf {A}})$

\begin{tabular}{c|c|c|c|c}
\hline $\operatorname{mg}(E)-\mathbf{1}$ & area $(E)-\mathbf{1}$ & $\mathrm{mg} \mathbf{A}$ & area A & response factor \\
\hline 5 & 49978 & 5 & 86235 & 1.73 \\
5 & 49401 & 5 & 85776 & 1.74 \\
5 & 45126 & 5 & 78925 & 1.75 \\
10 & 87356 & 2.5 & 37453 & 1.71 \\
10 & 89643 & 2.5 & 38445 & 1.72 \\
10 & 94233 & 2.5 & 40932 & 1.74 \\
2.5 & 21842 & 10 & 148045 & 1.69 \\
2.5 & 20310 & 10 & 135788 & 1.67 \\
2.5 & 20016 & 10 & 137004 & 1.71 \\
\hline
\end{tabular}

average 1.72 


\section{General Procedure for the Kinetic Measurements}

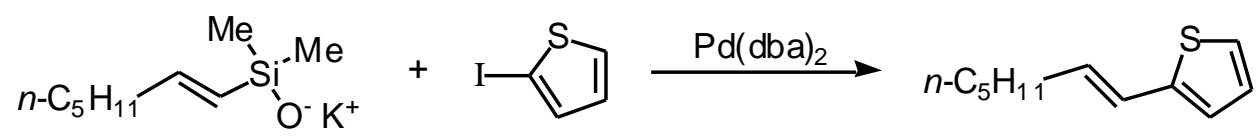

A pre-prepared solution of $\mathrm{K}^{+}(E)-1^{-}(0.5 \mathrm{M}$ in DME) was added to a flame-dried 2-neck, round-bottomed flask under argon. Dry DME was added to adjust the total volume depending on the desired concentration. The internal standard, biphenyl, and 2-iodothiophene were then added, and the reaction was stirred for $1 \mathrm{~min}$. The flask was immersed into a water-bath as necessary to ensure the internal temperature was adjusted to $23^{\circ} \mathrm{C} \pm 1^{\circ} \mathrm{C}$. A suspension of bis(dibenzylideneacetone)palladium in $1.0 \mathrm{~mL}$ of dry DME was then added. The dark red solution slowly turned turbid over time as the precipitation of KI proceeded. Aliquots $(200 \mu \mathrm{L})$ were removed and quenched after $0.33,0.66,1.0,1.33,1.66,2.0,2.5,3.0,4,5,7$, and $10 \mathrm{~min}$. The quench was performed as follows: the withdrawn aliquot of the reaction mixture was injected into an aqueous $20 \%$ solution of 2-dimethylaminoethanethiol hydrochloride. This colorless to yellow clear solution was filtered through a plug of silica gel. The plug was washed with diethyl ether to adjust the total sample volume to $\sim 2 \mathrm{~mL}$. This sample was subjected for GC analysis. All injections were made in triplicate and the progress of the coupling was monitored as a molar conversion.

Retention times (HP 5, 200 $\mathrm{C}, 15 \mathrm{psi})$ :

$t_{R}(\mathbf{A}): 7.00 \mathrm{~min}$.

$t_{R}((E)-2): 7.41 \mathrm{~min}$. 


\section{INDEX OF KINETIC EXPERIMENTS}

Page number

Order in 2-Iodothiophene

$25 \mathrm{mM}(0.5$ equiv $)$
$50 \mathrm{mM}(1.0$ equiv $)$
$100 \mathrm{mM}(2.0$ equiv $)$

Order in Palladium

$2.5 \mathrm{mM}(5 \mathrm{~mol} \%)$
$5 \mathrm{mM}(10 \mathrm{~mol} \%)$
$10 \mathrm{mM}(20 \mathrm{~mol} \%)$

Order in silanolate $\mathrm{K}^{+}(E)-\mathbf{1}^{-}$(with 0.05 equiv $\mathrm{Pd}(\mathrm{dba})_{2}$ )

$25 \mathrm{mM}(0.5$ equiv $)$
$31.25 \mathrm{mM}(0.63$ equiv $)$
$37.50 \mathrm{mM}(0.75$ equiv $)$
$50 \mathrm{mM}(1.0$ equiv $)$
$75 \mathrm{mM}(1.5$ equiv $)$
$100 \mathrm{mM}(2.0$ equiv)
$150 \mathrm{mM}(3.0$ equiv $)$

Order in silanolate $\mathrm{K}^{+}(E)-\mathbf{1}^{-}$(with 1.0 equiv $\mathrm{Pd}(\mathrm{dba})_{2}$ )

$12.5 \mathrm{mM}(0.5$ equiv $) \ldots \ldots \ldots \ldots$
$18.75 \mathrm{mM}(0.75$ equiv) $\ldots \ldots \ldots \ldots$
$25 \mathrm{mM}(1.0$ equiv $) \ldots \ldots \ldots \ldots$
$31.25 \mathrm{mM}(1.25$ equiv $)$

Effect of $\mathrm{K}^{+} \mathrm{I}^{-}$and $n-\mathrm{Bu}_{4} \mathrm{~N}^{+} \mathrm{I}^{-}$addition 109 


\section{Order in 2-Iodothiophene, 0.5 equiv.}

$\mathrm{K}^{+}(E)-\mathbf{1}^{-}$

2-Iodothiophene

Bis(dibenzylideneacetone)palladium $2.5 \mathrm{mM}$ (0.05 equiv)
$50 \mathrm{mM}$ (1 equiv)

$25 \mathrm{mM}(0.5$ equiv $)$

Following the General Procedure, $\mathrm{K}^{+}(E)-\mathbf{1}^{-}(0.53 \mathrm{~mL}, 0.474 \mathrm{M})$ and biphenyl $(7.8 \mathrm{mg})$ were dissolved in DME $(3.47 \mathrm{~mL})$ in a flame-dried, 2-neck round-bottomed flask, equipped with a stir bar and a septum under argon. The 2-iodothiophene (13.8 $\mu \mathrm{L}, 0.125 \mathrm{mmol})$ was then added and the reaction was stirred for $1 \mathrm{~min}$. A suspension of $\operatorname{Pd}(\mathrm{dba})_{2}(7.2 \mathrm{mg}, 0.0125 \mathrm{mmol})$ in dry THF $(1.0 \mathrm{~mL})$ was added. The dark red solution slowly turned turbid over time as the precipitation of KI proceeded. Aliquots $(\sim 200 \mu \mathrm{L})$ were withdrawn after $0.33,0.66,1.0,1.33$, $1.66,2.0,2.5,3.0,4,5,7$, and $10 \mathrm{~min}$. To quench, these samples were added to $100 \mu \mathrm{L}$ of a $20 \%$ aqueous solution of 2-dimethylaminoethanethiol hydrochloride. The clear colorless to slightlyyellow solution was then filtered through a plug of silica gel, and the silica gel was washed with diethyl ether to give a total sample volume of $\sim 2 \mathrm{~mL}$. This sample was injected into the GC three times.

initial rate $=0.0766$

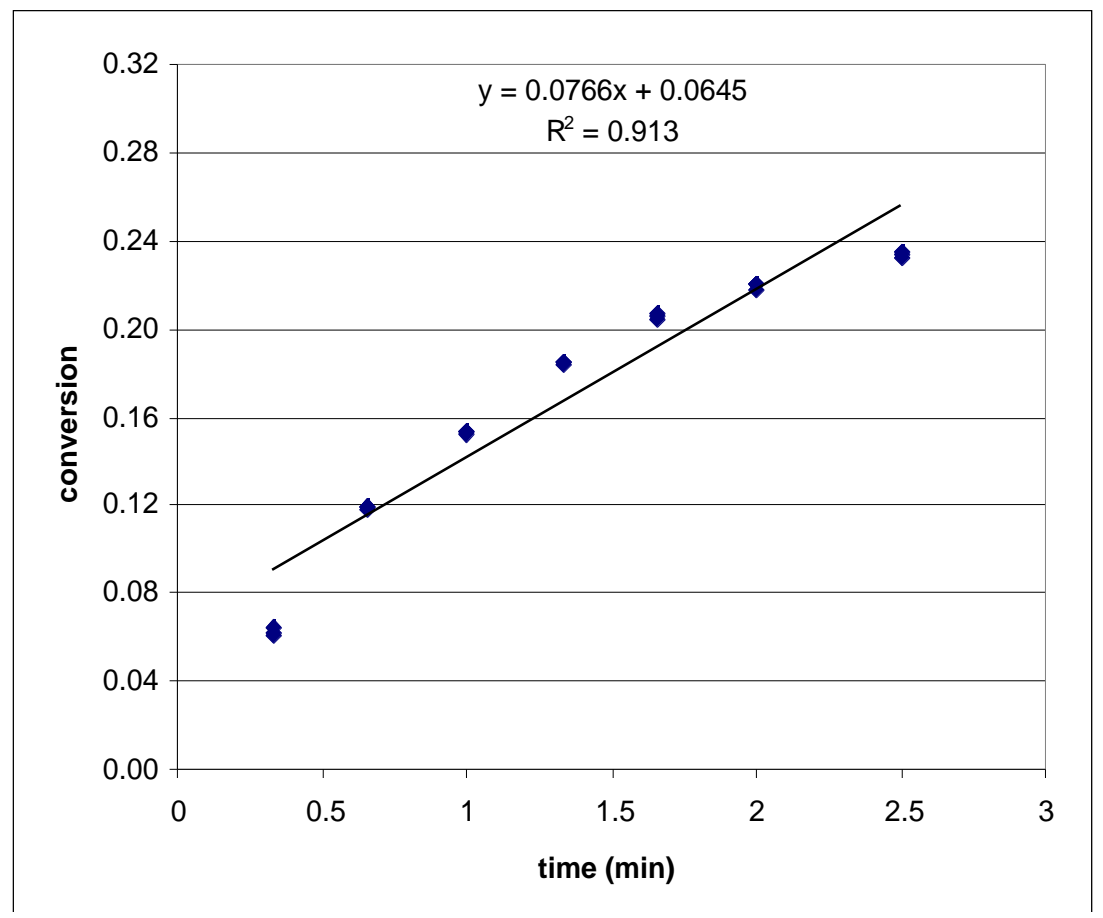




\begin{tabular}{c|c|c|c}
\hline time & area A & area 2 & conversion \\
\hline 0.33 & 8712 & 1843 & 0.062 \\
0.33 & 8894 & 1854 & 0.061 \\
0.33 & 8752 & 1907 & 0.064 \\
0.66 & 8596 & 3502 & 0.120 \\
0.66 & 8640 & 3510 & 0.120 \\
0.66 & 8641 & 3461 & 0.118 \\
1 & 10114 & 5222 & 0.152 \\
1 & 9977 & 5202 & 0.153 \\
1 & 9983 & 5214 & 0.154 \\
1.33 & 10118 & 6340 & 0.184 \\
1.33 & 9971 & 6263 & 0.185 \\
1.33 & 10242 & 6434 & 0.185 \\
1.66 & 9428 & 6603 & 0.206 \\
1.66 & 9416 & 6546 & 0.204 \\
1.66 & 9567 & 6714 & 0.206 \\
2 & 9757 & 7285 & 0.220 \\
2 & 9545 & 7074 & 0.218 \\
2 & 9490 & 7091 & 0.220 \\
2.5 & 11800 & 9394 & 0.234 \\
2.5 & 11711 & 9233 & 0.232 \\
2.5 & 11762 & 9366 & 0.234 \\
3 & 9385 & 8006 & 0.251 \\
3 & 9304 & 7920 & 0.250 \\
3 & 9198 & 7830 & 0.250 \\
5 & 9568 & 9540 & 0.293 \\
5 & 9598 & 9568 & 0.293 \\
5 & 9739 & 9641 & 0.291 \\
10 & 3644 & 4379 & 0.353 \\
10 & 10165 & 12257 & 0.353 \\
10 & 10094 & & 0.357 \\
& & &
\end{tabular}




\section{Order in 2-Iodothiophene, 0.5 equiv.}

$\mathrm{K}^{+}(E)-\mathbf{1}^{-}$

2-Iodothiophene

Bis(dibenzylideneacetone)palladium $2.5 \mathrm{mM}$ (0.05 equiv)
$50 \mathrm{mM}$ (1 equiv)

$25 \mathrm{mM}(0.5$ equiv $)$

Following the General Procedure, $\mathrm{K}^{+}(E) \mathbf{1}^{-}(0.53 \mathrm{~mL}, 0.474 \mathrm{M})$ and biphenyl $(8.2 \mathrm{mg})$ were dissolved in DME $(3.47 \mathrm{~mL})$ in a flame-dried, 2-neck round-bottomed flask, equipped with a stir bar and a septum under argon. The 2-iodothiophene (13.8 $\mu \mathrm{L}, 0.125 \mathrm{mmol})$ was then added and the reaction was stirred for $1 \mathrm{~min}$. A suspension of $\operatorname{Pd}(\mathrm{dba})_{2}(7.2 \mathrm{mg}, 0.0125 \mathrm{mmol})$ in dry THF $(1.0 \mathrm{~mL})$ was added. The dark red solution slowly turned turbid over time as the precipitation of KI proceeded. Aliquots $(\sim 200 \mu \mathrm{L})$ were withdrawn after $0.33,0.66,1.0,1.33$, $1.66,2.0,2.5,3.0,4,5,7$, and $10 \mathrm{~min}$. To quench, these samples were added to $100 \mu \mathrm{L}$ of a $20 \%$ aqueous solution of 2-dimethylaminoethanethiol hydrochloride. The clear colorless to slightlyyellow solution was then filtered through a plug of silica gel, and the silica gel was washed with diethyl ether to give a total sample volume of $\sim 2 \mathrm{~mL}$. This sample was injected into the GC three times.

initial rate $=0.0706$

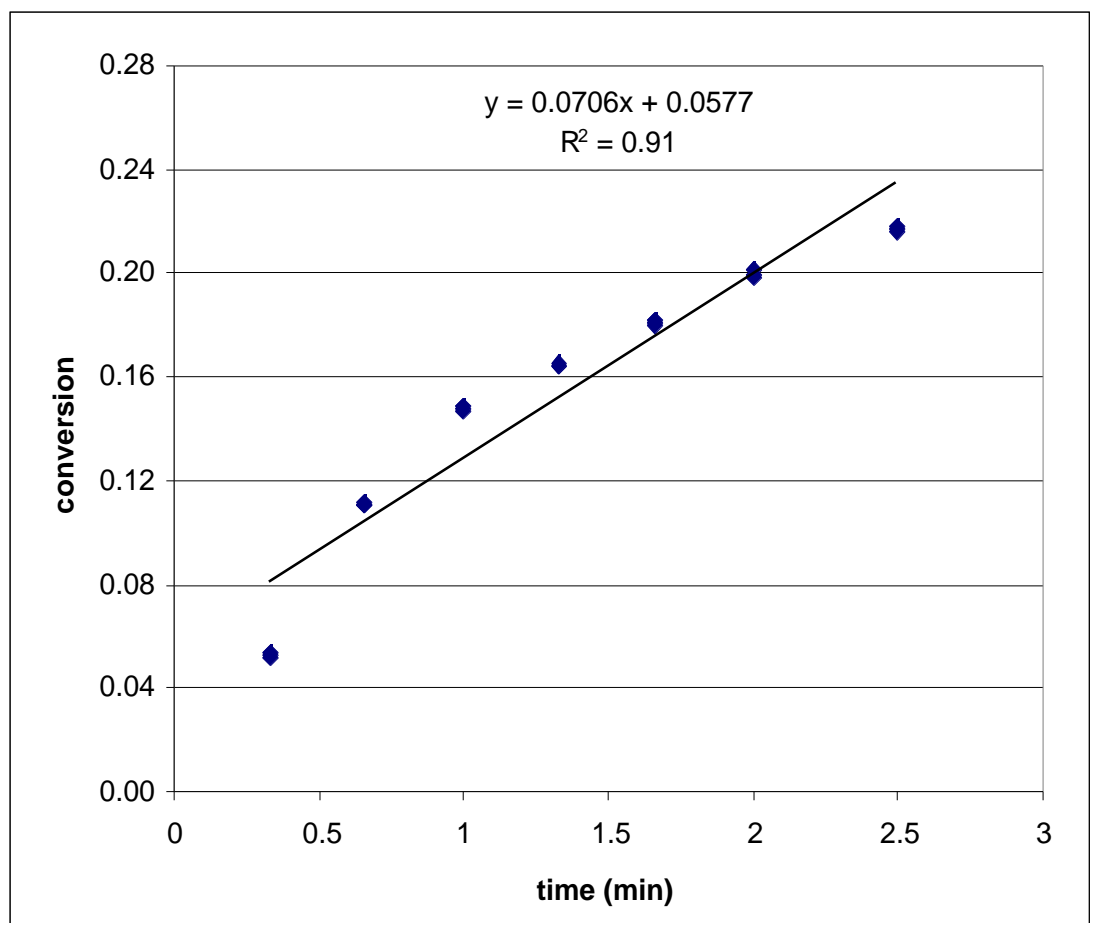




\begin{tabular}{|c|c|c|c|}
\hline time & area $\mathrm{A}$ & area 2 & conversion \\
\hline 0.33 & 9662 & 1601 & 0.051 \\
\hline 0.33 & 9692 & 1667 & 0.053 \\
\hline 0.33 & 9715 & 1689 & 0.054 \\
\hline 0.66 & 9736 & 3481 & 0.111 \\
\hline 0.66 & 9800 & 3535 & 0.112 \\
\hline 0.66 & 9896 & 3539 & 0.111 \\
\hline 1 & 9021 & 4269 & 0.146 \\
\hline 1 & 9198 & 4385 & 0.147 \\
\hline 1 & 9109 & 4390 & 0.149 \\
\hline 1.33 & 9387 & 5002 & 0.165 \\
\hline 1.33 & 9290 & 4953 & 0.165 \\
\hline 1.33 & 9259 & 4924 & 0.164 \\
\hline 1.66 & 11051 & 6411 & 0.179 \\
\hline 1.66 & 10920 & 6431 & 0.182 \\
\hline 1.66 & 11025 & 6449 & 0.181 \\
\hline 2 & 10578 & 6784 & 0.198 \\
\hline 2 & 10467 & 6760 & 0.200 \\
\hline 2 & 10613 & 6899 & 0.201 \\
\hline 2.5 & 9715 & 6815 & 0.217 \\
\hline 2.5 & 9703 & 6789 & 0.216 \\
\hline 2.5 & 9660 & 6821 & 0.218 \\
\hline 3 & 11582 & 8099 & 0.216 \\
\hline 3 & 11534 & 8155 & 0.219 \\
\hline 3 & 11363 & 8014 & 0.218 \\
\hline 5 & 10900 & 9101 & 0.258 \\
\hline 5 & 11006 & 9288 & 0.261 \\
\hline 5 & 10987 & 9258 & 0.261 \\
\hline 10 & 9296 & 9819 & 0.327 \\
\hline 10 & 9214 & 9837 & 0.330 \\
\hline 10 & 9135 & 9674 & 0.327 \\
\hline
\end{tabular}




\section{Order in 2-Iodothiophene, 0.5 equiv.}

$\mathrm{K}^{+}(E)-\mathbf{1}^{-}$

2-Iodothiophene

Bis(dibenzylideneacetone)palladium $2.5 \mathrm{mM}$ (0.05 equiv)
$50 \mathrm{mM}$ (1 equiv)

$25 \mathrm{mM}(0.5$ equiv $)$

Following the General Procedure, $\mathrm{K}^{+}(E)-\mathbf{1}^{-}(0.53 \mathrm{~mL}, 0.474 \mathrm{M})$ and biphenyl $(8.0 \mathrm{mg})$ were dissolved in DME $(3.47 \mathrm{~mL})$ in a flame-dried, 2-neck round-bottomed flask, equipped with a stir bar and a septum under argon. The 2-iodothiophene (13.8 $\mu \mathrm{L}, 0.125 \mathrm{mmol})$ was then added and the reaction was stirred for $1 \mathrm{~min}$. A suspension of $\operatorname{Pd}(\mathrm{dba})_{2}(7.2 \mathrm{mg}, 0.0125 \mathrm{mmol})$ in dry THF $(1.0 \mathrm{~mL})$ was added. The dark red solution slowly turned turbid over time as the precipitation of KI proceeded. Aliquots $(\sim 200 \mu \mathrm{L})$ were withdrawn after 0.33, 0.66, 1.0, 1.33, $1.66,2.0,2.5,3.0,4,5,7$, and $10 \mathrm{~min}$. To quench, these samples were added to $100 \mu \mathrm{L}$ of a $20 \%$ aqueous solution of 2-dimethylaminoethanethiol hydrochloride. The clear colorless to slightlyyellow solution was then filtered through a plug of silica gel, and the silica gel was washed with diethyl ether to give a total sample volume of $\sim 2 \mathrm{~mL}$. This sample was injected into the GC three times.

initial rate $=0.0687$

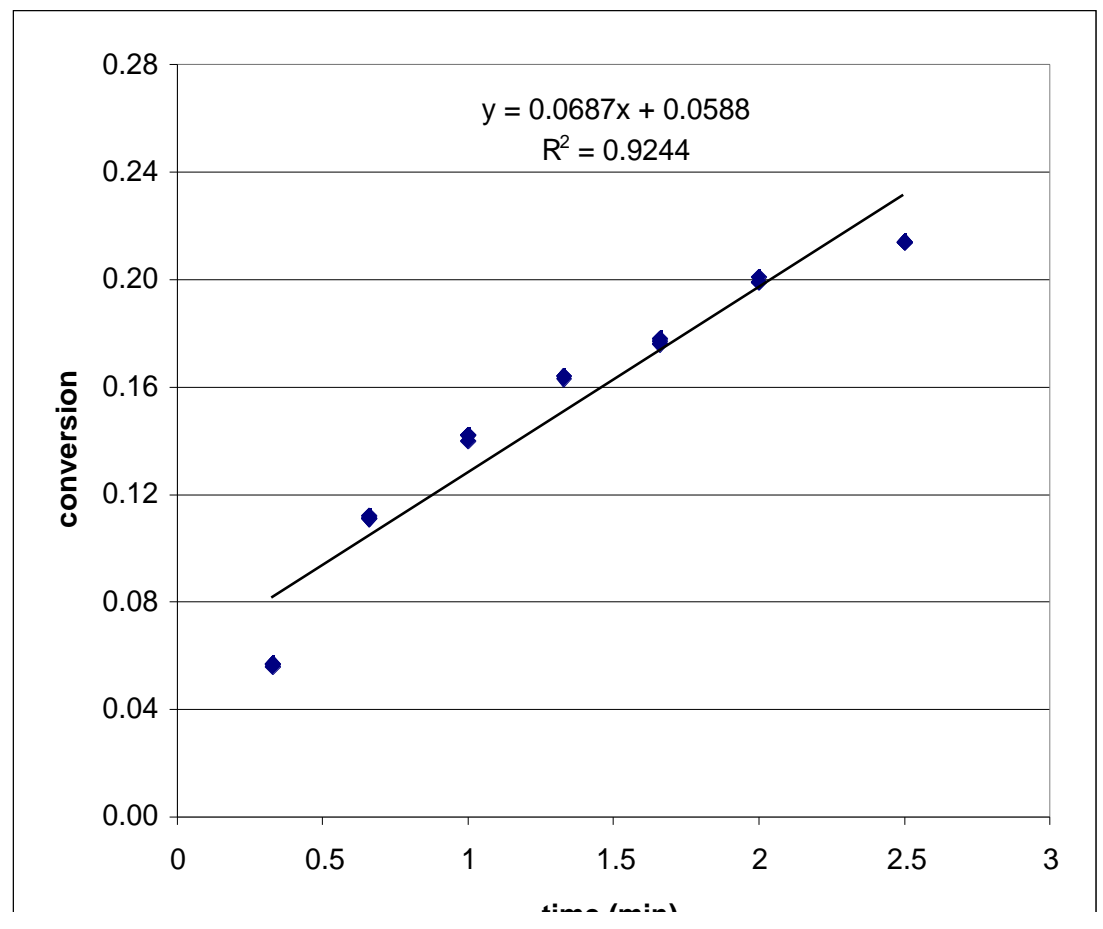




\begin{tabular}{|c|c|c|c|}
\hline time & area $\mathrm{A}$ & area 2 & conversion \\
\hline 0.33 & 10736 & 1997 & 0.056 \\
\hline 0.33 & 10803 & 2031 & 0.057 \\
\hline 0.33 & 10729 & 2013 & 0.057 \\
\hline 0.66 & 11725 & 4339 & 0.112 \\
\hline 0.66 & 11775 & 4321 & 0.111 \\
\hline 0.66 & 11756 & 4326 & 0.111 \\
\hline 1 & 10062 & 4725 & 0.142 \\
\hline 1 & 10144 & 4698 & 0.140 \\
\hline 1 & 10100 & 4751 & 0.142 \\
\hline 1.33 & 11952 & 6490 & 0.164 \\
\hline 1.33 & 11875 & 6414 & 0.163 \\
\hline 1.33 & 11909 & 6480 & 0.164 \\
\hline 1.66 & 9958 & 5832 & 0.177 \\
\hline 1.66 & 10034 & 5863 & 0.176 \\
\hline 1.66 & 10127 & 5961 & 0.178 \\
\hline 2 & 11386 & 7576 & 0.201 \\
\hline 2 & 11486 & 7586 & 0.199 \\
\hline 2 & 11512 & 7589 & 0.199 \\
\hline 2.5 & 11589 & 8222 & 0.214 \\
\hline 2.5 & 11280 & 7984 & 0.214 \\
\hline 2.5 & 11256 & 8001 & 0.214 \\
\hline 3 & 11088 & 8123 & 0.221 \\
\hline 3 & 11071 & 8051 & 0.219 \\
\hline 3 & 11118 & 8109 & 0.220 \\
\hline 5 & 12067 & 9747 & 0.244 \\
\hline 5 & 11979 & 9665 & 0.243 \\
\hline 5 & 11851 & 9688 & 0.247 \\
\hline 10 & 10425 & 10591 & 0.307 \\
\hline 10 & 10345 & 10522 & 0.307 \\
\hline 10 & 10498 & 10667 & 0.307 \\
\hline
\end{tabular}




\section{Order in 2-Iodothiophene, 1.0 equiv.}

$\begin{array}{ll}\mathrm{K}^{+}(E)-\mathbf{1}^{-} & 50 \mathrm{mM} \text { (1 equiv) } \\ \text { 2-Iodothiophene } & 50 \mathrm{mM} \text { (1 equiv) }\end{array}$

Bis(dibenzylideneacetone)palladium $2.5 \mathrm{mM}$ (0.05 equiv)

Following the General Procedure, $\mathrm{K}^{+}(E) \mathbf{1}^{-}(0.52 \mathrm{~mL}, 0.481 \mathrm{M})$ and biphenyl $(5.3 \mathrm{mg})$ were dissolved in DME $(3.48 \mathrm{~mL})$ in a flame-dried, 2-neck round-bottomed flask, equipped with a stir bar and a septum under argon. The 2-iodothiophene $(27.6 \mu \mathrm{L}, 0.25 \mathrm{mmol})$ was then added and the reaction was stirred for $1 \mathrm{~min}$. A suspension of $\mathrm{Pd}(\mathrm{dba})_{2}(7.2 \mathrm{mg}, 0.0125 \mathrm{mmol})$ in dry THF (1.0 mL) was added. The dark red solution slowly turned turbid over time as the precipitation of KI proceeded. Aliquots $(\sim 200 \mu \mathrm{L})$ were withdrawn after $0.33,0.66,1.0,1.33$, $1.66,2.0,2.5,3.0,4,5,7$, and $10 \mathrm{~min}$. To quench, these samples were added to $100 \mu \mathrm{L}$ of a $20 \%$ aqueous solution of 2-dimethylaminoethanethiol hydrochloride. The clear colorless to slightlyyellow solution was then filtered through a plug of silica gel, and the silica gel was washed with diethyl ether to give a total sample volume of $\sim 2 \mathrm{~mL}$. This sample was injected into the GC three times.

initial rate $=0.0775$

$\mathrm{k}_{\mathrm{obs}}=0.0381$
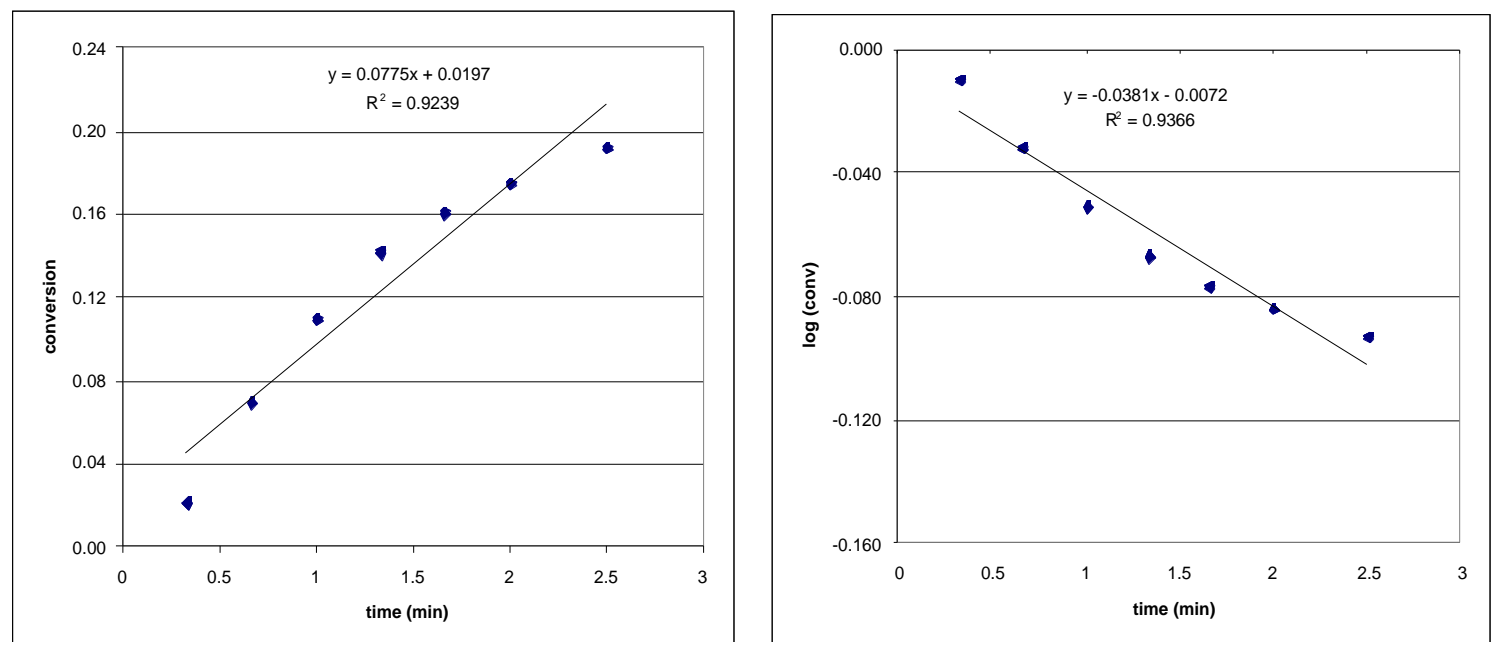


\begin{tabular}{c|c|c|c}
\hline time & area A & area 2 & conversion \\
\hline 0.33 & 5570 & 597 & 0.021 \\
0.33 & 5667 & 623 & 0.022 \\
0.33 & 5689 & 602 & 0.021 \\
0.66 & 5051 & 1764 & 0.070 \\
0.66 & 5036 & 1763 & 0.070 \\
0.66 & 5035 & 1774 & 0.070 \\
1 & 6603 & 3635 & 0.110 \\
1 & 6611 & 3656 & 0.111 \\
1 & 6589 & 3620 & 0.110 \\
1.33 & 5265 & 3775 & 0.143 \\
1.33 & 5204 & 3694 & 0.142 \\
1.33 & 5268 & 3729 & 0.141 \\
1.66 & 5964 & 4805 & 0.161 \\
1.66 & 5933 & 4763 & 0.160 \\
1.66 & 5945 & 4809 & 0.162 \\
2 & 6003 & 5268 & 0.175 \\
2 & 5984 & 5242 & 0.175 \\
2 & 6019 & 5285 & 0.176 \\
2.5 & 5586 & 5370 & 0.192 \\
2.5 & 5604 & 5381 & 0.192 \\
2.5 & 5590 & 5393 & 0.193 \\
3 & 5436 & 5552 & 0.204 \\
3 & 5434 & 5532 & 0.203 \\
3 & 5459 & 5579 & 0.204 \\
5 & 5077 & 6171 & 0.243 \\
5 & 5073 & 6132 & 0.242 \\
5 & 5084 & 6184 & 0.243 \\
10 & 4901 & 7417 & 0.302 \\
10 & 4891 & 7388 & 0.302 \\
10 & 4884 & & 0.302 \\
& & &
\end{tabular}




\section{Order in 2-Iodothiophene, 1.0 equiv.}

$\mathrm{K}^{+}(E)-\mathbf{1}^{-}$

2-Iodothiophene

Bis(dibenzylideneacetone)palladium $2.5 \mathrm{mM}$ (0.05 equiv)
$50 \mathrm{mM}$ (1 equiv)

$50 \mathrm{mM}$ (1 equiv)

Following the General Procedure, $\mathrm{K}^{+}(E) \mathbf{1}^{-}(0.52 \mathrm{~mL}, 0.481 \mathrm{M})$ and biphenyl $(7.0 \mathrm{mg})$ were dissolved in DME (3.48 mL) in a flame-dried, 2-neck round-bottomed flask, equipped with a stir bar and a septum under argon. The 2-iodothiophene $(27.6 \mu \mathrm{L}, 0.25 \mathrm{mmol})$ was then added and the reaction was stirred for $1 \mathrm{~min}$. A suspension of $\mathrm{Pd}(\mathrm{dba})_{2}(7.2 \mathrm{mg}, 0.0125 \mathrm{mmol})$ in dry THF (1.0 mL) was added. The dark red solution slowly turned turbid over time as the precipitation of KI proceeded. Aliquots $(\sim 200 \mu \mathrm{L})$ were withdrawn after $0.33,0.66,1.0,1.33$, $1.66,2.0,2.5,3.0,4,5,7$, and $10 \mathrm{~min}$. To quench, these samples were added to $100 \mu \mathrm{L}$ of a $20 \%$ aqueous solution of 2-dimethylaminoethanethiol hydrochloride. The clear colorless to slightlyyellow solution was then filtered through a plug of silica gel, and the silica gel was washed with diethyl ether to give a total sample volume of $\sim 2 \mathrm{~mL}$. This sample was injected into the GC three times.

initial rate $=0.0746$

$\mathrm{k}_{\mathrm{obs}}=0.0397$
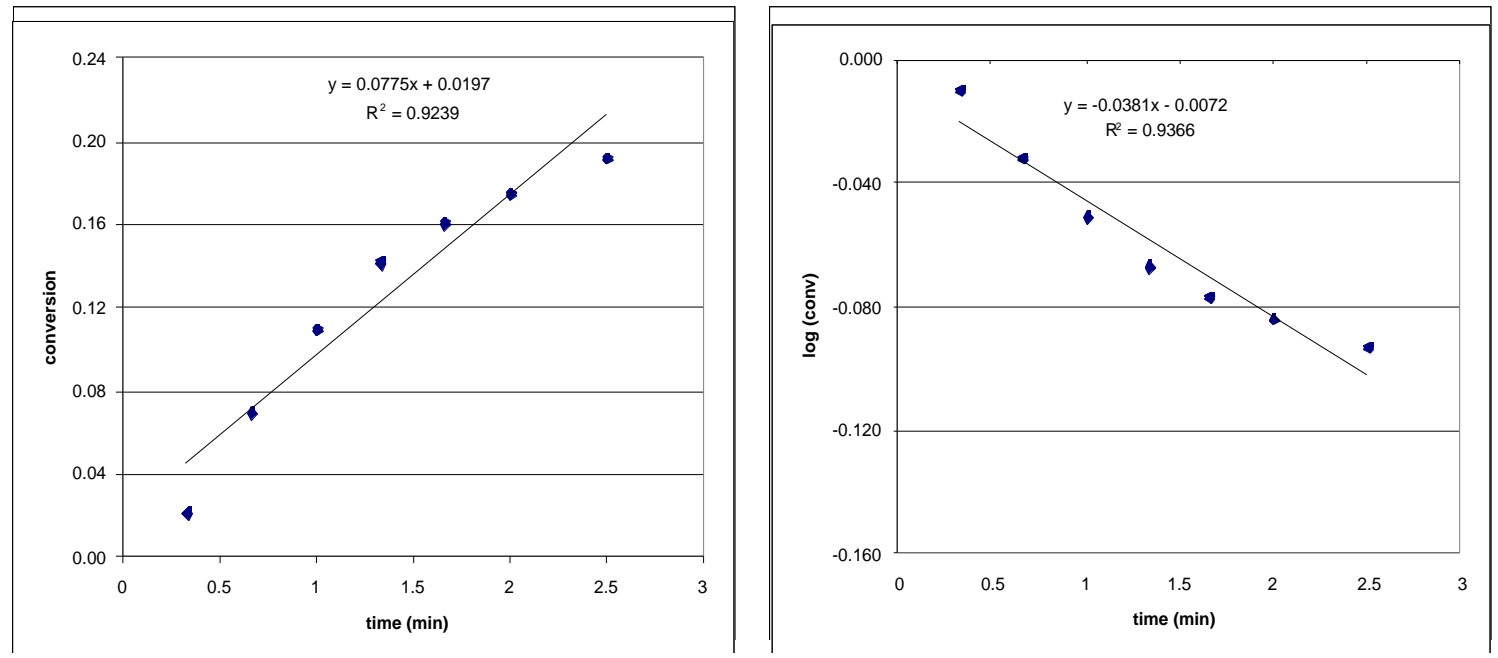


\begin{tabular}{|c|c|c|c|}
\hline time & area $\mathrm{A}$ & area 2 & conversion \\
\hline 0.33 & 7510 & 2322 & 0.082 \\
\hline 0.33 & 7693 & 2371 & 0.081 \\
\hline 0.33 & 7773 & 2413 & 0.082 \\
\hline 0.66 & 7068 & 4268 & 0.159 \\
\hline 0.66 & 6971 & 4202 & 0.159 \\
\hline 0.66 & 6981 & 4184 & 0.158 \\
\hline 1 & 7566 & 5497 & 0.192 \\
\hline 1 & 7530 & 5482 & 0.192 \\
\hline 1 & 7587 & 5504 & 0.192 \\
\hline 1.33 & 7121 & 5794 & 0.215 \\
\hline 1.33 & 7100 & 5766 & 0.214 \\
\hline 1.33 & 7145 & 5812 & 0.215 \\
\hline 1.66 & 8517 & 7448 & 0.231 \\
\hline 1.66 & 8507 & 7433 & 0.231 \\
\hline 1.66 & 8533 & 7443 & 0.230 \\
\hline 2 & 8377 & 7738 & 0.244 \\
\hline 2 & 8386 & 7749 & 0.244 \\
\hline 2 & 8369 & 7746 & 0.244 \\
\hline 2.5 & 8335 & 8221 & 0.260 \\
\hline 2.5 & 8305 & 8227 & 0.262 \\
\hline 2.5 & 8290 & 8183 & 0.261 \\
\hline 3 & 7549 & 7935 & 0.277 \\
\hline 3 & 7528 & 7907 & 0.277 \\
\hline 3 & 7560 & 7946 & 0.277 \\
\hline 5 & 7176 & 8863 & 0.326 \\
\hline 5 & 7189 & 8926 & 0.328 \\
\hline 5 & 7216 & 8987 & 0.329 \\
\hline 10 & 7784 & 12808 & 0.434 \\
\hline 10 & 7763 & 12810 & 0.436 \\
\hline 10 & 7764 & 12836 & 0.436 \\
\hline
\end{tabular}




\section{Order in 2-Iodothiophene, 1.0 equiv.}

$\mathrm{K}^{+}(E)-\mathbf{1}^{-}$

2-Iodothiophene

Bis(dibenzylideneacetone)palladium $2.5 \mathrm{mM}$ (0.05 equiv)
$50 \mathrm{mM}$ (1 equiv)

$50 \mathrm{mM}$ (1 equiv)

Following the General Procedure, $\mathrm{K}^{+}(E) \mathbf{1}^{-}(0.52 \mathrm{~mL}, 0.481 \mathrm{M})$ and biphenyl $(7.0 \mathrm{mg})$ were dissolved in DME (3.48 mL) in a flame-dried, 2-neck round-bottomed flask, equipped with a stir bar and a septum under argon. The 2-iodothiophene $(27.6 \mu \mathrm{L}, 0.25 \mathrm{mmol})$ was then added and the reaction was stirred for $1 \mathrm{~min}$. A suspension of $\mathrm{Pd}(\mathrm{dba})_{2}(7.2 \mathrm{mg}, 0.0125 \mathrm{mmol})$ in dry THF (1.0 mL) was added. The dark red solution slowly turned turbid over time as the precipitation of KI proceeded. Aliquots $(\sim 200 \mu \mathrm{L})$ were withdrawn after $0.33,0.66,1.0,1.33$, $1.66,2.0,2.5,3.0,4,5,7$, and 10 min. To quench, these samples were added to $100 \mu \mathrm{L}$ of a $20 \%$ aqueous solution of 2-dimethylaminoethanethiol hydrochloride. The clear colorless to slightlyyellow solution was then filtered through a plug of silica gel, and the silica gel was washed with diethyl ether to give a total sample volume of $\sim 2 \mathrm{~mL}$. This sample was injected into the GC three times.

initial rate $=0.0739$

$\mathrm{k}_{\mathrm{obs}}=0.039$
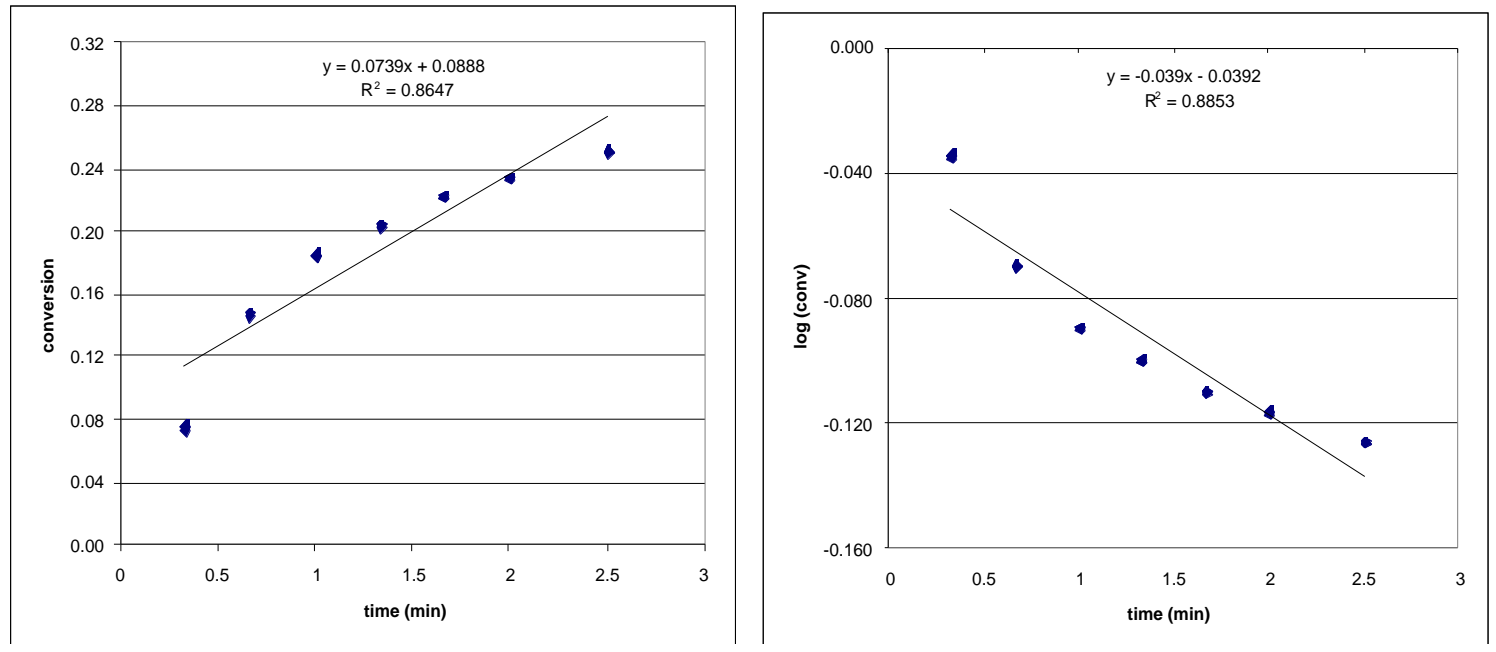


\begin{tabular}{c|c|c|c}
\hline time & area A & area 2 & Conversion \\
\hline 0.33 & 6011 & 1745 & 0.077 \\
0.33 & 6031 & 1726 & 0.076 \\
0.33 & 6027 & 1694 & 0.074 \\
0.66 & 7292 & 4096 & 0.148 \\
0.66 & 7270 & 4080 & 0.148 \\
0.66 & 7282 & 4049 & 0.147 \\
1 & 6462 & 4548 & 0.186 \\
1 & 6427 & 4510 & 0.185 \\
1 & 6416 & 4506 & 0.185 \\
1.33 & 5174 & 4015 & 0.205 \\
1.33 & 5172 & 4014 & 0.205 \\
1.33 & 5242 & 6040 & 0.203 \\
1.66 & 7337 & 6197 & 0.223 \\
1.66 & 7311 & 6177 & 0.224 \\
1.66 & 7323 & 6974 & 0.223 \\
2 & 7862 & 6994 & 0.234 \\
2 & 7848 & 6955 & 0.235 \\
2 & 7820 & 6363 & 0.235 \\
2.5 & 6706 & 6379 & 0.250 \\
2.5 & 6684 & 6428 & 0.252 \\
2.5 & 6737 & 7128 & 0.252 \\
3 & 7054 & 7059 & 0.267 \\
3 & 6972 & 7101 & 0.267 \\
3 & 7051 & 8764 & 0.266 \\
5 & 7313 & 8770 & 0.316 \\
5 & 7308 & 12397 & 0.317 \\
5 & 7279 & 12362 & 0.315 \\
10 & 8052 & 0.402 \\
10 & 8121 & 0.402 \\
10 & 8090 & &
\end{tabular}




\section{Order in 2-Iodothiophene, 2.0 equiv.}

$\mathrm{K}^{+}(E)-\mathbf{1}^{-}$

2-Iodothiophene

Bis(dibenzylideneacetone)palladium $2.5 \mathrm{mM}$ (0.05 equiv)
$50 \mathrm{mM}$ (1 equiv)

$100 \mathrm{mM}$ (2 equiv)

Following the General Procedure, $\mathrm{K}^{+}(E) \mathbf{1}^{-}(0.53 \mathrm{~mL}, 0.474 \mathrm{M})$ and biphenyl $(9.1 \mathrm{mg})$ were dissolved in DME $(3.47 \mathrm{~mL})$ in a flame-dried, 2-neck round-bottomed flask, equipped with a stir bar and a septum under argon. The 2-iodothiophene $(55.2 \mu \mathrm{L}, 0.25 \mathrm{mmol})$ was then added and the reaction was stirred for $1 \mathrm{~min}$. A suspension of $\mathrm{Pd}(\mathrm{dba})_{2}(7.2 \mathrm{mg}, 0.0125 \mathrm{mmol})$ in dry THF (1.0 mL) was added. The dark red solution slowly turned turbid over time as the precipitation of KI proceeded. Aliquots $(\sim 200 \mu \mathrm{L})$ were withdrawn after $0.33,0.66,1.0,1.33$, $1.66,2.0,2.5,3.0,4,5,7$, and $10 \mathrm{~min}$. To quench, these samples were added to $100 \mu \mathrm{L}$ of a $20 \%$ aqueous solution of 2-dimethylaminoethanethiol hydrochloride. The clear colorless to slightlyyellow solution was then filtered through a plug of silica gel, and the silica gel was washed with diethyl ether to give a total sample volume of $\sim 2 \mathrm{~mL}$. This sample was injected into the GC three times.

initial rate $=0.0667$

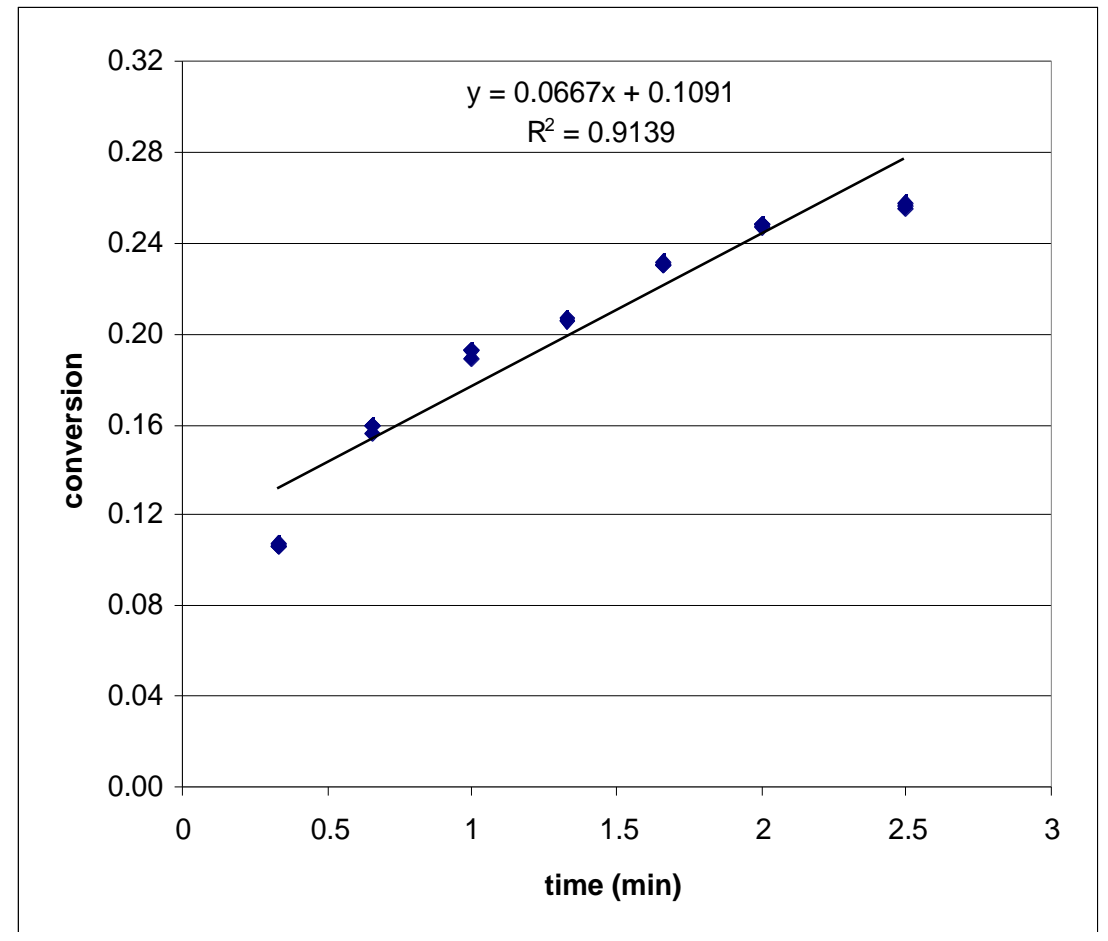




\begin{tabular}{|c|c|c|c|}
\hline time & area $\mathrm{A}$ & area 2 & Conversion \\
\hline 0.33 & 11142 & 3439 & 0.106 \\
\hline 0.33 & 11106 & 3446 & 0.106 \\
\hline 0.33 & 11366 & 3570 & 0.108 \\
\hline 0.66 & 9603 & 4457 & 0.159 \\
\hline 0.66 & 9650 & 4372 & 0.155 \\
\hline 0.66 & 9490 & 4412 & 0.160 \\
\hline 1 & 10453 & 5846 & 0.192 \\
\hline 1 & 9388 & 5177 & 0.189 \\
\hline 1 & 11748 & 6584 & 0.192 \\
\hline 1.33 & 9300 & 5552 & 0.205 \\
\hline 1.33 & 9376 & 5661 & 0.207 \\
\hline 1.33 & 9577 & 5726 & 0.205 \\
\hline 1.66 & 8474 & 5722 & 0.232 \\
\hline 1.66 & 8483 & 5705 & 0.231 \\
\hline 1.66 & 8459 & 5664 & 0.230 \\
\hline 2 & 11574 & 8340 & 0.247 \\
\hline 2 & 11379 & 8206 & 0.247 \\
\hline 2 & 11507 & 8327 & 0.248 \\
\hline 2.5 & 11107 & 8316 & 0.257 \\
\hline 2.5 & 11233 & 8354 & 0.255 \\
\hline 2.5 & 10697 & 7993 & 0.256 \\
\hline 3 & 12362 & 9952 & 0.276 \\
\hline 3 & 11762 & 9455 & 0.276 \\
\hline 3 & 12573 & 10107 & 0.276 \\
\hline 5 & 10256 & 10219 & 0.342 \\
\hline 5 & 10634 & 10605 & 0.342 \\
\hline 5 & 10933 & 10895 & 0.342 \\
\hline 10 & 11609 & 14737 & 0.436 \\
\hline 10 & 11233 & 14168 & 0.433 \\
\hline 10 & 11158 & 14085 & 0.433 \\
\hline
\end{tabular}




\section{Order in 2-Iodothiophene, 2.0 equiv.}

$\mathrm{K}^{+}(E)-\mathbf{1}^{-}$

2-Iodothiophene

Bis(dibenzylideneacetone)palladium $2.5 \mathrm{mM}$ (0.05 equiv)
$50 \mathrm{mM}$ (1 equiv)

$100 \mathrm{mM}$ (2 equiv)

Following the General Procedure, $\mathrm{K}^{+}(E) \mathbf{1}^{-}(0.53 \mathrm{~mL}, 0.474 \mathrm{M})$ and biphenyl $(5.7 \mathrm{mg})$ were dissolved in DME $(3.47 \mathrm{~mL})$ in a flame-dried, 2-neck round-bottomed flask, equipped with a stir bar and a septum under argon. The 2-iodothiophene $(55.2 \mu \mathrm{L}, 0.25 \mathrm{mmol})$ was then added and the reaction was stirred for $1 \mathrm{~min}$. A suspension of $\mathrm{Pd}(\mathrm{dba})_{2}(7.2 \mathrm{mg}, 0.0125 \mathrm{mmol})$ in dry THF (1.0 mL) was added. The dark red solution slowly turned turbid over time as the precipitation of KI proceeded. Aliquots $(\sim 200 \mu \mathrm{L})$ were withdrawn after $0.33,0.66,1.0,1.33$, $1.66,2.0,2.5,3.0,4,5,7$, and $10 \mathrm{~min}$. To quench, these samples were added to $100 \mu \mathrm{L}$ of a $20 \%$ aqueous solution of 2-dimethylaminoethanethiol hydrochloride. The clear colorless to slightlyyellow solution was then filtered through a plug of silica gel, and the silica gel was washed with diethyl ether to give a total sample volume of $\sim 2 \mathrm{~mL}$. This sample was injected into the GC three times.

initial rate $=0.0655$

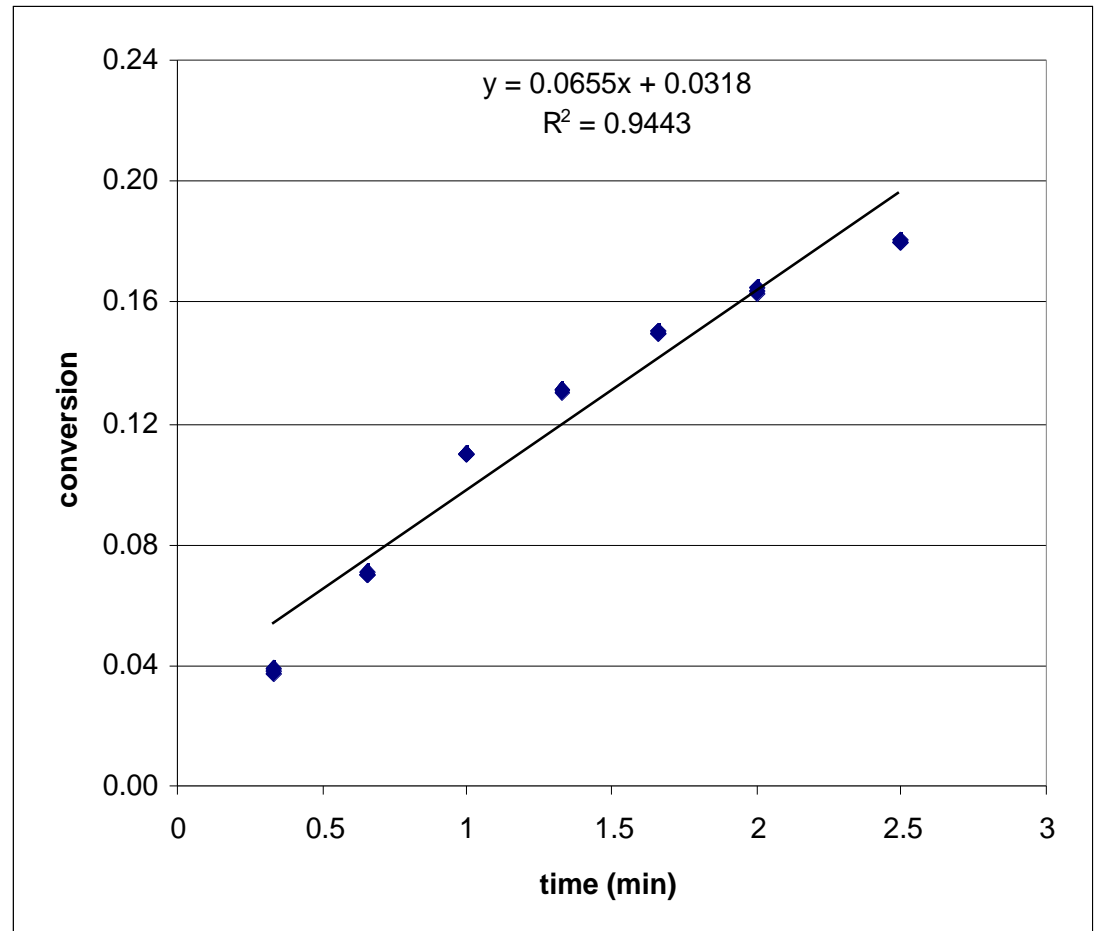




\begin{tabular}{c|c|c|c}
\hline time & area A & area 2 & Conversion \\
\hline 0.33 & 4887 & 891 & 0.039 \\
0.33 & 4861 & 847 & 0.037 \\
0.33 & 4938 & 874 & 0.038 \\
0.66 & 7772 & 2542 & 0.070 \\
0.66 & 7690 & 2505 & 0.070 \\
0.66 & 7652 & 2518 & 0.071 \\
1 & 8227 & 4207 & 0.110 \\
1 & 8242 & 4206 & 0.110 \\
1 & 8297 & 4247 & 0.110 \\
1.33 & 8257 & 5026 & 0.131 \\
1.33 & 8164 & 4953 & 0.130 \\
1.33 & 8239 & 5007 & 0.131 \\
1.66 & 7830 & 5461 & 0.150 \\
1.66 & 7929 & 5516 & 0.150 \\
1.66 & 7803 & 5466 & 0.151 \\
2 & 10127 & 7722 & 0.164 \\
2 & 10214 & 7814 & 0.164 \\
2 & 10000 & 7597 & 0.163 \\
2.5 & 9344 & 7837 & 0.180 \\
2.5 & 9486 & 7940 & 0.180 \\
2.5 & 9428 & 7894 & 0.180 \\
3 & 9300 & 8475 & 0.196 \\
3 & 9470 & 8652 & 0.196 \\
3 & 9372 & 8501 & 0.195 \\
5 & 8480 & 9164 & 0.232 \\
5 & 8357 & 9108 & 0.234 \\
5 & 7984 & 10951 & 0.234 \\
10 & 7984 & 11007 & 0.295 \\
10 & & & 0.296 \\
10 & & & 0.297 \\
& & &
\end{tabular}




\section{Order in 2-Iodothiophene, 2.0 equiv.}

$\mathrm{K}^{+}(E)-\mathbf{1}^{-}$

2-Iodothiophene

Bis(dibenzylideneacetone)palladium $2.5 \mathrm{mM}$ (0.05 equiv)
$50 \mathrm{mM}$ (1 equiv)
$100 \mathrm{mM}$ (2 equiv)

Following the General Procedure, $\mathrm{K}^{+}(E) \mathbf{1}^{-}(0.53 \mathrm{~mL}, 0.474 \mathrm{M})$ and biphenyl $(5.9 \mathrm{mg})$ were dissolved in DME $(3.47 \mathrm{~mL})$ in a flame-dried, 2-neck round-bottomed flask, equipped with a stir bar and a septum under argon. The 2-iodothiophene $(55.2 \mu \mathrm{L}, 0.25 \mathrm{mmol})$ was then added and the reaction was stirred for $1 \mathrm{~min}$. A suspension of $\mathrm{Pd}(\mathrm{dba})_{2}(7.2 \mathrm{mg}, 0.0125 \mathrm{mmol})$ in dry THF (1.0 mL) was added. The dark red solution slowly turned turbid over time as the precipitation of KI proceeded. Aliquots $(\sim 200 \mu \mathrm{L})$ were withdrawn after $0.33,0.66,1.0,1.33$, $1.66,2.0,2.5,3.0,4,5,7$, and $10 \mathrm{~min}$. To quench, these samples were added to $100 \mu \mathrm{L}$ of a $20 \%$ aqueous solution of 2-dimethylaminoethanethiol hydrochloride. The clear colorless to slightlyyellow solution was then filtered through a plug of silica gel, and the silica gel was washed with diethyl ether to give a total sample volume of $\sim 2 \mathrm{~mL}$. This sample was injected into the GC three times.

initial rate $=0.0632$

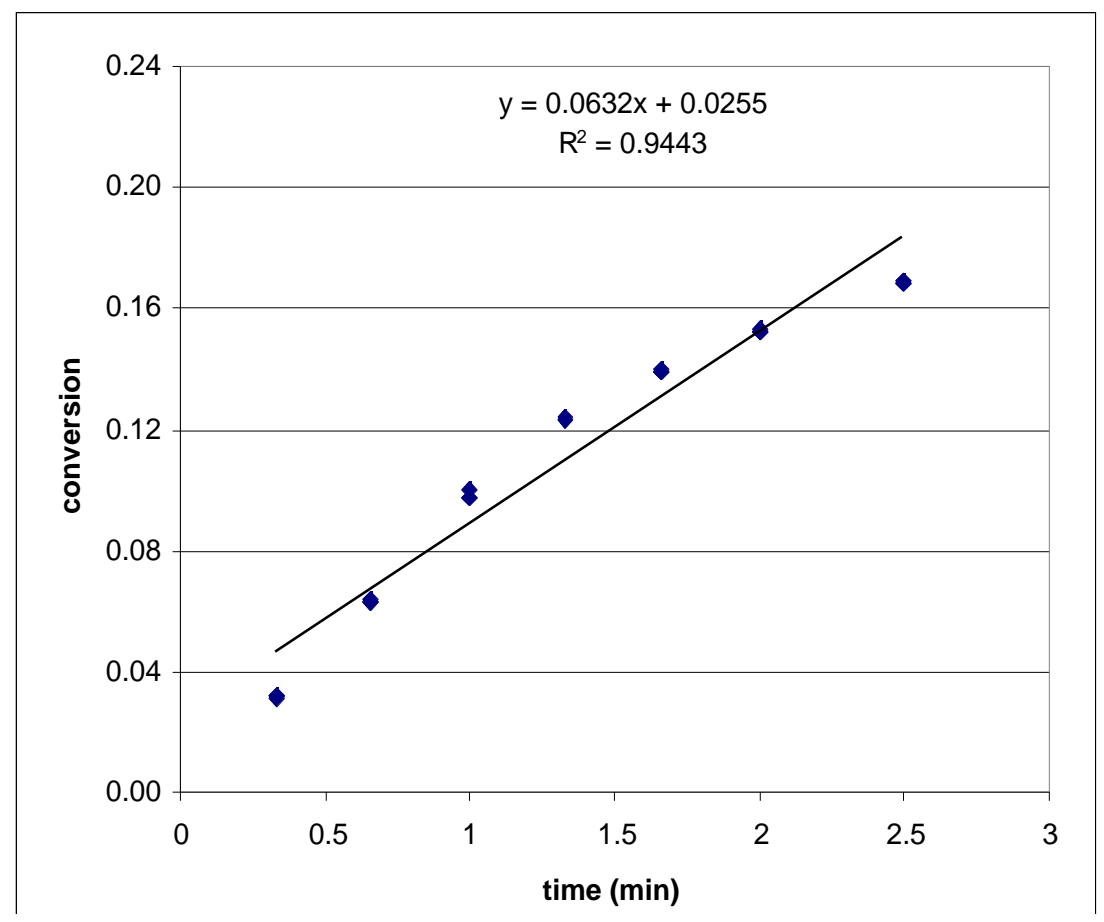




\begin{tabular}{|c|c|c|c|}
\hline time & $\operatorname{area} \mathrm{A}$ & area 2 & Conversion \\
\hline 0.33 & 8234 & 1196 & 0.032 \\
\hline 0.33 & 8173 & 1155 & 0.031 \\
\hline 0.33 & 8311 & 1174 & 0.031 \\
\hline 0.66 & 7003 & 1981 & 0.063 \\
\hline 0.66 & 6970 & 1977 & 0.063 \\
\hline 0.66 & 6900 & 1984 & 0.064 \\
\hline 1 & 6797 & 2985 & 0.098 \\
\hline 1 & 6904 & 3023 & 0.097 \\
\hline 1 & 6820 & 3076 & 0.100 \\
\hline 1.33 & 7964 & 4403 & 0.123 \\
\hline 1.33 & 7804 & 4345 & 0.124 \\
\hline 1.33 & 7835 & 4329 & 0.123 \\
\hline 1.66 & 8150 & 5121 & 0.140 \\
\hline 1.66 & 8384 & 5240 & 0.139 \\
\hline 1.66 & 8227 & 5155 & 0.139 \\
\hline 2 & 8216 & 5634 & 0.153 \\
\hline 2 & 8290 & 5713 & 0.153 \\
\hline 2 & 8006 & 5481 & 0.152 \\
\hline 2.5 & 7503 & 5696 & 0.169 \\
\hline 2.5 & 7827 & 5923 & 0.168 \\
\hline 2.5 & 7568 & 5728 & 0.168 \\
\hline 3 & 8381 & 6830 & 0.181 \\
\hline 3 & 8665 & 7089 & 0.182 \\
\hline 3 & 8821 & 7203 & 0.182 \\
\hline 5 & 8268 & 8151 & 0.219 \\
\hline 5 & 8238 & 8170 & 0.221 \\
\hline 5 & 8175 & 8080 & 0.220 \\
\hline 10 & 8469 & 10737 & 0.282 \\
\hline 10 & 8086 & 10297 & 0.283 \\
\hline 10 & 8384 & 10685 & 0.284 \\
\hline
\end{tabular}




\section{Order in Palladium, 0.05 equiv.}

$\begin{array}{ll}\mathrm{K}^{+}(E)-\mathbf{1}^{-} & 50 \mathrm{mM} \text { (1 equiv) } \\ \text { 2-Iodothiophene } & 50 \mathrm{mM} \text { (1 equiv) }\end{array}$

Bis(dibenzylideneacetone)palladium $2.5 \mathrm{mM}$ ( 0.05 equiv)

Following the General Procedure, $\mathrm{K}^{+}(E)-\mathbf{1}^{-}(0.52 \mathrm{~mL}, 0.481 \mathrm{M})$ and biphenyl $(5.3 \mathrm{mg})$ were dissolved in DME $(3.48 \mathrm{~mL})$ in a flame-dried, 2-neck round-bottomed flask, equipped with a stir bar and a septum under argon. The 2-iodothiophene $(27.6 \mu \mathrm{L}, 0.25 \mathrm{mmol})$ was then added and the reaction was stirred for $1 \mathrm{~min}$. A suspension of $\mathrm{Pd}(\mathrm{dba})_{2}(7.2 \mathrm{mg}, 0.0125 \mathrm{mmol})$ in dry THF (1.0 mL) was added. The dark red solution slowly turned turbid over time as the precipitation of KI proceeded. Aliquots $(\sim 200 \mu \mathrm{L})$ were withdrawn after $0.33,0.66,1.0,1.33$, $1.66,2.0,2.5,3.0,4,5,7$, and $10 \mathrm{~min}$. To quench, these samples were added to $100 \mu \mathrm{L}$ of a $20 \%$ aqueous solution of 2-dimethylaminoethanethiol hydrochloride. The clear colorless to slightlyyellow solution was then filtered through a plug of silica gel, and the silica gel was washed with diethyl ether to give a total sample volume of $\sim 2 \mathrm{~mL}$. This sample was injected into the GC three times.

initial rate $=0.0775$

$\mathrm{k}_{\mathrm{obs}}=0.0381$
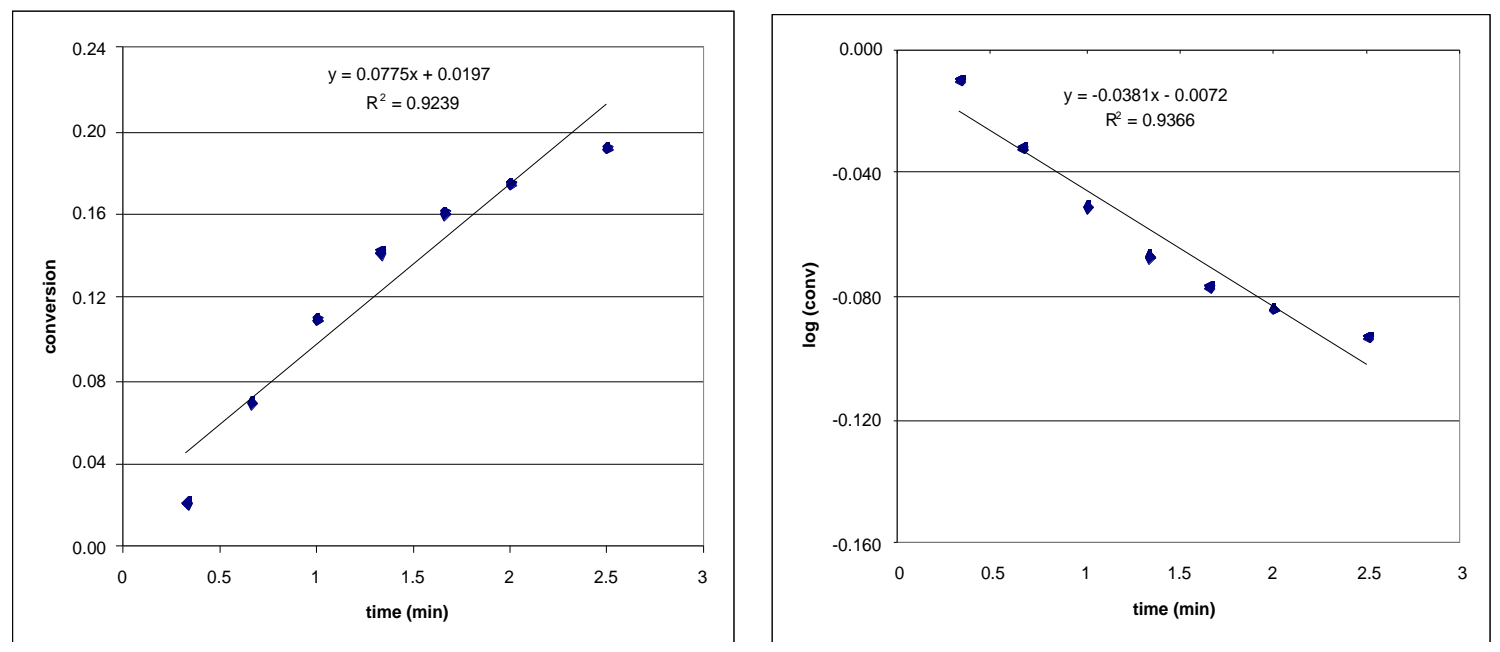


\begin{tabular}{|c|c|c|c|}
\hline time & area $\mathrm{A}$ & area 2 & conversion \\
\hline 0.33 & 5570 & 597 & 0.021 \\
\hline 0.33 & 5667 & 623 & 0.022 \\
\hline 0.33 & 5689 & 602 & 0.021 \\
\hline 0.66 & 5051 & 1764 & 0.070 \\
\hline 0.66 & 5036 & 1763 & 0.070 \\
\hline 0.66 & 5035 & 1774 & 0.070 \\
\hline 1 & 6603 & 3635 & 0.110 \\
\hline 1 & 6611 & 3656 & 0.111 \\
\hline 1 & 6589 & 3620 & 0.110 \\
\hline 1.33 & 5265 & 3775 & 0.143 \\
\hline 1.33 & 5204 & 3694 & 0.142 \\
\hline 1.33 & 5268 & 3729 & 0.141 \\
\hline 1.66 & 5964 & 4805 & 0.161 \\
\hline 1.66 & 5933 & 4763 & 0.160 \\
\hline 1.66 & 5945 & 4809 & 0.162 \\
\hline 2 & 6003 & 5268 & 0.175 \\
\hline 2 & 5984 & 5242 & 0.175 \\
\hline 2 & 6019 & 5285 & 0.176 \\
\hline 2.5 & 5586 & 5370 & 0.192 \\
\hline 2.5 & 5604 & 5381 & 0.192 \\
\hline 2.5 & 5590 & 5393 & 0.193 \\
\hline 3 & 5436 & 5552 & 0.204 \\
\hline 3 & 5434 & 5532 & 0.203 \\
\hline 3 & 5459 & 5579 & 0.204 \\
\hline 5 & 5077 & 6171 & 0.243 \\
\hline 5 & 5073 & 6132 & 0.242 \\
\hline 5 & 5084 & 6184 & 0.243 \\
\hline 10 & 4901 & 7417 & 0.302 \\
\hline 10 & 4891 & 7390 & 0.302 \\
\hline 10 & 4884 & 7388 & 0.302 \\
\hline
\end{tabular}




\section{Order in Palladium, 0.05 equiv.}

$\begin{array}{ll}\mathrm{K}^{+}(E)-\mathbf{1}^{-} & 50 \mathrm{mM} \text { (1 equiv) } \\ \text { 2-Iodothiophene } & 50 \mathrm{mM} \text { (1 equiv) }\end{array}$

Bis(dibenzylideneacetone)palladium $2.5 \mathrm{mM}$ (0.05 equiv)

Following the General Procedure, $\mathrm{K}^{+}(E)-\mathbf{1}^{-}(0.52 \mathrm{~mL}, 0.481 \mathrm{M})$ and biphenyl $(7.0 \mathrm{mg})$ were dissolved in DME $(3.48 \mathrm{~mL})$ in a flame-dried, 2-neck round-bottomed flask, equipped with a stir bar and a septum under argon. The 2-iodothiophene $(27.6 \mu \mathrm{L}, 0.25 \mathrm{mmol})$ was then added and the reaction was stirred for $1 \mathrm{~min}$. A suspension of $\mathrm{Pd}(\mathrm{dba})_{2}(7.2 \mathrm{mg}, 0.0125 \mathrm{mmol})$ in dry THF (1.0 mL) was added. The dark red solution slowly turned turbid over time as the precipitation of KI proceeded. Aliquots $(\sim 200 \mu \mathrm{L})$ were withdrawn after $0.33,0.66,1.0,1.33$, $1.66,2.0,2.5,3.0,4,5,7$, and $10 \mathrm{~min}$. To quench, these samples were added to $100 \mu \mathrm{L}$ of a $20 \%$ aqueous solution of 2-dimethylaminoethanethiol hydrochloride. The clear colorless to slightlyyellow solution was then filtered through a plug of silica gel, and the silica gel was washed with diethyl ether to give a total sample volume of $\sim 2 \mathrm{~mL}$. This sample was injected into the GC three times.

initial rate $=0.0746$

$\mathrm{k}_{\mathrm{obs}}=0.0397$
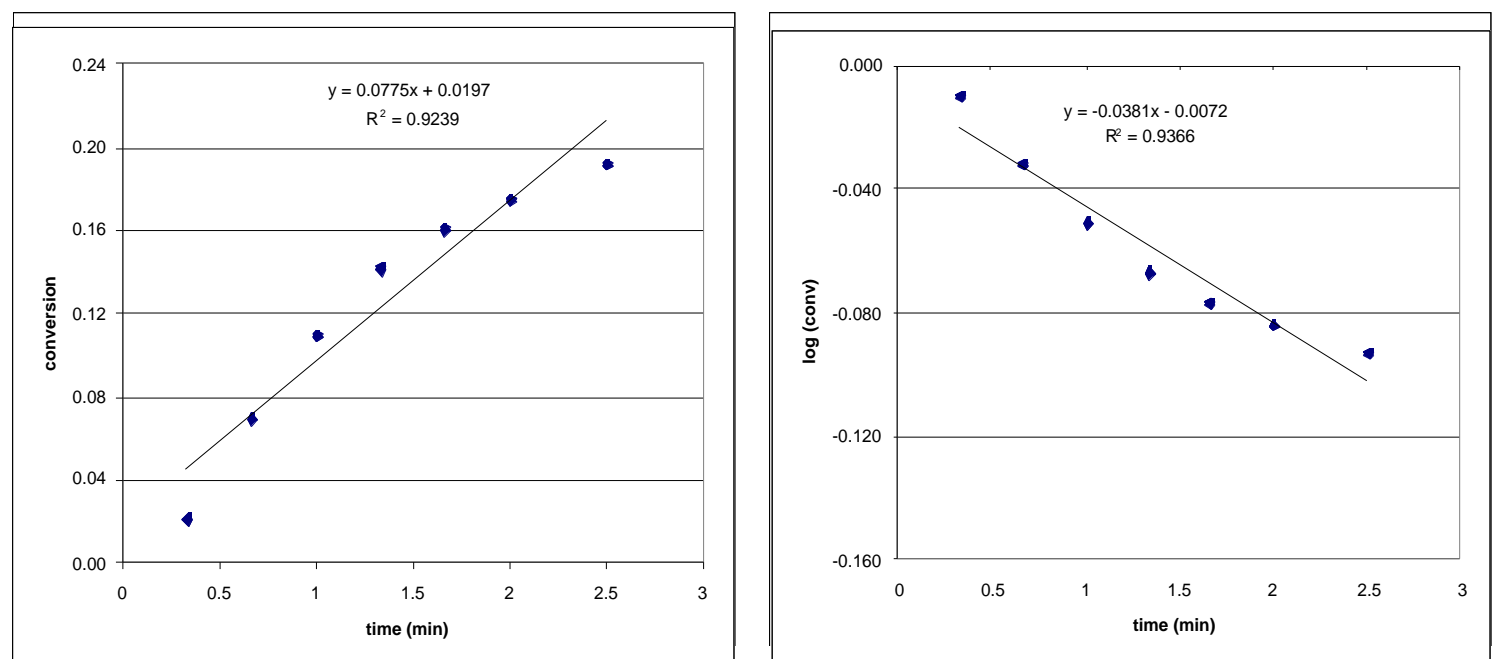


\begin{tabular}{c|c|c|c}
\hline time & area A & area 2 & conversion \\
\hline 0.33 & 7510 & 2322 & 0.082 \\
0.33 & 7693 & 2371 & 0.081 \\
0.33 & 7773 & 2413 & 0.082 \\
0.66 & 7068 & 4268 & 0.159 \\
0.66 & 6971 & 4202 & 0.159 \\
0.66 & 6981 & 4184 & 0.158 \\
1 & 7566 & 5497 & 0.192 \\
1 & 7530 & 5482 & 0.192 \\
1 & 7587 & 5504 & 0.192 \\
1.33 & 7121 & 5794 & 0.215 \\
1.33 & 7100 & 5766 & 0.214 \\
1.33 & 7145 & 5812 & 0.215 \\
1.66 & 8517 & 7448 & 0.231 \\
1.66 & 8507 & 7433 & 0.231 \\
1.66 & 8533 & 7738 & 0.230 \\
2 & 8377 & 7749 & 0.244 \\
2 & 8386 & 7746 & 0.244 \\
2 & 8369 & 8221 & 0.244 \\
2.5 & 8335 & 8227 & 0.260 \\
2.5 & 8305 & 8183 & 0.262 \\
2.5 & 8290 & 7935 & 0.261 \\
3 & 7549 & 7907 & 0.277 \\
3 & 7528 & 7946 & 0.277 \\
3 & 7560 & 8863 & 0.277 \\
5 & 7176 & 8926 & 0.326 \\
5 & 7189 & 8987 & 0.328 \\
5 & 7216 & 12808 & 0.329 \\
10 & 7784 & 12836 & 0.434 \\
10 & 7763 & & 0.436 \\
10 & 7764 & & 0.436 \\
& & &
\end{tabular}




\section{Order in Palladium, 0.05 equiv.}

$\begin{array}{ll}\mathrm{K}^{+}(E)-\mathbf{1}^{-} & 50 \mathrm{mM} \text { (1 equiv) } \\ \text { 2-Iodothiophene } & 50 \mathrm{mM} \text { (1 equiv) }\end{array}$

Bis(dibenzylideneacetone)palladium $2.5 \mathrm{mM}$ ( 0.05 equiv)

Following the General Procedure, $\mathrm{K}^{+}(E)-\mathbf{1}^{-}(0.52 \mathrm{~mL}, 0.481 \mathrm{M})$ and biphenyl $(7.0 \mathrm{mg})$ were dissolved in DME $(3.48 \mathrm{~mL})$ in a flame-dried, 2-neck round-bottomed flask, equipped with a stir bar and a septum under argon. The 2-iodothiophene $(27.6 \mu \mathrm{L}, 0.25 \mathrm{mmol})$ was then added and the reaction was stirred for $1 \mathrm{~min}$. A suspension of $\mathrm{Pd}(\mathrm{dba})_{2}(7.2 \mathrm{mg}, 0.0125 \mathrm{mmol})$ in dry THF (1.0 mL) was added. The dark red solution slowly turned turbid over time as the precipitation of KI proceeded. Aliquots $(\sim 200 \mu \mathrm{L})$ were withdrawn after $0.33,0.66,1.0,1.33$, $1.66,2.0,2.5,3.0,4,5,7$, and $10 \mathrm{~min}$. To quench, these samples were added to $100 \mu \mathrm{L}$ of a $20 \%$ aqueous solution of 2-dimethylaminoethanethiol hydrochloride. The clear colorless to slightlyyellow solution was then filtered through a plug of silica gel, and the silica gel was washed with diethyl ether to give a total sample volume of $\sim 2 \mathrm{~mL}$. This sample was injected into the GC three times.

initial rate $=0.0739$

$\mathrm{k}_{\mathrm{obs}}=0.039$
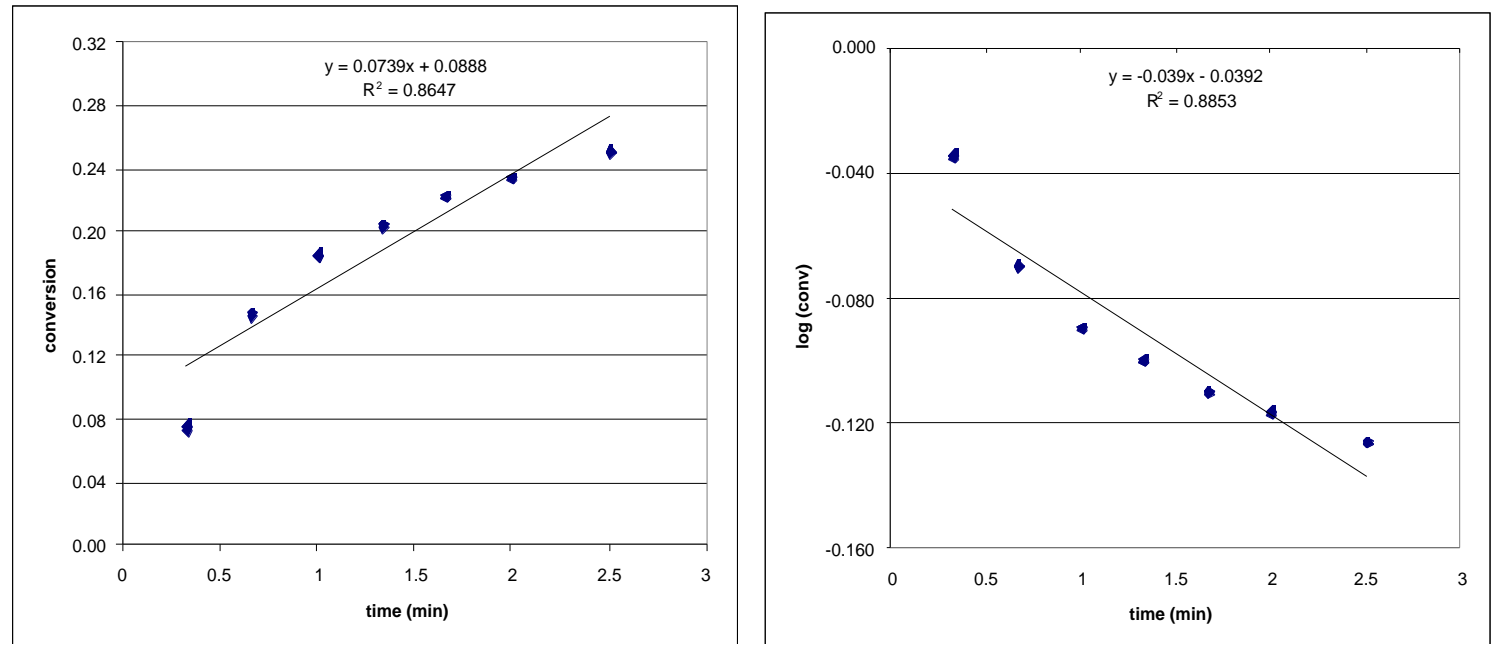


\begin{tabular}{c|c|c|c}
\hline time & area A & area 2 & Conversion \\
\hline 0.33 & 6011 & 1745 & 0.077 \\
0.33 & 6031 & 1726 & 0.076 \\
0.33 & 6027 & 1694 & 0.074 \\
0.66 & 7292 & 4096 & 0.148 \\
0.66 & 7270 & 4080 & 0.148 \\
0.66 & 7282 & 4049 & 0.147 \\
1 & 6462 & 4548 & 0.186 \\
1 & 6427 & 4510 & 0.185 \\
1 & 6416 & 4506 & 0.185 \\
1.33 & 5174 & 4015 & 0.205 \\
1.33 & 5172 & 4014 & 0.205 \\
1.33 & 5242 & 6040 & 0.203 \\
1.66 & 7337 & 6197 & 0.223 \\
1.66 & 7311 & 6177 & 0.224 \\
1.66 & 7323 & 6974 & 0.223 \\
2 & 7862 & 6994 & 0.234 \\
2 & 7848 & 6955 & 0.235 \\
2 & 7820 & 6363 & 0.235 \\
2.5 & 6706 & 6379 & 0.250 \\
2.5 & 6684 & 6428 & 0.252 \\
2.5 & 6737 & 7128 & 0.252 \\
3 & 7054 & 7059 & 0.267 \\
3 & 6972 & 7101 & 0.267 \\
3 & 7051 & 8764 & 0.266 \\
5 & 7313 & 8770 & 0.316 \\
5 & 7308 & 12397 & 0.317 \\
5 & 7279 & 12362 & 0.315 \\
10 & 8052 & 0.402 \\
10 & 8121 & 0.402 \\
10 & 8090 & &
\end{tabular}




\section{Order in Palladium, 0.10 equiv.}

$\mathrm{K}^{+}(E)-\mathbf{1}^{-}$

2-Iodothiophene

Bis(dibenzylideneacetone)palladium $5 \mathrm{mM}$ ( 0.10 equiv)
$50 \mathrm{mM}$ (1 equiv)

$50 \mathrm{mM}$ (1 equiv)

Following the General Procedure, $\mathrm{K}^{+}(E)-\mathbf{1}^{-}(0.54 \mathrm{~mL}, 0.466 \mathrm{M})$ and biphenyl $(12.5 \mathrm{mg})$ were dissolved in DME (3.46 mL) in a flame-dried, 2-neck round-bottomed flask, equipped with a stir bar and a septum under argon. The 2-iodothiophene $(27.6 \mu \mathrm{L}, 0.25 \mathrm{mmol})$ was then added and the reaction was stirred for $1 \mathrm{~min}$. A suspension of $\mathrm{Pd}(\mathrm{dba})_{2}(14.4 \mathrm{mg}, 0.025 \mathrm{mmol})$ in dry THF (1.0 mL) was added. The dark red solution slowly turned turbid over time as the precipitation of KI proceeded. Aliquots $(\sim 200 \mu \mathrm{L})$ were withdrawn after 0.33, 0.66, 1.0, 1.33, $1.66,2.0,2.5,3.0,4,5,7$, and $10 \mathrm{~min}$. To quench, these samples were added to $100 \mu \mathrm{L}$ of a $20 \%$ aqueous solution of 2-dimethylaminoethanethiol hydrochloride. The clear colorless to slightlyyellow solution was then filtered through a plug of silica gel, and the silica gel was washed with diethyl ether to give a total sample volume of $\sim 2 \mathrm{~mL}$. This sample was injected into the GC three times.

$$
\mathrm{k}_{\mathrm{obs}}=0.0756
$$

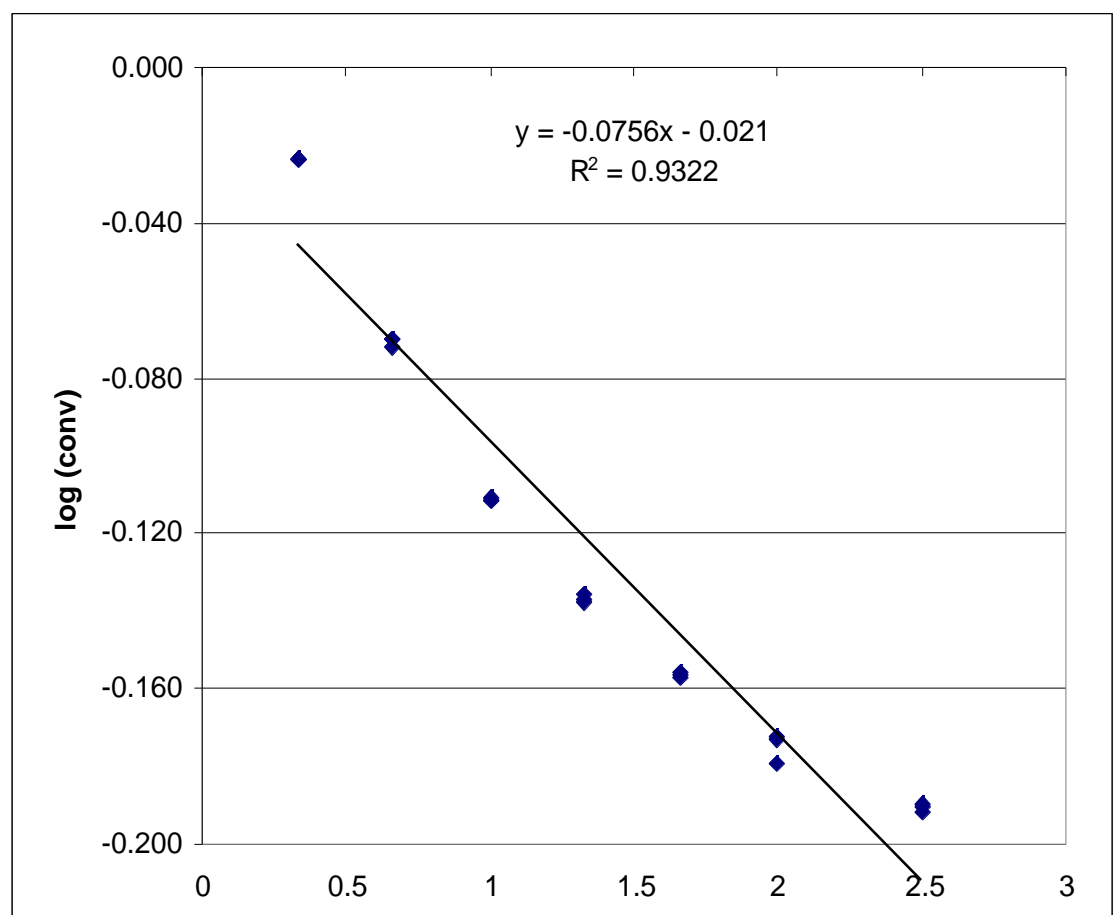




\begin{tabular}{|c|c|c|c|}
\hline time & area $\mathrm{A}$ & area 2 & Conversion \\
\hline 0.33 & 8906 & 995 & 0.053 \\
\hline 0.33 & 8908 & 983 & 0.052 \\
\hline 0.33 & 8900 & 995 & 0.053 \\
\hline 0.66 & 9042 & 2918 & 0.152 \\
\hline 0.66 & 9035 & 2857 & 0.149 \\
\hline 0.66 & 8740 & 2768 & 0.149 \\
\hline 1 & 7042 & 3387 & 0.227 \\
\hline 1 & 6965 & 3327 & 0.225 \\
\hline 1 & 7029 & 3372 & 0.226 \\
\hline 1.33 & 7904 & 4552 & 0.271 \\
\hline 1.33 & 7943 & 4515 & 0.268 \\
\hline 1.33 & 8033 & 4601 & 0.270 \\
\hline 1.66 & 8029 & 5166 & 0.303 \\
\hline 1.66 & 10302 & 6597 & 0.302 \\
\hline 1.66 & 8512 & 5443 & 0.301 \\
\hline 2 & 8284 & 5775 & 0.329 \\
\hline 2 & 9394 & 6733 & 0.338 \\
\hline 2 & 7988 & 5546 & 0.327 \\
\hline 2.5 & 9230 & 6929 & 0.354 \\
\hline 2.5 & 9783 & 7357 & 0.355 \\
\hline 2.5 & 9892 & 7483 & 0.357 \\
\hline 3 & 10591 & 8661 & 0.386 \\
\hline 3 & 13080 & 10710 & 0.386 \\
\hline 3 & 9469 & 7748 & 0.386 \\
\hline 5 & 9113 & 8961 & 0.464 \\
\hline 5 & 9734 & 9598 & 0.465 \\
\hline 5 & 8776 & 8628 & 0.463 \\
\hline 10 & 13250 & 16782 & 0.597 \\
\hline 10 & 9465 & 11983 & 0.597 \\
\hline 10 & 7912 & 9959 & 0.593 \\
\hline
\end{tabular}




\section{Order in Palladium, 0.10 equiv.}

$\mathrm{K}^{+}(E)-\mathbf{1}^{-}$

2-Iodothiophene

Bis(dibenzylideneacetone)palladium $5 \mathrm{mM}$ ( 0.10 equiv)
$50 \mathrm{mM}$ (1 equiv)

$50 \mathrm{mM}$ (1 equiv)

Following the General Procedure, $\mathrm{K}^{+}(E)-\mathbf{1}^{-}(0.54 \mathrm{~mL}, 0.466 \mathrm{M})$ and biphenyl $(10.8 \mathrm{mg})$ were dissolved in DME (3.46 mL) in a flame-dried, 2-neck round-bottomed flask, equipped with a stir bar and a septum under argon. The 2-iodothiophene $(27.6 \mu \mathrm{L}, 0.25 \mathrm{mmol})$ was then added and the reaction was stirred for $1 \mathrm{~min}$. A suspension of $\mathrm{Pd}(\mathrm{dba})_{2}(14.4 \mathrm{mg}, 0.025 \mathrm{mmol})$ in dry THF (1.0 mL) was added. The dark red solution slowly turned turbid over time as the precipitation of KI proceeded. Aliquots $(\sim 200 \mu \mathrm{L})$ were withdrawn after 0.33, 0.66, 1.0, 1.33, $1.66,2.0,2.5,3.0,4,5,7$, and $10 \mathrm{~min}$. To quench, these samples were added to $100 \mu \mathrm{L}$ of a $20 \%$ aqueous solution of 2-dimethylaminoethanethiol hydrochloride. The clear colorless to slightlyyellow solution was then filtered through a plug of silica gel, and the silica gel was washed with diethyl ether to give a total sample volume of $\sim 2 \mathrm{~mL}$. This sample was injected into the GC three times.

$$
\mathrm{k}_{\mathrm{obs}}=0.0702
$$

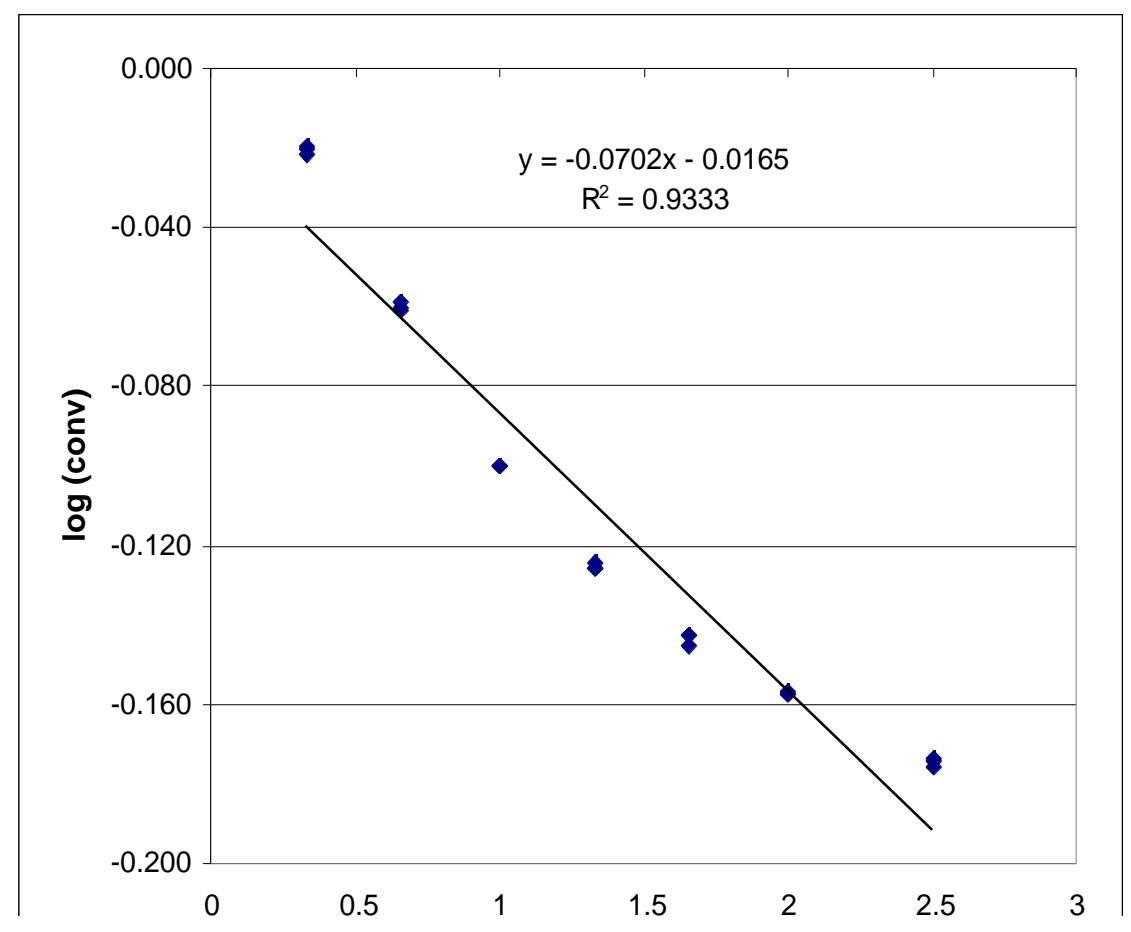




\begin{tabular}{c|c|c|c}
\hline time & area A & area 2 & Conversion \\
\hline 0.33 & 6212 & 667 & 0.044 \\
0.33 & 8300 & 975 & 0.048 \\
0.33 & 7780 & 869 & 0.045 \\
0.66 & 5066 & 1578 & 0.127 \\
0.66 & 5939 & 1910 & 0.131 \\
0.66 & 6218 & 1964 & 0.129 \\
1 & 9816 & 4951 & 0.205 \\
1 & 9107 & 4601 & 0.206 \\
1 & 9261 & 4680 & 0.206 \\
1.33 & 8303 & 5118 & 0.251 \\
1.33 & 8087 & 4999 & 0.252 \\
1.33 & 7992 & 4888 & 0.249 \\
1.66 & 8431 & 5795 & 0.280 \\
1.66 & 8418 & 5877 & 0.284 \\
1.66 & 8454 & 5809 & 0.280 \\
2 & 8946 & 6685 & 0.304 \\
2 & 8680 & 6482 & 0.304 \\
2 & 8535 & 6344 & 0.303 \\
2.5 & 7790 & 6314 & 0.330 \\
2.5 & 7761 & 6331 & 0.332 \\
2.5 & 7634 & 6175 & 0.329 \\
3 & 9772 & 8293 & 0.346 \\
3 & 9224 & 7811 & 0.345 \\
3 & 9510 & 8081 & 0.346 \\
5 & 7229 & 7275 & 0.410 \\
5 & 7111 & 7198 & 0.412 \\
5 & 7207 & 9227 & 0.410 \\
10 & 7317 & 0.514 \\
10 & 7419 & & 0.512 \\
10 & 7232 &
\end{tabular}




\section{Order in Palladium, 0.10 equiv.}

$\mathrm{K}^{+}(E)-\mathbf{1}^{-}$

2-Iodothiophene

Bis(dibenzylideneacetone)palladium $5 \mathrm{mM}$ ( 0.10 equiv)
$50 \mathrm{mM}$ (1 equiv)

$50 \mathrm{mM}$ (1 equiv)

Following the General Procedure, $\mathrm{K}^{+}(E)-\mathbf{1}^{-}(0.54 \mathrm{~mL}, 0.466 \mathrm{M})$ and biphenyl (13.2 $\left.\mathrm{mg}\right)$ were dissolved in DME (3.46 mL) in a flame-dried, 2-neck round-bottomed flask, equipped with a stir bar and a septum under argon. The 2-iodothiophene $(27.6 \mu \mathrm{L}, 0.25 \mathrm{mmol})$ was then added and the reaction was stirred for $1 \mathrm{~min}$. A suspension of $\mathrm{Pd}(\mathrm{dba})_{2}(14.4 \mathrm{mg}, 0.025 \mathrm{mmol})$ in dry THF (1.0 mL) was added. The dark red solution slowly turned turbid over time as the precipitation of KI proceeded. Aliquots $(\sim 200 \mu \mathrm{L})$ were withdrawn after 0.33, 0.66, 1.0, 1.33, $1.66,2.0,2.5,3.0,4,5,7$, and $10 \mathrm{~min}$. To quench, these samples were added to $100 \mu \mathrm{L}$ of a $20 \%$ aqueous solution of 2-dimethylaminoethanethiol hydrochloride. The clear colorless to slightlyyellow solution was then filtered through a plug of silica gel, and the silica gel was washed with diethyl ether to give a total sample volume of $\sim 2 \mathrm{~mL}$. This sample was injected into the GC three times.

$$
\mathrm{k}_{\mathrm{obs}}=0.0736
$$

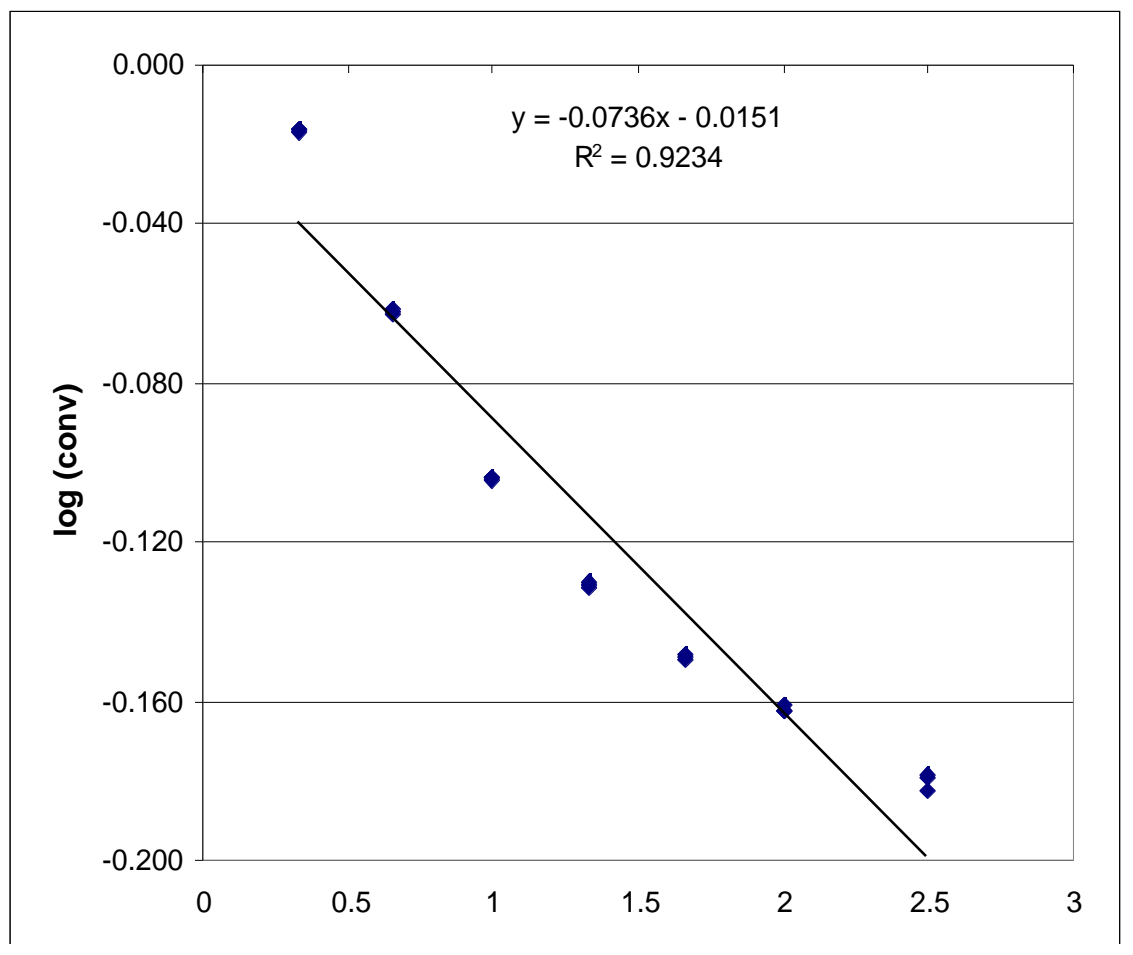




\begin{tabular}{|c|c|c|c|}
\hline time & $\operatorname{area} \mathrm{A}$ & area 2 & Conversion \\
\hline 0.33 & 10577 & 817 & 0.038 \\
\hline 0.33 & 10002 & 740 & 0.037 \\
\hline 0.33 & 9664 & 711 & 0.037 \\
\hline 0.66 & 8644 & 2340 & 0.135 \\
\hline 0.66 & 8823 & 2368 & 0.134 \\
\hline 0.66 & 9575 & 2535 & 0.132 \\
\hline 1 & 7566 & 3233 & 0.213 \\
\hline 1 & 7955 & 3396 & 0.213 \\
\hline 1 & 7575 & 3253 & 0.214 \\
\hline 1.33 & 8935 & 4686 & 0.261 \\
\hline 1.33 & 9004 & 4698 & 0.260 \\
\hline 1.33 & 7831 & 4068 & 0.259 \\
\hline 1.66 & 8326 & 4849 & 0.290 \\
\hline 1.66 & 8251 & 4787 & 0.289 \\
\hline 1.66 & 8238 & 4816 & 0.291 \\
\hline 2 & 9308 & 5785 & 0.309 \\
\hline 2 & 9262 & 5806 & 0.312 \\
\hline 2 & 9442 & 5911 & 0.312 \\
\hline 2.5 & 10262 & 6951 & 0.337 \\
\hline 2.5 & 10444 & 7202 & 0.343 \\
\hline 2.5 & 10387 & 7058 & 0.338 \\
\hline 3 & 11245 & 8132 & 0.360 \\
\hline 3 & 11226 & 8136 & 0.361 \\
\hline 3 & 10862 & 7861 & 0.360 \\
\hline 5 & 8805 & 7736 & 0.437 \\
\hline 5 & 9007 & 7894 & 0.436 \\
\hline 5 & 9628 & 8480 & 0.438 \\
\hline 10 & 8983 & 9843 & 0.545 \\
\hline 10 & 9177 & 10056 & 0.545 \\
\hline 10 & 9595 & 10443 & 0.542 \\
\hline
\end{tabular}




\section{Order in Palladium, 0.20 equiv.}

$\mathrm{K}^{+}(E)-\mathbf{1}^{-}$

2-Iodothiophene

Bis(dibenzylideneacetone)palladium $10 \mathrm{mM}$ (0.20 equiv)
$50 \mathrm{mM}$ (1 equiv)

$50 \mathrm{mM}$ (1 equiv)

Following the General Procedure, $\mathrm{K}^{+}(E)-\mathbf{1}^{-}(0.54 \mathrm{~mL}, 0.466 \mathrm{M})$ and biphenyl (15.9 mg) were dissolved in DME (3.46 mL) in a flame-dried, 2-neck round-bottomed flask, equipped with a stir bar and a septum under argon. The 2-iodothiophene $(27.6 \mu \mathrm{L}, 0.25 \mathrm{mmol})$ was then added and the reaction was stirred for $1 \mathrm{~min}$. A suspension of $\mathrm{Pd}(\mathrm{dba})_{2}(28.8 \mathrm{mg}, 0.050 \mathrm{mmol})$ in dry THF (1.0 mL) was added. The dark red solution slowly turned turbid over time as the precipitation of KI proceeded. Aliquots $(\sim 200 \mu \mathrm{L})$ were withdrawn after 0.33, 0.66, 1.0, 1.33, $1.66,2.0,2.5,3.0,4,5,7$, and $10 \mathrm{~min}$. To quench, these samples were added to $100 \mu \mathrm{L}$ of a $20 \%$ aqueous solution of 2-dimethylaminoethanethiol hydrochloride. The clear colorless to slightlyyellow solution was then filtered through a plug of silica gel, and the silica gel was washed with diethyl ether to give a total sample volume of $\sim 2 \mathrm{~mL}$. This sample was injected into the GC three times.

$$
\mathrm{k}_{\mathrm{obs}}=0.1654
$$

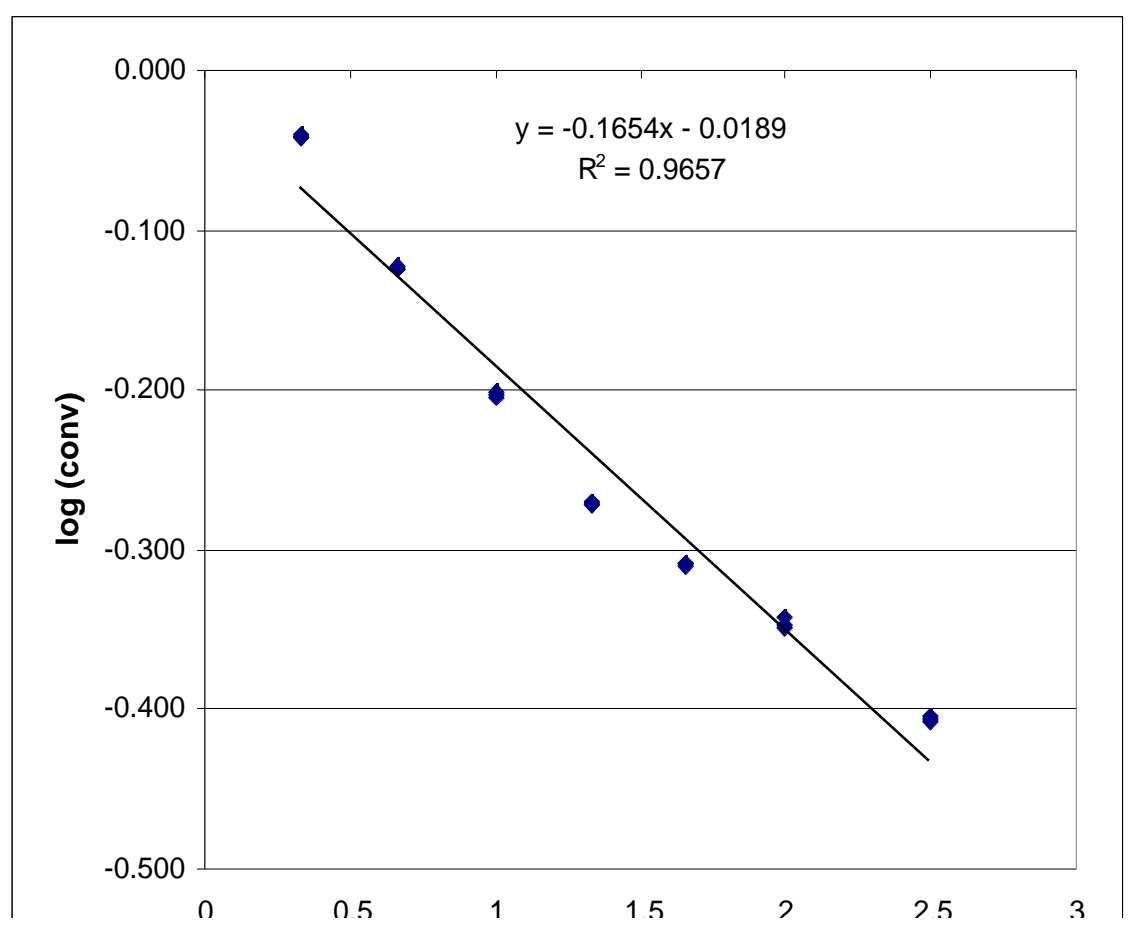




\begin{tabular}{|c|c|c|c|}
\hline time & area $\mathrm{A}$ & area 2 & Conversion \\
\hline 0.33 & 6875 & 1064 & 0.093 \\
\hline 0.33 & 6838 & 1029 & 0.090 \\
\hline 0.33 & 6817 & 1054 & 0.093 \\
\hline 0.66 & 6901 & 2835 & 0.246 \\
\hline 0.66 & 6861 & 2853 & 0.249 \\
\hline 0.66 & 6984 & 2880 & 0.247 \\
\hline 1 & 7149 & 4423 & 0.371 \\
\hline 1 & 7176 & 4483 & 0.375 \\
\hline 1 & 7100 & 4431 & 0.374 \\
\hline 1.33 & 5799 & 4491 & 0.464 \\
\hline 1.33 & 5730 & 4440 & 0.465 \\
\hline 1.33 & 5770 & 4459 & 0.463 \\
\hline 1.66 & 6729 & 5705 & 0.508 \\
\hline 1.66 & 6860 & 5825 & 0.509 \\
\hline 1.66 & 6824 & 5811 & 0.511 \\
\hline 2 & 6411 & 5908 & 0.553 \\
\hline 2 & 6301 & 5723 & 0.545 \\
\hline 2 & 6395 & 5867 & 0.550 \\
\hline 2.5 & 8027 & 8149 & 0.609 \\
\hline 2.5 & 8113 & 8200 & 0.606 \\
\hline 2.5 & 7998 & 8091 & 0.607 \\
\hline 3 & 7619 & 8235 & 0.648 \\
\hline 3 & 7637 & 8259 & 0.648 \\
\hline 3 & 7792 & 8464 & 0.651 \\
\hline 5 & 8302 & 10452 & 0.755 \\
\hline 5 & 8022 & 10754 & 0.804 \\
\hline 5 & 7997 & 10556 & 0.792 \\
\hline 10 & 11426 & 18634 & 0.978 \\
\hline 10 & 12171 & 20016 & 0.986 \\
\hline 10 & 12249 & 20107 & 0.984 \\
\hline
\end{tabular}




\section{Order in Palladium, 0.20 equiv.}

$\mathrm{K}^{+}(E)-\mathbf{1}^{-}$

2-Iodothiophene

Bis(dibenzylideneacetone)palladium $10 \mathrm{mM}$ (0.20 equiv)
$50 \mathrm{mM}$ (1 equiv)

$50 \mathrm{mM}$ (1 equiv)

Following the General Procedure, $\mathrm{K}^{+}(E)-\mathbf{1}^{-}(0.54 \mathrm{~mL}, 0.466 \mathrm{M})$ and biphenyl (11.4 mg) were dissolved in DME (3.46 mL) in a flame-dried, 2-neck round-bottomed flask, equipped with a stir bar and a septum under argon. The 2-iodothiophene $(27.6 \mu \mathrm{L}, 0.25 \mathrm{mmol})$ was then added and the reaction was stirred for $1 \mathrm{~min}$. A suspension of $\mathrm{Pd}(\mathrm{dba})_{2}(28.8 \mathrm{mg}, 0.050 \mathrm{mmol})$ in dry THF (1.0 mL) was added. The dark red solution slowly turned turbid over time as the precipitation of KI proceeded. Aliquots $(\sim 200 \mu \mathrm{L})$ were withdrawn after 0.33, 0.66, 1.0, 1.33, $1.66,2.0,2.5,3.0,4,5,7$, and $10 \mathrm{~min}$. To quench, these samples were added to $100 \mu \mathrm{L}$ of a $20 \%$ aqueous solution of 2-dimethylaminoethanethiol hydrochloride. The clear colorless to slightlyyellow solution was then filtered through a plug of silica gel, and the silica gel was washed with diethyl ether to give a total sample volume of $\sim 2 \mathrm{~mL}$. This sample was injected into the GC three times.

$$
\mathrm{k}_{\mathrm{obs}}=0.1682
$$

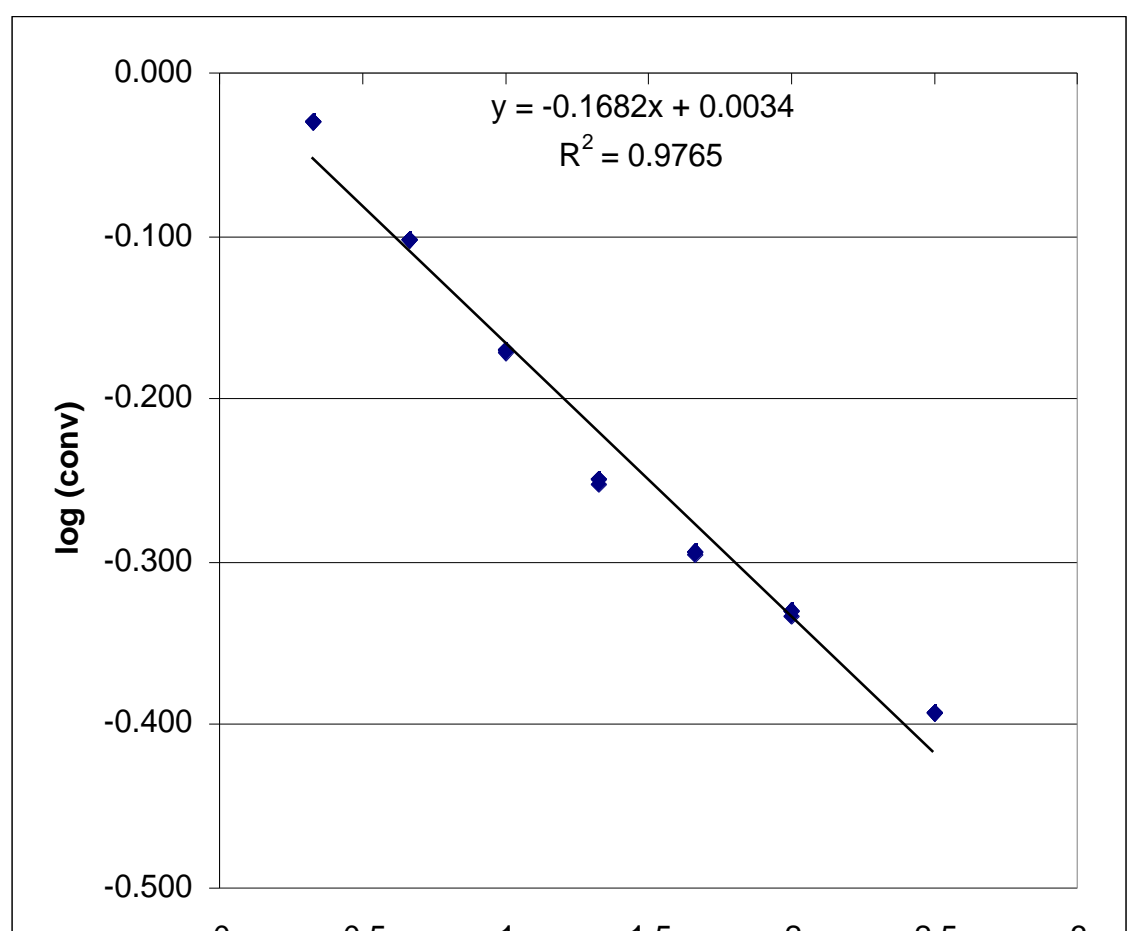




\begin{tabular}{|c|c|c|c|}
\hline time & area $\mathrm{A}$ & area 2 & Conversion \\
\hline 0.33 & 9410 & 1469 & 0.067 \\
\hline 0.33 & 9717 & 1481 & 0.066 \\
\hline 0.33 & 10457 & 1631 & 0.067 \\
\hline 0.66 & 13302 & 6462 & 0.209 \\
\hline 0.66 & 13197 & 6487 & 0.211 \\
\hline 0.66 & 12067 & 5924 & 0.211 \\
\hline 1 & 15637 & 11813 & 0.325 \\
\hline 1 & 4535 & 3413 & 0.324 \\
\hline 1 & 4296 & 3256 & 0.326 \\
\hline 1.33 & 9805 & 10037 & 0.440 \\
\hline 1.33 & 9826 & 9977 & 0.437 \\
\hline 1.33 & 9602 & 9729 & 0.436 \\
\hline 1.66 & 9441 & 10814 & 0.492 \\
\hline 1.66 & 11665 & 13383 & 0.493 \\
\hline 1.66 & 9331 & 10672 & 0.492 \\
\hline 2 & 10640 & 13174 & 0.532 \\
\hline 2 & 10526 & 13039 & 0.533 \\
\hline 2 & 10780 & 13419 & 0.535 \\
\hline 2.5 & 12085 & 16715 & 0.595 \\
\hline 2.5 & 12369 & 17143 & 0.596 \\
\hline 2.5 & 12265 & 16981 & 0.595 \\
\hline 3 & 10546 & 15714 & 0.641 \\
\hline 3 & 10083 & 15073 & 0.643 \\
\hline 3 & 10450 & 15631 & 0.643 \\
\hline 5 & 10744 & 19789 & 0.792 \\
\hline 5 & 9596 & 17867 & 0.801 \\
\hline 5 & 10300 & 18941 & 0.791 \\
\hline 10 & 10639 & 24475 & 0.989 \\
\hline 10 & 11280 & 26043 & 0.993 \\
\hline 10 & 10880 & 25044 & 0.990 \\
\hline
\end{tabular}




\section{Order in Palladium, 0.20 equiv.}

$\mathrm{K}^{+}(E)-\mathbf{1}^{-}$

2-Iodothiophene

Bis(dibenzylideneacetone)palladium $10 \mathrm{mM}$ (0.20 equiv)
$50 \mathrm{mM}$ (1 equiv)

$50 \mathrm{mM}$ (1 equiv)

Following the General Procedure, $\mathrm{K}^{+}(E)-\mathbf{1}^{-}(0.54 \mathrm{~mL}, 0.466 \mathrm{M})$ and biphenyl $(10.7 \mathrm{mg})$ were dissolved in DME (3.46 mL) in a flame-dried, 2-neck round-bottomed flask, equipped with a stir bar and a septum under argon. The 2-iodothiophene $(27.6 \mu \mathrm{L}, 0.25 \mathrm{mmol})$ was then added and the reaction was stirred for $1 \mathrm{~min}$. A suspension of $\mathrm{Pd}(\mathrm{dba})_{2}(28.8 \mathrm{mg}, 0.050 \mathrm{mmol})$ in dry THF (1.0 mL) was added. The dark red solution slowly turned turbid over time as the precipitation of KI proceeded. Aliquots $(\sim 200 \mu \mathrm{L})$ were withdrawn after 0.33, 0.66, 1.0, 1.33, $1.66,2.0,2.5,3.0,4,5,7$, and $10 \mathrm{~min}$. To quench, these samples were added to $100 \mu \mathrm{L}$ of a $20 \%$ aqueous solution of 2-dimethylaminoethanethiol hydrochloride. The clear colorless to slightlyyellow solution was then filtered through a plug of silica gel, and the silica gel was washed with diethyl ether to give a total sample volume of $\sim 2 \mathrm{~mL}$. This sample was injected into the GC three times.

$$
\mathrm{k}_{\mathrm{obs}}=0.182
$$

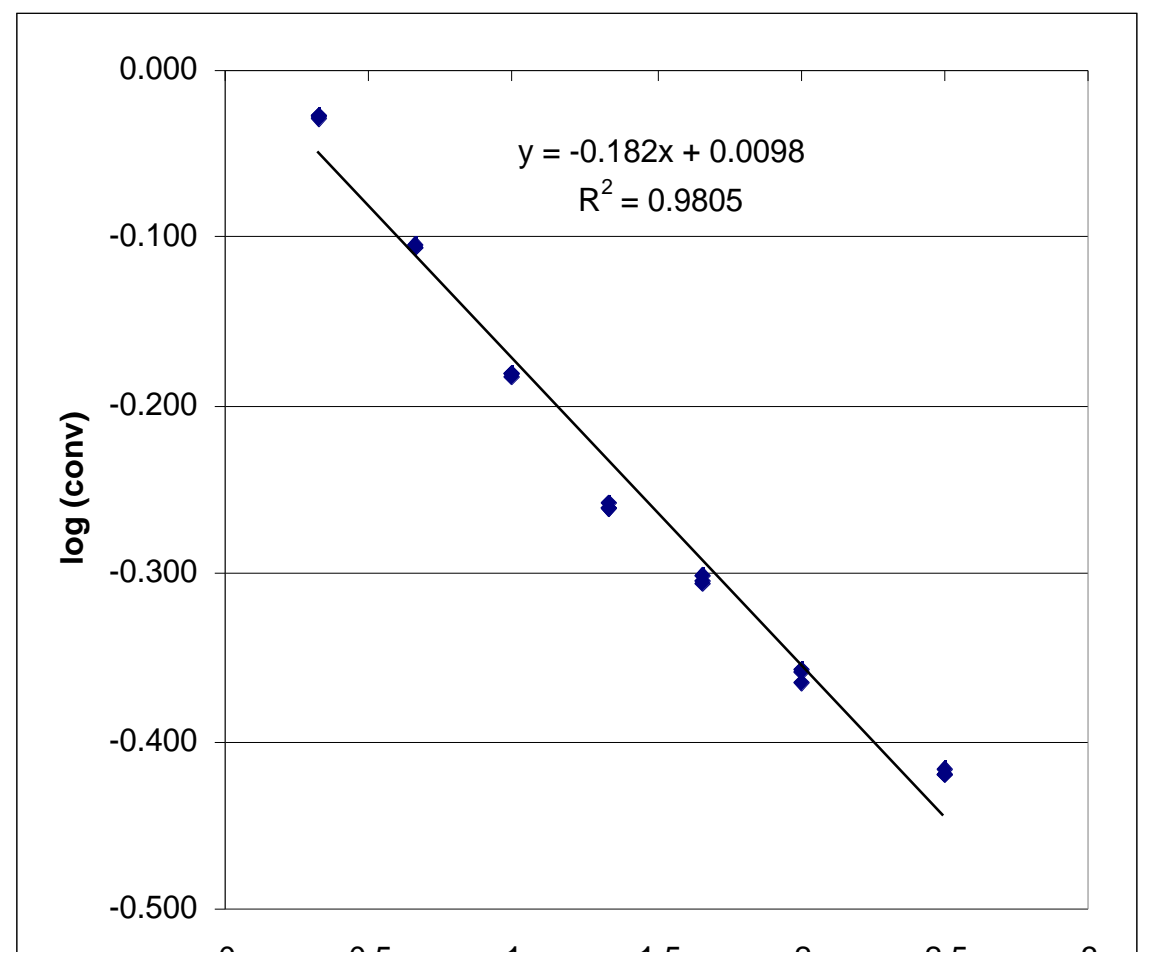




\begin{tabular}{|c|c|c|c|}
\hline time & area $\mathrm{A}$ & area 2 & Conversion \\
\hline 0.33 & 10805 & 1686 & 0.063 \\
\hline 0.33 & 11536 & 1743 & 0.061 \\
\hline 0.33 & 11442 & 1716 & 0.061 \\
\hline 0.66 & 11967 & 6300 & 0.212 \\
\hline 0.66 & 11776 & 6340 & 0.217 \\
\hline 0.66 & 11213 & 6010 & 0.216 \\
\hline 1 & 9946 & 8394 & 0.341 \\
\hline 1 & 9177 & 7791 & 0.343 \\
\hline 1 & 9426 & 7951 & 0.340 \\
\hline 1.33 & 11029 & 12222 & 0.447 \\
\hline 1.33 & 11587 & 12961 & 0.451 \\
\hline 1.33 & 10659 & 11966 & 0.453 \\
\hline 1.66 & 11241 & 13938 & 0.500 \\
\hline 1.66 & 11791 & 14736 & 0.504 \\
\hline 1.66 & 10333 & 12932 & 0.505 \\
\hline 2 & 8516 & 11829 & 0.561 \\
\hline 2 & 11146 & 15538 & 0.563 \\
\hline 2 & 9571 & 13488 & 0.569 \\
\hline 2.5 & 9706 & 14893 & 0.619 \\
\hline 2.5 & 9509 & 14608 & 0.620 \\
\hline 2.5 & 9114 & 13931 & 0.617 \\
\hline 3 & 11061 & 18113 & 0.661 \\
\hline 3 & 10882 & 17850 & 0.662 \\
\hline 3 & 10955 & 17919 & 0.660 \\
\hline 5 & 9953 & 19520 & 0.791 \\
\hline 5 & 9466 & 18667 & 0.796 \\
\hline 5 & 8905 & 17504 & 0.793 \\
\hline 10 & 8649 & 21431 & 1.000 \\
\hline 10 & 8705 & 21596 & 1.001 \\
\hline 10 & 8562 & 20891 & 0.985 \\
\hline
\end{tabular}




\section{Order in $\mathrm{K}^{+}(E)-1^{-}, 0.5$ equiv.}

$\mathrm{K}^{+}(E)-\mathbf{1}^{-}$

2-Iodothiophene

Bis(dibenzylideneacetone)palladium $2.5 \mathrm{mM}$ ( 0.05 equiv)
$25 \mathrm{mM}(0.5$ equiv)

$50 \mathrm{mM}$ (1.0 equiv)

Following the General Procedure, $\mathrm{K}^{+}(E)-\mathbf{1}^{-}(0.28 \mathrm{~mL}, 0.452 \mathrm{M})$ and biphenyl $(6.7 \mathrm{mg})$ were dissolved in DME (3.72 mL) in a flame-dried, 2-neck round-bottomed flask, equipped with a stir bar and a septum under argon. The 2-iodothiophene $(27.6 \mu \mathrm{L}, 0.25 \mathrm{mmol})$ was then added and the reaction was stirred for $1 \mathrm{~min}$. A suspension of $\mathrm{Pd}(\mathrm{dba})_{2}(7.2 \mathrm{mg}, 0.0125 \mathrm{mmol})$ in dry THF $(1.0 \mathrm{~mL})$ was added. The dark red solution slowly turned turbid over time as the precipitation of KI proceeded. Aliquots $(\sim 200 \mu \mathrm{L})$ were withdrawn after 0.33, 0.66, 1.0, 1.33, $1.66,2.0,2.5,3.0,4,5,7$, and $10 \mathrm{~min}$. To quench, these samples were added to $100 \mu \mathrm{L}$ of a $20 \%$ aqueous solution of 2-dimethylaminoethanethiol hydrochloride. The clear colorless to slightlyyellow solution was then filtered through a plug of silica gel, and the silica gel was washed with diethyl ether to give a total sample volume of $\sim 2 \mathrm{~mL}$. This sample was injected into the GC three times.

initial rate $=0.0431$

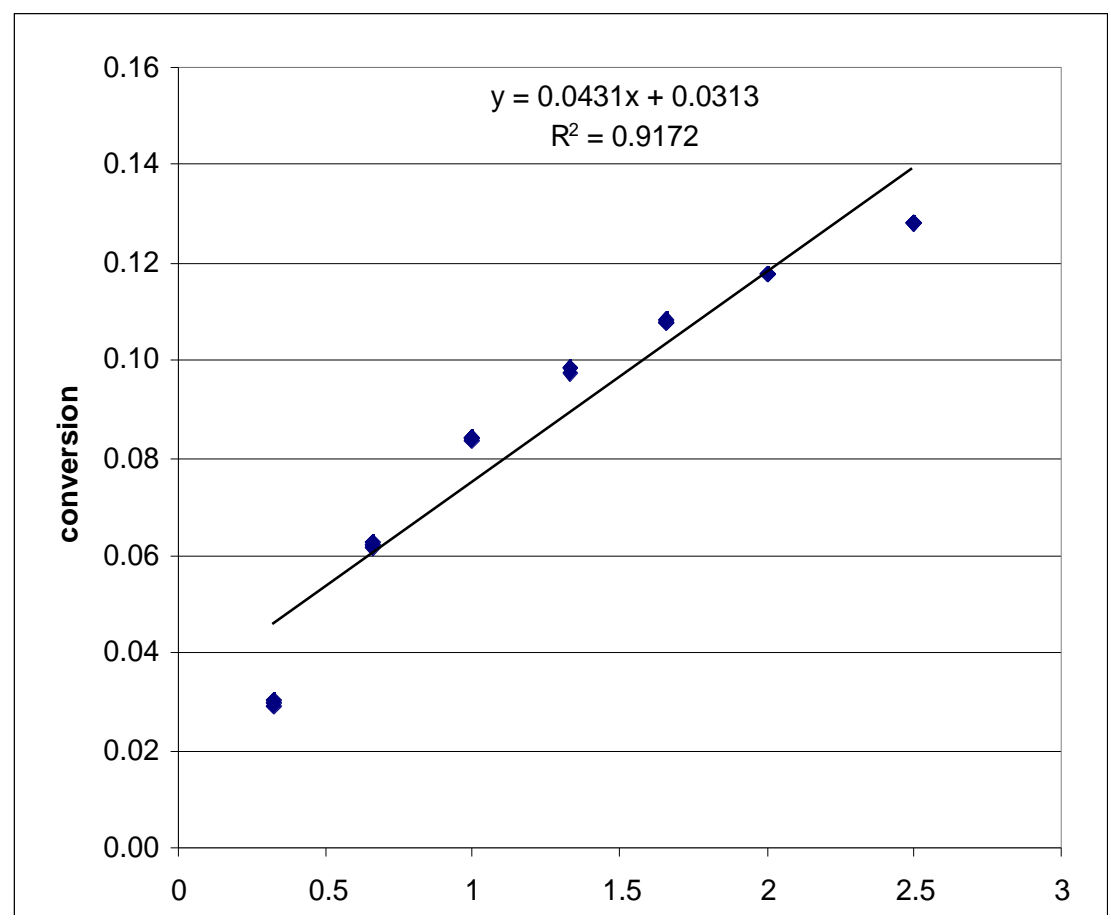




\begin{tabular}{c|c|c|c}
\hline time & area A & area 2 & Conversion \\
\hline 0.33 & 8322 & 977 & 0.030 \\
0.33 & 8289 & 989 & 0.030 \\
0.33 & 8478 & 987 & 0.029 \\
0.66 & 7689 & 1907 & 0.063 \\
0.66 & 7681 & 1893 & 0.062 \\
0.66 & 7717 & 1884 & 0.062 \\
1 & 8060 & 2664 & 0.084 \\
1 & 8083 & 2692 & 0.084 \\
1 & 8023 & 2672 & 0.084 \\
1.33 & 8669 & 3341 & 0.097 \\
1.33 & 8704 & 3383 & 0.098 \\
1.33 & 8794 & 3434 & 0.099 \\
1.66 & 9643 & 4127 & 0.108 \\
1.66 & 9480 & 4048 & 0.108 \\
1.66 & 9572 & 4090 & 0.108 \\
2 & 10318 & 4803 & 0.118 \\
2 & 10315 & 4797 & 0.118 \\
2 & 10304 & 4799 & 0.118 \\
2.5 & 9729 & 4923 & 0.128 \\
2.5 & 9719 & 4932 & 0.128 \\
2.5 & 9678 & 4908 & 0.128 \\
3 & 8760 & 4806 & 0.139 \\
3 & 8810 & 4832 & 0.139 \\
3 & 8755 & 4829 & 0.139 \\
5 & 7826 & 5218 & 0.168 \\
5 & 7822 & 5236 & 0.169 \\
5 & 7836 & 5241 & 0.169 \\
10 & 8093 & 6833 & 0.213 \\
10 & 8070 & & 0.214 \\
10 & & &
\end{tabular}




\section{Order in $\mathrm{K}^{+}(E)-1^{-}, 0.5$ equiv.}

$\mathrm{K}^{+}(E)-1^{-}$

2-Iodothiophene

Bis(dibenzylideneacetone)palladium $2.5 \mathrm{mM}$ (0.05 equiv)
$25 \mathrm{mM}(0.5$ equiv $)$

$50 \mathrm{mM}$ (1.0 equiv)

Following the General Procedure, $\mathrm{K}^{+}(E)-\mathbf{1}^{-}(0.28 \mathrm{~mL}, 0.452 \mathrm{M})$ and biphenyl $(6.2 \mathrm{mg})$ were dissolved in DME (3.72 mL) in a flame-dried, 2-neck round-bottomed flask, equipped with a stir bar and a septum under argon. The 2-iodothiophene $(27.6 \mu \mathrm{L}, 0.25 \mathrm{mmol})$ was then added and the reaction was stirred for $1 \mathrm{~min}$. A suspension of $\mathrm{Pd}(\mathrm{dba})_{2}(7.2 \mathrm{mg}, 0.0125 \mathrm{mmol})$ in dry THF (1.0 mL) was added. The dark red solution slowly turned turbid over time as the precipitation of KI proceeded. Aliquots $(\sim 200 \mu \mathrm{L})$ were withdrawn after $0.33,0.66,1.0,1.33$, $1.66,2.0,2.5,3.0,4,5,7$, and $10 \mathrm{~min}$. To quench, these samples were added to $100 \mu \mathrm{L}$ of a $20 \%$ aqueous solution of 2-dimethylaminoethanethiol hydrochloride. The clear colorless to slightlyyellow solution was then filtered through a plug of silica gel, and the silica gel was washed with diethyl ether to give a total sample volume of $\sim 2 \mathrm{~mL}$. This sample was injected into the GC three times.

initial rate $=0.0381$

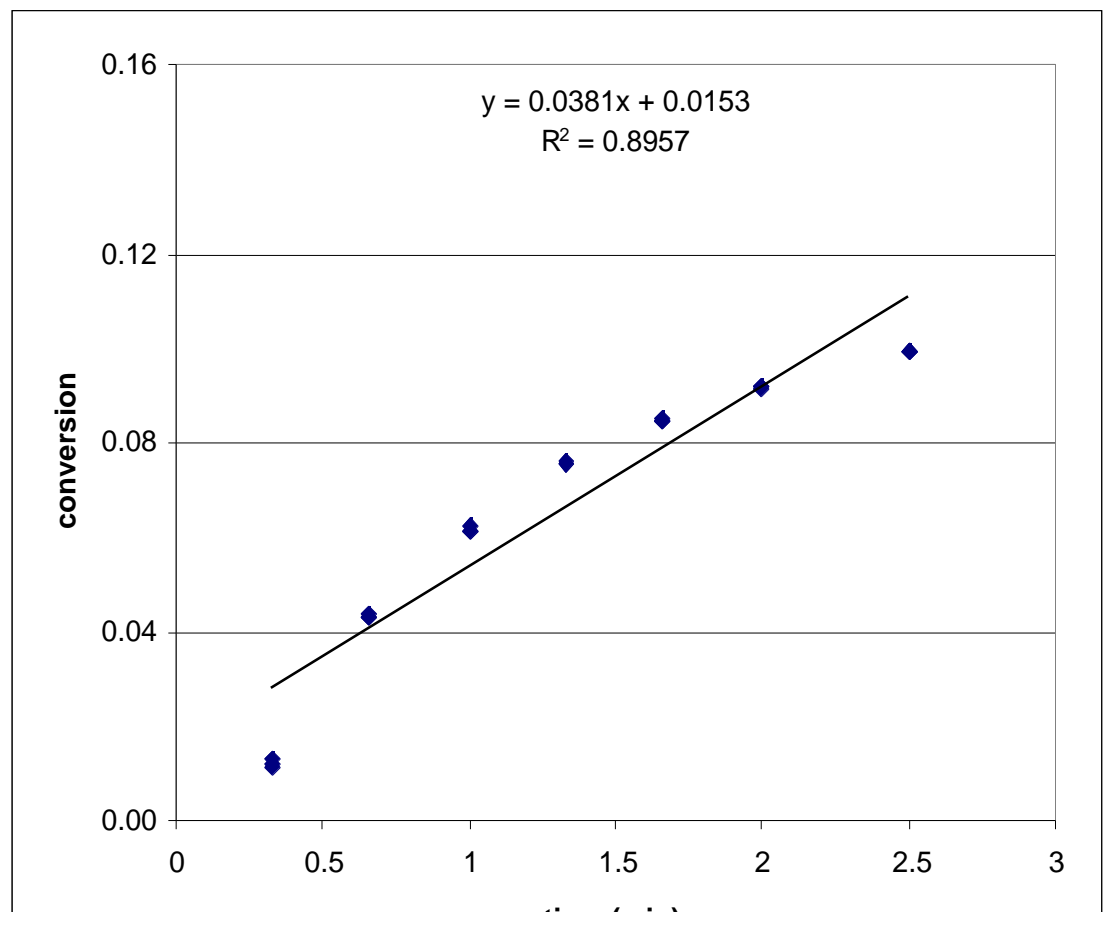




\begin{tabular}{c|c|c|c}
\hline time & area A & area 2 & Conversion \\
\hline 0.33 & 9438 & 517 & 0.013 \\
0.33 & 9245 & 471 & 0.012 \\
0.33 & 9424 & 469 & 0.012 \\
0.66 & 7739 & 1432 & 0.043 \\
0.66 & 7716 & 1419 & 0.043 \\
0.66 & 7667 & 1435 & 0.044 \\
1 & 9311 & 2448 & 0.061 \\
1 & 9325 & 2484 & 0.062 \\
1 & 9395 & 2471 & 0.062 \\
1.33 & 10318 & 3359 & 0.076 \\
1.33 & 10258 & 3314 & 0.076 \\
1.33 & 10258 & 3317 & 0.076 \\
1.66 & 8596 & 3113 & 0.085 \\
1.66 & 8630 & 3122 & 0.085 \\
1.66 & 8750 & 3180 & 0.085 \\
2 & 8940 & 3512 & 0.092 \\
2 & 8846 & 3470 & 0.092 \\
2 & 8871 & 3470 & 0.091 \\
2.5 & 9977 & 4240 & 0.099 \\
2.5 & 9968 & 4229 & 0.099 \\
2.5 & 9916 & 4208 & 0.099 \\
3 & 13382 & 6032 & 0.105 \\
3 & 13023 & 5862 & 0.105 \\
3 & 12822 & 5805 & 0.106 \\
5 & 7396 & 3976 & 0.126 \\
5 & 7409 & 3971 & 0.125 \\
5 & 7335 & 3933 & 0.125 \\
10 & 7804 & 5297 & 0.159 \\
10 & 7738 & 5098 & 0.158 \\
10 & 7567 & & 0.158 \\
& & &
\end{tabular}




\section{Order in $\mathrm{K}^{+}(E)-1^{-}, 0.5$ equiv.}

$\mathrm{K}^{+}(E)-1^{-}$

2-Iodothiophene

Bis(dibenzylideneacetone)palladium $2.5 \mathrm{mM}$ (0.05 equiv)
$25 \mathrm{mM}(0.5$ equiv $)$

$50 \mathrm{mM}(1.0$ equiv)

Following the General Procedure, $\mathrm{K}^{+}(E)-\mathbf{1}^{-}(0.28 \mathrm{~mL}, 0.452 \mathrm{M})$ and biphenyl $(6.8 \mathrm{mg})$ were dissolved in DME $(3.72 \mathrm{~mL})$ in a flame-dried, 2-neck round-bottomed flask, equipped with a stir bar and a septum under argon. The 2-iodothiophene $(27.6 \mu \mathrm{L}, 0.25 \mathrm{mmol})$ was then added and the reaction was stirred for $1 \mathrm{~min}$. A suspension of $\mathrm{Pd}(\mathrm{dba})_{2}(7.2 \mathrm{mg}, 0.0125 \mathrm{mmol})$ in dry THF (1.0 mL) was added. The dark red solution slowly turned turbid over time as the precipitation of KI proceeded. Aliquots $(\sim 200 \mu \mathrm{L})$ were withdrawn after $0.33,0.66,1.0,1.33$, $1.66,2.0,2.5,3.0,4,5,7$, and $10 \mathrm{~min}$. To quench, these samples were added to $100 \mu \mathrm{L}$ of a $20 \%$ aqueous solution of 2-dimethylaminoethanethiol hydrochloride. The clear colorless to slightlyyellow solution was then filtered through a plug of silica gel, and the silica gel was washed with diethyl ether to give a total sample volume of $\sim 2 \mathrm{~mL}$. This sample was injected into the GC three times.

initial rate $=0.0362$

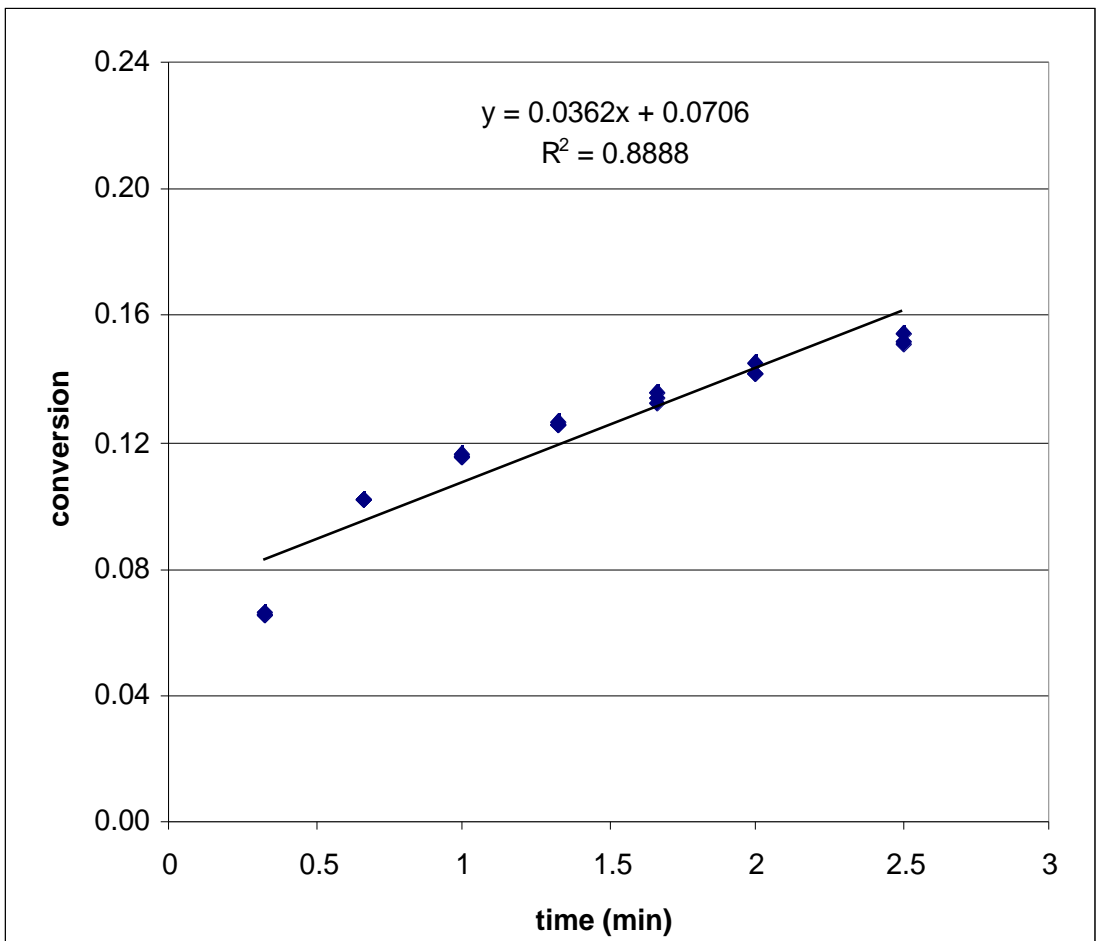




\begin{tabular}{c|c|c|c}
\hline time & area A & area 2 & Conversion \\
\hline 0.33 & 7102 & 1804 & 0.065 \\
0.33 & 7099 & 1824 & 0.066 \\
0.33 & 7143 & 1812 & 0.065 \\
0.66 & 9372 & 3716 & 0.102 \\
0.66 & 9388 & 3722 & 0.102 \\
0.66 & 9396 & 3739 & 0.102 \\
1 & 7384 & 3324 & 0.115 \\
1 & 7359 & 3336 & 0.116 \\
1 & 7389 & 3325 & 0.115 \\
1.33 & 9244 & 4542 & 0.126 \\
1.33 & 9239 & 4532 & 0.126 \\
1.33 & 9252 & 4535 & 0.126 \\
1.66 & 5805 & 3064 & 0.135 \\
1.66 & 5814 & 3044 & 0.134 \\
1.66 & 5832 & 3010 & 0.132 \\
2 & 7420 & 4107 & 0.142 \\
2 & 7467 & 4219 & 0.145 \\
2 & 7424 & 4099 & 0.142 \\
2.5 & 7986 & 4726 & 0.152 \\
2.5 & 7953 & 4680 & 0.151 \\
2.5 & 8028 & 4837 & 0.155 \\
3 & 9179 & 5626 & 0.157 \\
3 & 9226 & 5665 & 0.157 \\
3 & 9199 & 5662 & 0.158 \\
5 & 7764 & 4999 & 0.165 \\
5 & 7735 & 5007 & 0.166 \\
5 & 7760 & 5004 & 0.165 \\
10 & 7721 & 5128 & 0.170 \\
10 & 7654 & 5082 & 0.170 \\
10 & 7690 & & 0.171 \\
& & &
\end{tabular}




\section{Order in $\mathrm{K}^{+}(E)-1^{-}, 0.63$ equiv.}

$\mathrm{K}^{+}(E)-\mathbf{1}^{-}$

2-Iodothiophene

Bis(dibenzylideneacetone)palladium $2.5 \mathrm{mM}$ ( 0.05 equiv)
$31.25 \mathrm{mM}$ ( 0.63 equiv)

$50 \mathrm{mM}$ (1.0 equiv)

Following the General Procedure, $\mathrm{K}^{+}(E)-\mathbf{1}^{-}(0.35 \mathrm{~mL}, 0.452 \mathrm{M})$ and biphenyl $(6.0 \mathrm{mg})$ were dissolved in DME (3.65 mL) in a flame-dried, 2-neck round-bottomed flask, equipped with a stir bar and a septum under argon. The 2-iodothiophene $(27.6 \mu \mathrm{L}, 0.25 \mathrm{mmol})$ was then added and the reaction was stirred for $1 \mathrm{~min}$. A suspension of $\mathrm{Pd}(\mathrm{dba})_{2}(7.2 \mathrm{mg}, 0.0125 \mathrm{mmol})$ in dry THF $(1.0 \mathrm{~mL})$ was added. The dark red solution slowly turned turbid over time as the precipitation of KI proceeded. Aliquots $(\sim 200 \mu \mathrm{L})$ were withdrawn after 0.33, 0.66, 1.0, 1.33, $1.66,2.0,2.5,3.0,4,5,7$, and $10 \mathrm{~min}$. To quench, these samples were added to $100 \mu \mathrm{L}$ of a $20 \%$ aqueous solution of 2-dimethylaminoethanethiol hydrochloride. The clear colorless to slightlyyellow solution was then filtered through a plug of silica gel, and the silica gel was washed with diethyl ether to give a total sample volume of $\sim 2 \mathrm{~mL}$. This sample was injected into the GC three times.

initial rate $=0.0486$

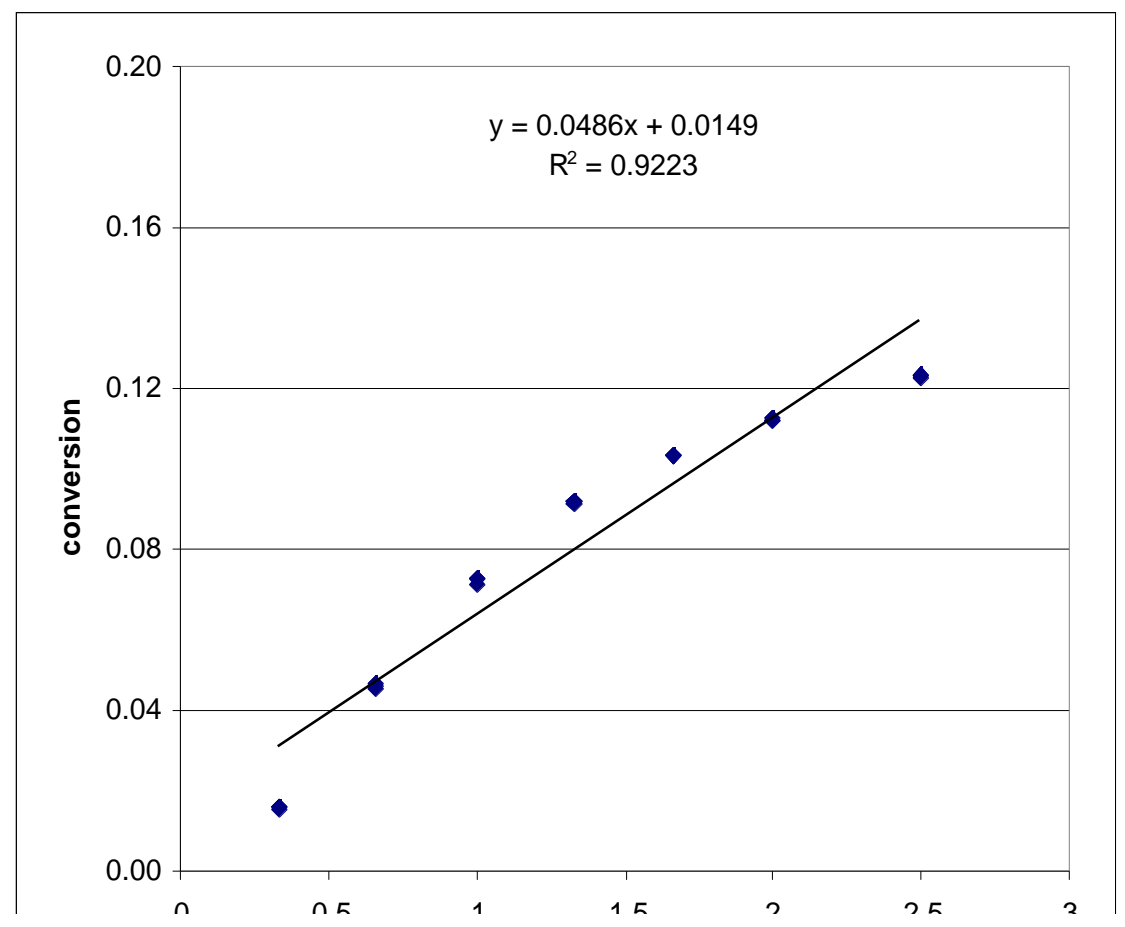




\begin{tabular}{|c|c|c|c|}
\hline time & area $\mathrm{A}$ & area 2 & Conversion \\
\hline 0.33 & 7473 & 533 & 0.016 \\
\hline 0.33 & 7105 & 507 & 0.016 \\
\hline 0.33 & 7099 & 483 & 0.015 \\
\hline 0.66 & 7053 & 1423 & 0.046 \\
\hline 0.66 & 7334 & 1483 & 0.046 \\
\hline 0.66 & 7159 & 1476 & 0.047 \\
\hline 1 & 6398 & 2052 & 0.073 \\
\hline 1 & 6385 & 2022 & 0.072 \\
\hline 1 & 6223 & 1990 & 0.072 \\
\hline 1.33 & 6805 & 2758 & 0.092 \\
\hline 1.33 & 6806 & 2755 & 0.092 \\
\hline 1.33 & 6662 & 2711 & 0.092 \\
\hline 1.66 & 6534 & 2992 & 0.104 \\
\hline 1.66 & 6371 & 2913 & 0.103 \\
\hline 1.66 & 6267 & 2867 & 0.104 \\
\hline 2 & 7798 & 3864 & 0.112 \\
\hline 2 & 8063 & 4002 & 0.112 \\
\hline 2 & 7831 & 3889 & 0.112 \\
\hline 2.5 & 6565 & 3584 & 0.124 \\
\hline 2.5 & 6623 & 3581 & 0.122 \\
\hline 2.5 & 6584 & 3593 & 0.123 \\
\hline 3 & 6375 & 3709 & 0.132 \\
\hline 3 & 6466 & 3774 & 0.132 \\
\hline 3 & 6574 & 3837 & 0.132 \\
\hline 5 & 5632 & 3995 & 0.160 \\
\hline 5 & 5496 & 3843 & 0.158 \\
\hline 5 & 5675 & 4009 & 0.160 \\
\hline 10 & 6975 & 6572 & 0.213 \\
\hline 10 & 7503 & 7066 & 0.213 \\
\hline 10 & 7450 & 6976 & 0.212 \\
\hline
\end{tabular}




\section{Order in $\mathrm{K}^{+}(E)-1^{-}, 0.63$ equiv.}

$\mathrm{K}^{+}(E)-\mathbf{1}^{-}$

2-Iodothiophene

Bis(dibenzylideneacetone)palladium $2.5 \mathrm{mM}$ (0.05 equiv)
$31.25 \mathrm{mM}$ ( 0.63 equiv)

$50 \mathrm{mM}$ (1.0 equiv)

Following the General Procedure, $\mathrm{K}^{+}(E)-\mathbf{1}^{-}(0.35 \mathrm{~mL}, 0.452 \mathrm{M})$ and biphenyl $(5.3 \mathrm{mg})$ were dissolved in DME (3.65 mL) in a flame-dried, 2-neck round-bottomed flask, equipped with a stir bar and a septum under argon. The 2-iodothiophene $(27.6 \mu \mathrm{L}, 0.25 \mathrm{mmol})$ was then added and the reaction was stirred for $1 \mathrm{~min}$. A suspension of $\mathrm{Pd}(\mathrm{dba})_{2}(7.2 \mathrm{mg}, 0.0125 \mathrm{mmol})$ in dry THF (1.0 mL) was added. The dark red solution slowly turned turbid over time as the precipitation of KI proceeded. Aliquots $(\sim 200 \mu \mathrm{L})$ were withdrawn after $0.33,0.66,1.0,1.33$, $1.66,2.0,2.5,3.0,4,5,7$, and $10 \mathrm{~min}$. To quench, these samples were added to $100 \mu \mathrm{L}$ of a $20 \%$ aqueous solution of 2-dimethylaminoethanethiol hydrochloride. The clear colorless to slightlyyellow solution was then filtered through a plug of silica gel, and the silica gel was washed with diethyl ether to give a total sample volume of $\sim 2 \mathrm{~mL}$. This sample was injected into the GC three times.

initial rate $=0.048$

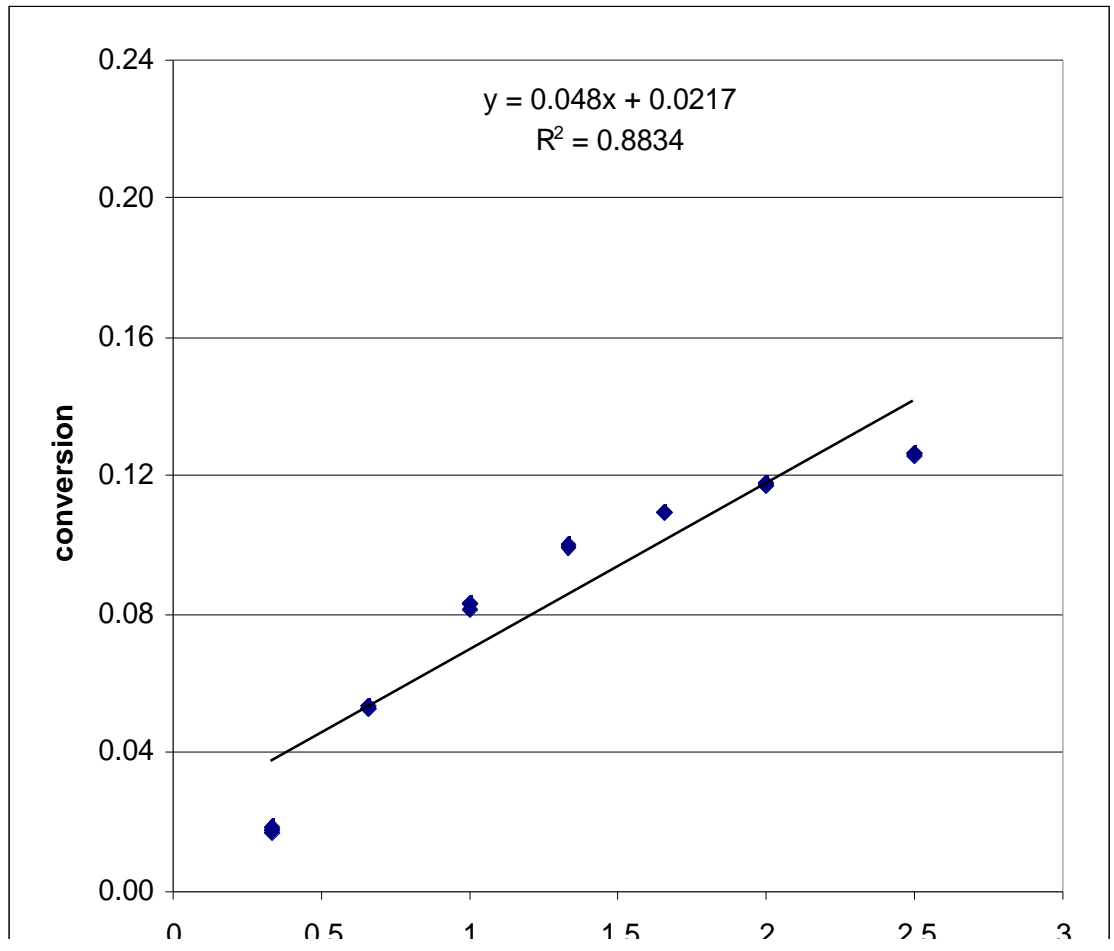




\begin{tabular}{|c|c|c|c|}
\hline time & area $\mathrm{A}$ & area 2 & Conversion \\
\hline 0.33 & 8888 & 773 & 0.017 \\
\hline 0.33 & 8548 & 767 & 0.018 \\
\hline 0.33 & 8640 & 798 & 0.018 \\
\hline 0.66 & 8727 & 2322 & 0.053 \\
\hline 0.66 & 8924 & 2355 & 0.053 \\
\hline 0.66 & 8957 & 2405 & 0.054 \\
\hline 1 & 7638 & 3174 & 0.083 \\
\hline 1 & 8147 & 3384 & 0.083 \\
\hline 1 & 8133 & 3332 & 0.082 \\
\hline 1.33 & 8474 & 4219 & 0.100 \\
\hline 1.33 & 8502 & 4260 & 0.100 \\
\hline 1.33 & 8406 & 4182 & 0.099 \\
\hline 1.66 & 8007 & 4378 & 0.109 \\
\hline 1.66 & 7915 & 4348 & 0.110 \\
\hline 1.66 & 8065 & 4422 & 0.110 \\
\hline 2 & 8713 & 5123 & 0.118 \\
\hline 2 & 9063 & 5351 & 0.118 \\
\hline 2 & 8867 & 5213 & 0.118 \\
\hline 2.5 & 9001 & 5691 & 0.126 \\
\hline 2.5 & 8676 & 5479 & 0.126 \\
\hline 2.5 & 8727 & 5510 & 0.126 \\
\hline 3 & 8037 & 5373 & 0.134 \\
\hline 3 & 8285 & 5549 & 0.134 \\
\hline 3 & 7988 & 5351 & 0.134 \\
\hline 5 & 8299 & 6503 & 0.157 \\
\hline 5 & 8568 & 6731 & 0.157 \\
\hline 5 & 8387 & 6573 & 0.157 \\
\hline 10 & 7560 & 7385 & 0.195 \\
\hline 10 & 7911 & 7783 & 0.197 \\
\hline 10 & 7834 & 7671 & 0.196 \\
\hline
\end{tabular}




\section{Order in $\mathrm{K}^{+}(E)-1^{-}, 0.63$ equiv.}

$\mathrm{K}^{+}(E)-\mathbf{1}^{-}$

2-Iodothiophene

Bis(dibenzylideneacetone)palladium $2.5 \mathrm{mM}$ (0.05 equiv)
$31.25 \mathrm{mM}$ ( 0.63 equiv)

$50 \mathrm{mM}$ (1.0 equiv)

Following the General Procedure, $\mathrm{K}^{+}(E)-\mathbf{1}^{-}(0.35 \mathrm{~mL}, 0.452 \mathrm{M})$ and biphenyl $(5.8 \mathrm{mg})$ were dissolved in DME (3.65 mL) in a flame-dried, 2-neck round-bottomed flask, equipped with a stir bar and a septum under argon. The 2-iodothiophene $(27.6 \mu \mathrm{L}, 0.25 \mathrm{mmol})$ was then added and the reaction was stirred for $1 \mathrm{~min}$. A suspension of $\mathrm{Pd}(\mathrm{dba})_{2}(7.2 \mathrm{mg}, 0.0125 \mathrm{mmol})$ in dry THF (1.0 mL) was added. The dark red solution slowly turned turbid over time as the precipitation of KI proceeded. Aliquots $(\sim 200 \mu \mathrm{L})$ were withdrawn after $0.33,0.66,1.0,1.33$, $1.66,2.0,2.5,3.0,4,5,7$, and $10 \mathrm{~min}$. To quench, these samples were added to $100 \mu \mathrm{L}$ of a $20 \%$ aqueous solution of 2-dimethylaminoethanethiol hydrochloride. The clear colorless to slightlyyellow solution was then filtered through a plug of silica gel, and the silica gel was washed with diethyl ether to give a total sample volume of $\sim 2 \mathrm{~mL}$. This sample was injected into the GC three times.

initial rate $=0.0454$

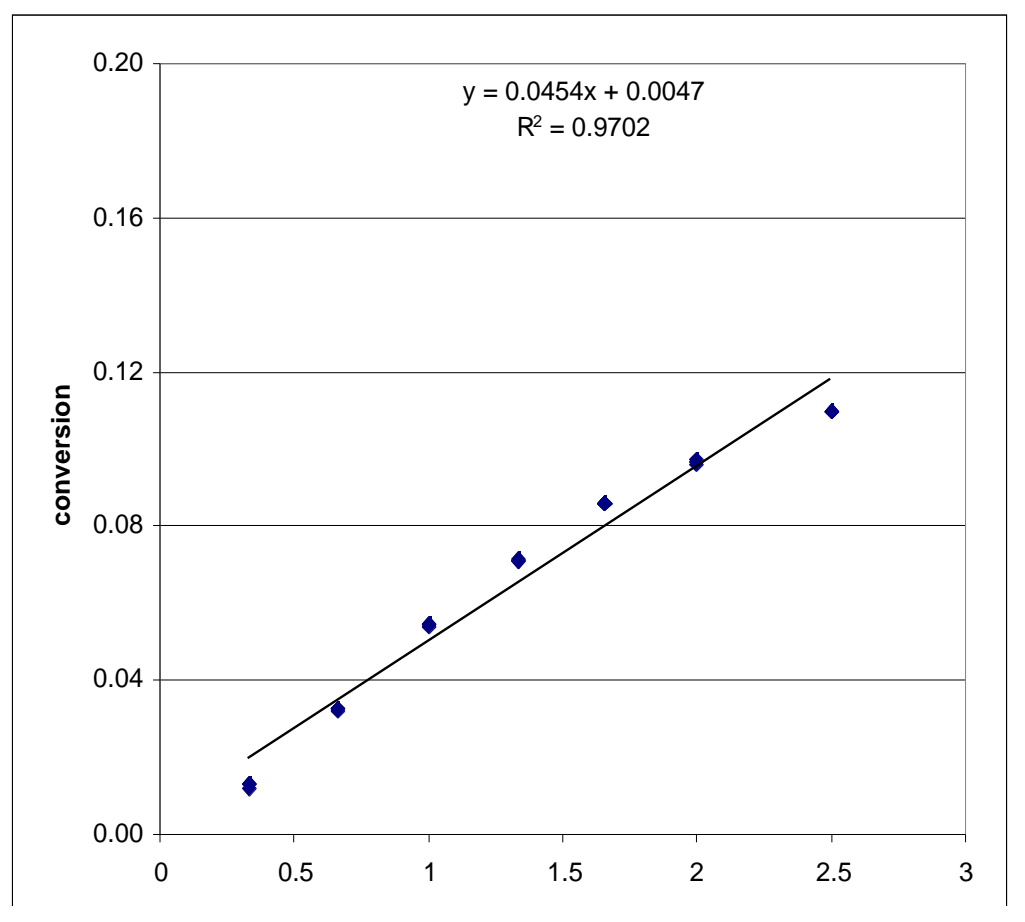




\begin{tabular}{|c|c|c|c|}
\hline time & $\operatorname{area} \mathrm{A}$ & area 2 & Conversion \\
\hline 0.33 & 6389 & 381 & 0.013 \\
\hline 0.33 & 6644 & 358 & 0.012 \\
\hline 0.33 & 6559 & 386 & 0.013 \\
\hline 0.66 & 7780 & 1134 & 0.032 \\
\hline 0.66 & 7804 & 1161 & 0.033 \\
\hline 0.66 & 7818 & 1175 & 0.033 \\
\hline 1 & 7755 & 1942 & 0.055 \\
\hline 1 & 7606 & 1899 & 0.055 \\
\hline 1 & 7872 & 1944 & 0.054 \\
\hline 1.33 & 11652 & 3763 & 0.071 \\
\hline 1.33 & 11810 & 3854 & 0.071 \\
\hline 1.33 & 11880 & 3848 & 0.071 \\
\hline 1.66 & 6703 & 2638 & 0.086 \\
\hline 1.66 & 6858 & 2701 & 0.086 \\
\hline 1.66 & 6682 & 2624 & 0.086 \\
\hline 2 & 7609 & 3390 & 0.097 \\
\hline 2 & 7482 & 3297 & 0.096 \\
\hline 2 & 7520 & 3290 & 0.096 \\
\hline 2.5 & 9162 & 4607 & 0.110 \\
\hline 2.5 & 8573 & 4291 & 0.109 \\
\hline 2.5 & 8705 & 4360 & 0.110 \\
\hline 3 & 9250 & 5102 & 0.121 \\
\hline 3 & 9931 & 5485 & 0.121 \\
\hline 3 & 8700 & 4770 & 0.120 \\
\hline 5 & 7184 & 4978 & 0.152 \\
\hline 5 & 7377 & 5127 & 0.152 \\
\hline 5 & 8007 & 5555 & 0.152 \\
\hline 10 & 7817 & 7103 & 0.199 \\
\hline 10 & 8487 & 7728 & 0.199 \\
\hline 10 & 8761 & 7959 & 0.199 \\
\hline
\end{tabular}




\section{Order in $\mathrm{K}^{+}(E)-1^{-}, 0.75$ equiv.}

$\mathrm{K}^{+}(E)-\mathbf{1}^{-}$

2-Iodothiophene

Bis(dibenzylideneacetone)palladium $2.5 \mathrm{mM}$ (0.05 equiv)
$37.5 \mathrm{mM}(0.75$ equiv $)$

$50 \mathrm{mM}$ (1.0 equiv)

Following the General Procedure, $\mathrm{K}^{+}(E)-\mathbf{1}^{-}(0.41 \mathrm{~mL}, 0.452 \mathrm{M})$ and biphenyl $(6.5 \mathrm{mg})$ were dissolved in DME (3.59 mL) in a flame-dried, 2-neck round-bottomed flask, equipped with a stir bar and a septum under argon. The 2-iodothiophene $(27.6 \mu \mathrm{L}, 0.25 \mathrm{mmol})$ was then added and the reaction was stirred for $1 \mathrm{~min}$. A suspension of $\mathrm{Pd}(\mathrm{dba})_{2}(7.2 \mathrm{mg}, 0.0125 \mathrm{mmol})$ in dry THF (1.0 mL) was added. The dark red solution slowly turned turbid over time as the precipitation of KI proceeded. Aliquots $(\sim 200 \mu \mathrm{L})$ were withdrawn after 0.33, 0.66, 1.0, 1.33, $1.66,2.0,2.5,3.0,4,5,7$, and $10 \mathrm{~min}$. To quench, these samples were added to $100 \mu \mathrm{L}$ of a $20 \%$ aqueous solution of 2-dimethylaminoethanethiol hydrochloride. The clear colorless to slightlyyellow solution was then filtered through a plug of silica gel, and the silica gel was washed with diethyl ether to give a total sample volume of $\sim 2 \mathrm{~mL}$. This sample was injected into the GC three times.

initial rate $=0.0517$

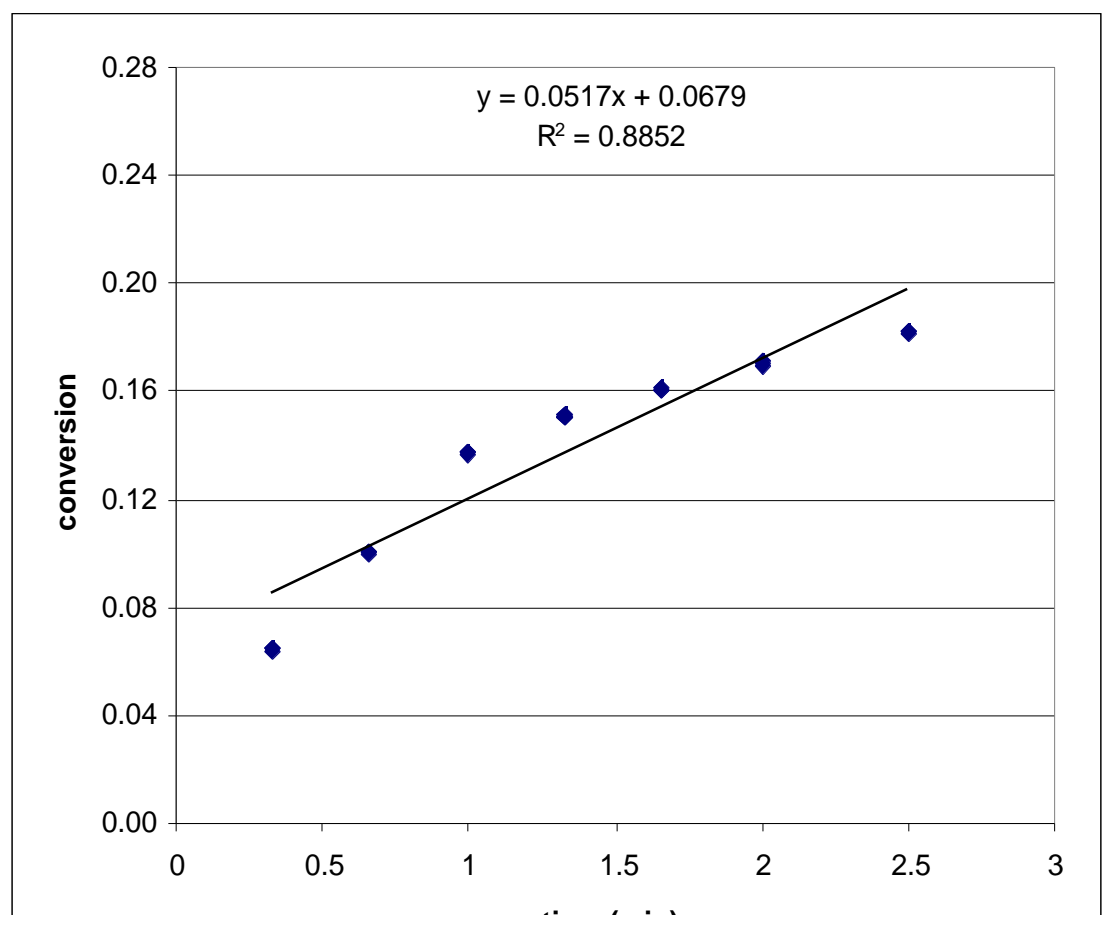




\begin{tabular}{|c|c|c|c|}
\hline time & area $\mathrm{A}$ & area 2 & Conversion \\
\hline 0.33 & 5482 & 1424 & 0.064 \\
\hline 0.33 & 5689 & 1506 & 0.065 \\
\hline 0.33 & 5584 & 1471 & 0.065 \\
\hline 0.66 & 5951 & 2451 & 0.101 \\
\hline 0.66 & 5986 & 2459 & 0.101 \\
\hline 0.66 & 6011 & 2434 & 0.099 \\
\hline 1 & 6841 & 3834 & 0.137 \\
\hline 1 & 6749 & 3775 & 0.137 \\
\hline 1 & 6814 & 3799 & 0.137 \\
\hline 1.33 & 8390 & 5150 & 0.150 \\
\hline 1.33 & 8408 & 5154 & 0.150 \\
\hline 1.33 & 8442 & 5210 & 0.151 \\
\hline 1.66 & 7414 & 4864 & 0.161 \\
\hline 1.66 & 7351 & 4817 & 0.161 \\
\hline 1.66 & 7404 & 4877 & 0.161 \\
\hline 2 & 7320 & 5103 & 0.171 \\
\hline 2 & 7367 & 5084 & 0.169 \\
\hline 2 & 7331 & 5106 & 0.171 \\
\hline 2.5 & 7838 & 5838 & 0.183 \\
\hline 2.5 & 7894 & 5856 & 0.182 \\
\hline 2.5 & 7839 & 5821 & 0.182 \\
\hline 3 & 10553 & 8230 & 0.191 \\
\hline 3 & 10555 & 8230 & 0.191 \\
\hline 3 & 10550 & 8258 & 0.192 \\
\hline 5 & 7996 & 7526 & 0.231 \\
\hline 5 & 8076 & 7570 & 0.230 \\
\hline 5 & 8073 & 7552 & 0.229 \\
\hline 10 & 7874 & 9946 & 0.310 \\
\hline 10 & 7901 & 9988 & 0.310 \\
\hline 10 & 7960 & 10052 & 0.310 \\
\hline
\end{tabular}




\section{Order in $\mathrm{K}^{+}(E)-1^{-}, 0.75$ equiv.}

$\mathrm{K}^{+}(E)-\mathbf{1}^{-}$

2-Iodothiophene

Bis(dibenzylideneacetone)palladium $2.5 \mathrm{mM}$ (0.05 equiv)
$37.5 \mathrm{mM}(0.75$ equiv $)$

$50 \mathrm{mM}$ (1.0 equiv)

Following the General Procedure, $\mathrm{K}^{+}(E)-\mathbf{1}^{-}(0.41 \mathrm{~mL}, 0.452 \mathrm{M})$ and biphenyl $(5.5 \mathrm{mg})$ were dissolved in DME (3.59 mL) in a flame-dried, 2-neck round-bottomed flask, equipped with a stir bar and a septum under argon. The 2-iodothiophene $(27.6 \mu \mathrm{L}, 0.25 \mathrm{mmol})$ was then added and the reaction was stirred for $1 \mathrm{~min}$. A suspension of $\mathrm{Pd}(\mathrm{dba})_{2}(7.2 \mathrm{mg}, 0.0125 \mathrm{mmol})$ in dry THF (1.0 mL) was added. The dark red solution slowly turned turbid over time as the precipitation of KI proceeded. Aliquots $(\sim 200 \mu \mathrm{L})$ were withdrawn after 0.33, 0.66, 1.0, 1.33, $1.66,2.0,2.5,3.0,4,5,7$, and $10 \mathrm{~min}$. To quench, these samples were added to $100 \mu \mathrm{L}$ of a $20 \%$ aqueous solution of 2-dimethylaminoethanethiol hydrochloride. The clear colorless to slightlyyellow solution was then filtered through a plug of silica gel, and the silica gel was washed with diethyl ether to give a total sample volume of $\sim 2 \mathrm{~mL}$. This sample was injected into the GC three times.

initial rate $=0.0560$

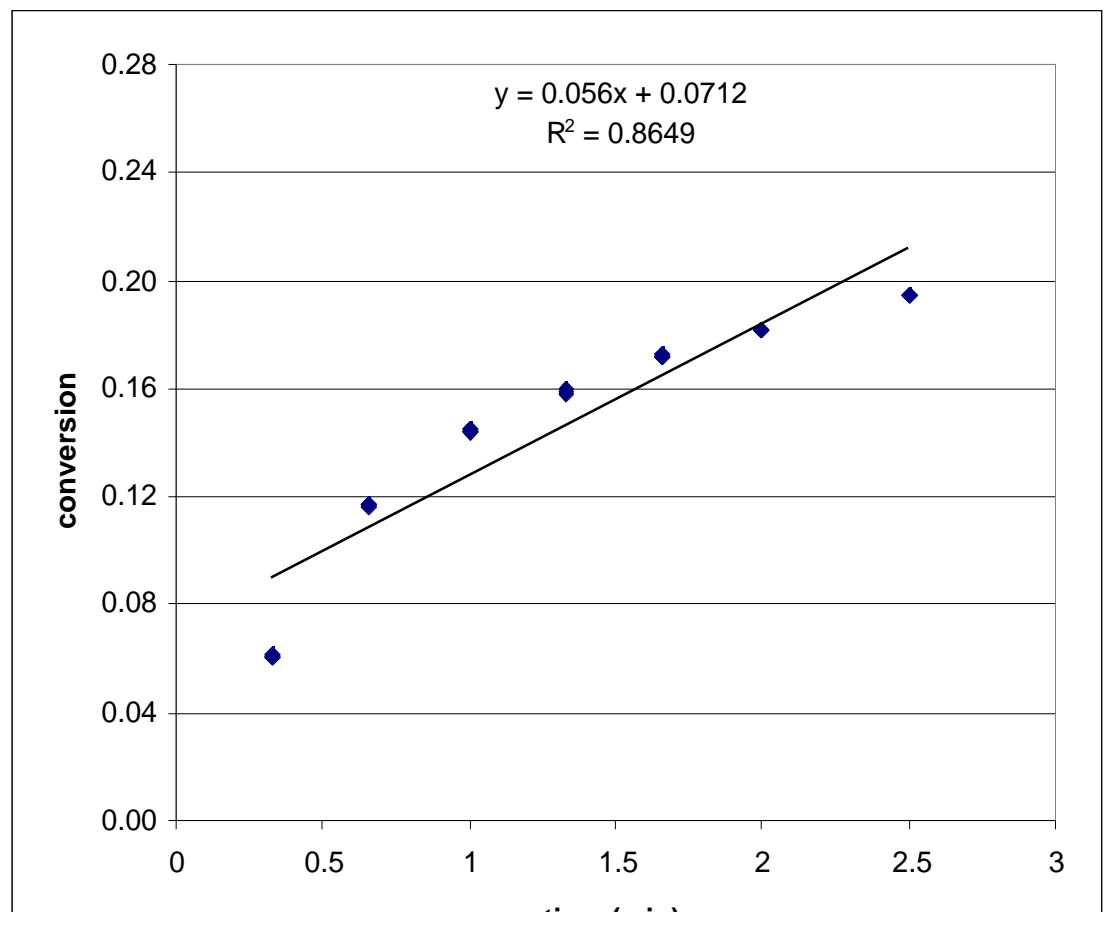




\begin{tabular}{|c|c|c|c|}
\hline time & $\operatorname{area} \mathrm{A}$ & area 2 & Conversion \\
\hline 0.33 & 7723 & 2278 & 0.061 \\
\hline 0.33 & 7697 & 2259 & 0.061 \\
\hline 0.33 & 7745 & 2257 & 0.060 \\
\hline 0.66 & 8913 & 5019 & 0.117 \\
\hline 0.66 & 8945 & 5019 & 0.116 \\
\hline 0.66 & 8989 & 5072 & 0.117 \\
\hline 1 & 7736 & 5376 & 0.144 \\
\hline 1 & 7755 & 5368 & 0.144 \\
\hline 1 & 7728 & 5390 & 0.145 \\
\hline 1.33 & 8452 & 6446 & 0.158 \\
\hline 1.33 & 8402 & 6436 & 0.159 \\
\hline 1.33 & 8409 & 6475 & 0.160 \\
\hline 1.66 & 9220 & 7649 & 0.172 \\
\hline 1.66 & 9206 & 7616 & 0.172 \\
\hline 1.66 & 9272 & 7710 & 0.172 \\
\hline 2 & 9079 & 7971 & 0.182 \\
\hline 2 & 10670 & 9344 & 0.182 \\
\hline 2 & 15532 & 13611 & 0.182 \\
\hline 2.5 & 58615 & 55049 & 0.195 \\
\hline 2.5 & 9046 & 8477 & 0.194 \\
\hline 2.5 & 9297 & 8743 & 0.195 \\
\hline 3 & 7779 & 7799 & 0.208 \\
\hline 3 & 7817 & 7826 & 0.208 \\
\hline 3 & 7834 & 7843 & 0.208 \\
\hline 5 & 8747 & 10624 & 0.252 \\
\hline 5 & 8783 & 10632 & 0.251 \\
\hline 5 & 8805 & 10711 & 0.252 \\
\hline 10 & 8985 & 14522 & 0.335 \\
\hline 10 & 9024 & 14574 & 0.335 \\
\hline 10 & 9032 & 14613 & 0.336 \\
\hline
\end{tabular}




\section{Order in $\mathrm{K}^{+}(E)-1^{-}, 0.75$ equiv.}

$\mathrm{K}^{+}(E)-\mathbf{1}^{-}$

2-Iodothiophene

Bis(dibenzylideneacetone)palladium $2.5 \mathrm{mM}$ (0.05 equiv)
$37.5 \mathrm{mM}(0.75$ equiv $)$

$50 \mathrm{mM}$ (1.0 equiv)

Following the General Procedure, $\mathrm{K}^{+}(E)-\mathbf{1}^{-}(0.41 \mathrm{~mL}, 0.452 \mathrm{M})$ and biphenyl $(5.4 \mathrm{mg})$ were dissolved in DME (3.59 mL) in a flame-dried, 2-neck round-bottomed flask, equipped with a stir bar and a septum under argon. The 2-iodothiophene $(27.6 \mu \mathrm{L}, 0.25 \mathrm{mmol})$ was then added and the reaction was stirred for $1 \mathrm{~min}$. A suspension of $\mathrm{Pd}(\mathrm{dba})_{2}(7.2 \mathrm{mg}, 0.0125 \mathrm{mmol})$ in dry THF (1.0 mL) was added. The dark red solution slowly turned turbid over time as the precipitation of KI proceeded. Aliquots $(\sim 200 \mu \mathrm{L})$ were withdrawn after $0.33,0.66,1.0,1.33$, $1.66,2.0,2.5,3.0,4,5,7$, and $10 \mathrm{~min}$. To quench, these samples were added to $100 \mu \mathrm{L}$ of a $20 \%$ aqueous solution of 2-dimethylaminoethanethiol hydrochloride. The clear colorless to slightlyyellow solution was then filtered through a plug of silica gel, and the silica gel was washed with diethyl ether to give a total sample volume of $\sim 2 \mathrm{~mL}$. This sample was injected into the GC three times.

initial rate $=0.0546$

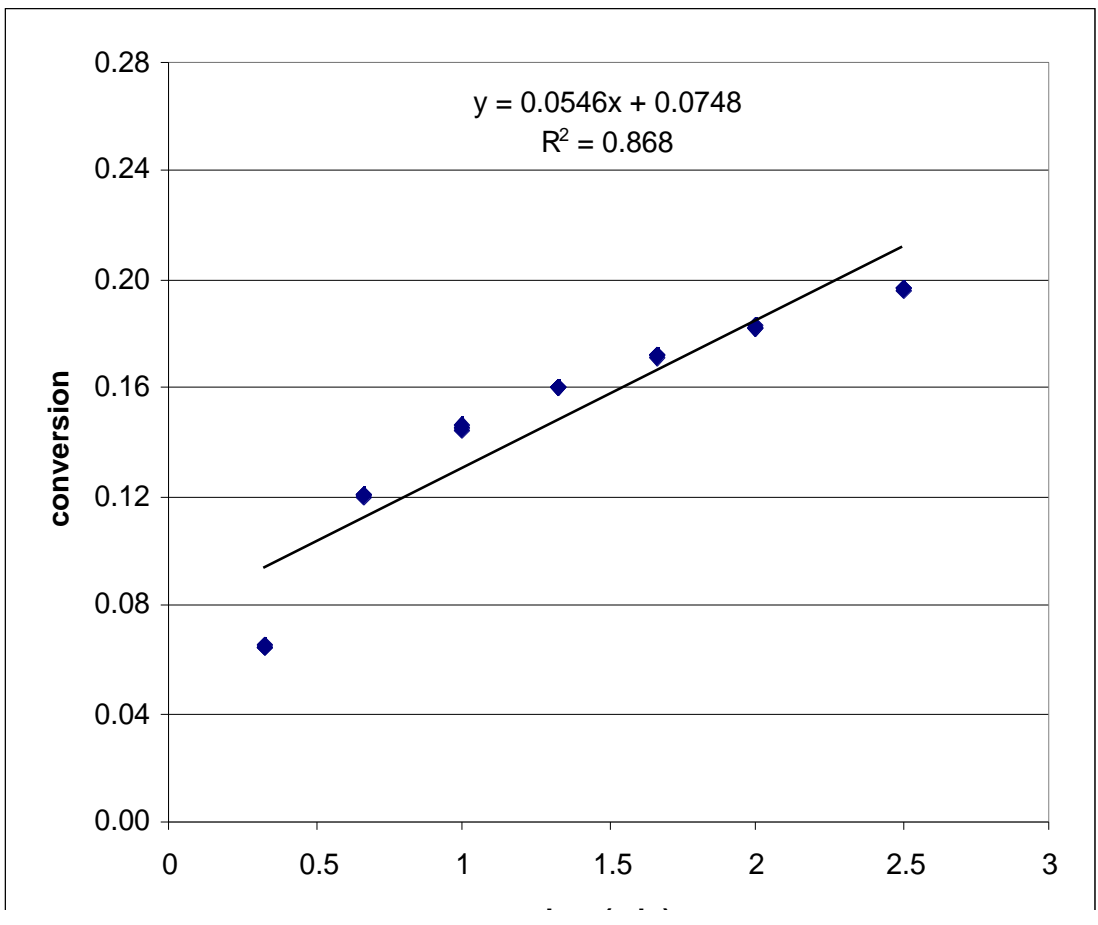




\begin{tabular}{c|c|c|c}
\hline time & area A & area 2 & Conversion \\
\hline 0.33 & 9449 & 2985 & 0.064 \\
0.33 & 9502 & 3000 & 0.064 \\
0.33 & 9488 & 3042 & 0.065 \\
0.66 & 9390 & 5555 & 0.120 \\
0.66 & 9412 & 5553 & 0.120 \\
0.66 & 9436 & 5594 & 0.121 \\
1 & 8868 & 6372 & 0.146 \\
1 & 8824 & 6279 & 0.145 \\
1 & 8828 & 6324 & 0.146 \\
1.33 & 10719 & 8416 & 0.160 \\
1.33 & 10713 & 8453 & 0.161 \\
1.33 & 10699 & 8422 & 0.160 \\
1.66 & 9961 & 8368 & 0.171 \\
1.66 & 9942 & 8399 & 0.172 \\
1.66 & 9921 & 8376 & 0.172 \\
2 & 9171 & 8211 & 0.182 \\
2 & 9120 & 8197 & 0.183 \\
2 & 9148 & 8181 & 0.182 \\
2.5 & 11379 & 10978 & 0.196 \\
2.5 & 11358 & 10971 & 0.197 \\
2.5 & 11454 & 11044 & 0.196 \\
3 & 10563 & 10801 & 0.208 \\
3 & 10525 & 10776 & 0.209 \\
3 & 10535 & 10798 & 0.209 \\
5 & 9337 & 11600 & 0.253 \\
5 & 9345 & 11611 & 0.253 \\
5 & 9257 & 11533 & 0.254 \\
10 & 10963 & 17583 & 0.327 \\
10 & 11028 & 17643 & 0.326 \\
10 & 10958 & & 0.331 \\
& & &
\end{tabular}




\section{Order in $\mathrm{K}^{+}(E)-1^{-}$, 1.0 equiv.}

$\mathrm{K}^{+}(E)-\mathbf{1}^{-}$

2-Iodothiophene

Bis(dibenzylideneacetone)palladium $2.5 \mathrm{mM}$ (0.05 equiv)
$50 \mathrm{mM}$ (1.0 equiv)

$50 \mathrm{mM}$ (1.0 equiv)

Following the General Procedure, $\mathrm{K}^{+}(E)-\mathbf{1}^{-}(0.52 \mathrm{~mL}, 0.481 \mathrm{M})$ and biphenyl $(5.3 \mathrm{mg})$ were dissolved in DME $(3.48 \mathrm{~mL})$ in a flame-dried, 2-neck round-bottomed flask, equipped with a stir bar and a septum under argon. The 2-iodothiophene $(27.6 \mu \mathrm{L}, 0.25 \mathrm{mmol})$ was then added and the reaction was stirred for $1 \mathrm{~min}$. A suspension of $\mathrm{Pd}(\mathrm{dba})_{2}(7.2 \mathrm{mg}, 0.0125 \mathrm{mmol})$ in dry THF (1.0 mL) was added. The dark red solution slowly turned turbid over time as the precipitation of KI proceeded. Aliquots $(\sim 200 \mu \mathrm{L})$ were withdrawn after $0.33,0.66,1.0,1.33$, $1.66,2.0,2.5,3.0,4,5,7$, and $10 \mathrm{~min}$. To quench, these samples were added to $100 \mu \mathrm{L}$ of a $20 \%$ aqueous solution of 2-dimethylaminoethanethiol hydrochloride. The clear colorless to slightlyyellow solution was then filtered through a plug of silica gel, and the silica gel was washed with diethyl ether to give a total sample volume of $\sim 2 \mathrm{~mL}$. This sample was injected into the GC three times.

initial rate $=0.0775$

$\mathrm{k}_{\mathrm{obs}}=0.0381$
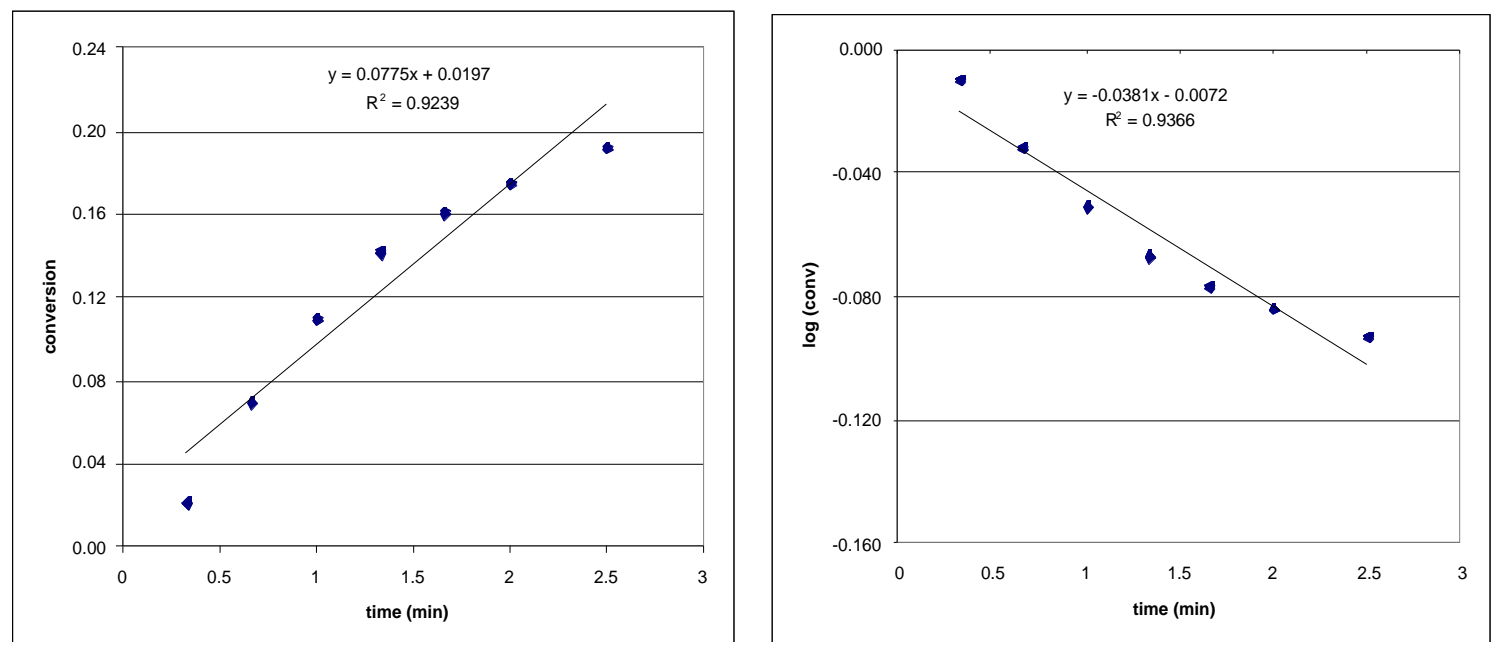


\begin{tabular}{|c|c|c|c|}
\hline time & area $\mathrm{A}$ & area 2 & conversion \\
\hline 0.33 & 5570 & 597 & 0.021 \\
\hline 0.33 & 5667 & 623 & 0.022 \\
\hline 0.33 & 5689 & 602 & 0.021 \\
\hline 0.66 & 5051 & 1764 & 0.070 \\
\hline 0.66 & 5036 & 1763 & 0.070 \\
\hline 0.66 & 5035 & 1774 & 0.070 \\
\hline 1 & 6603 & 3635 & 0.110 \\
\hline 1 & 6611 & 3656 & 0.111 \\
\hline 1 & 6589 & 3620 & 0.110 \\
\hline 1.33 & 5265 & 3775 & 0.143 \\
\hline 1.33 & 5204 & 3694 & 0.142 \\
\hline 1.33 & 5268 & 3729 & 0.141 \\
\hline 1.66 & 5964 & 4805 & 0.161 \\
\hline 1.66 & 5933 & 4763 & 0.160 \\
\hline 1.66 & 5945 & 4809 & 0.162 \\
\hline 2 & 6003 & 5268 & 0.175 \\
\hline 2 & 5984 & 5242 & 0.175 \\
\hline 2 & 6019 & 5285 & 0.176 \\
\hline 2.5 & 5586 & 5370 & 0.192 \\
\hline 2.5 & 5604 & 5381 & 0.192 \\
\hline 2.5 & 5590 & 5393 & 0.193 \\
\hline 3 & 5436 & 5552 & 0.204 \\
\hline 3 & 5434 & 5532 & 0.203 \\
\hline 3 & 5459 & 5579 & 0.204 \\
\hline 5 & 5077 & 6171 & 0.243 \\
\hline 5 & 5073 & 6132 & 0.242 \\
\hline 5 & 5084 & 6184 & 0.243 \\
\hline 10 & 4901 & 7417 & 0.302 \\
\hline 10 & 4891 & 7390 & 0.302 \\
\hline 10 & 4884 & 7388 & 0.302 \\
\hline
\end{tabular}




\section{Order in $\mathrm{K}^{+}(E)-1^{-}$, 1.0 equiv.}

$\mathrm{K}^{+}(E)-\mathbf{1}^{-}$

2-Iodothiophene

Bis(dibenzylideneacetone)palladium $2.5 \mathrm{mM}$ (0.05 equiv)
$50 \mathrm{mM}$ (1.0 equiv)

$50 \mathrm{mM}$ (1.0 equiv)

Following the General Procedure, $\mathrm{K}^{+}(E)-\mathbf{1}^{-}(0.52 \mathrm{~mL}, 0.481 \mathrm{M})$ and biphenyl $(7.0 \mathrm{mg})$ were dissolved in DME $(3.48 \mathrm{~mL})$ in a flame-dried, 2-neck round-bottomed flask, equipped with a stir bar and a septum under argon. The 2-iodothiophene $(27.6 \mu \mathrm{L}, 0.25 \mathrm{mmol})$ was then added and the reaction was stirred for $1 \mathrm{~min}$. A suspension of $\mathrm{Pd}(\mathrm{dba})_{2}(7.2 \mathrm{mg}, 0.0125 \mathrm{mmol})$ in dry THF (1.0 mL) was added. The dark red solution slowly turned turbid over time as the precipitation of KI proceeded. Aliquots $(\sim 200 \mu \mathrm{L})$ were withdrawn after $0.33,0.66,1.0,1.33$, $1.66,2.0,2.5,3.0,4,5,7$, and $10 \mathrm{~min}$. To quench, these samples were added to $100 \mu \mathrm{L}$ of a $20 \%$ aqueous solution of 2-dimethylaminoethanethiol hydrochloride. The clear colorless to slightlyyellow solution was then filtered through a plug of silica gel, and the silica gel was washed with diethyl ether to give a total sample volume of $\sim 2 \mathrm{~mL}$. This sample was injected into the GC three times.

initial rate $=0.0746$

$\mathrm{k}_{\mathrm{obs}}=0.0397$
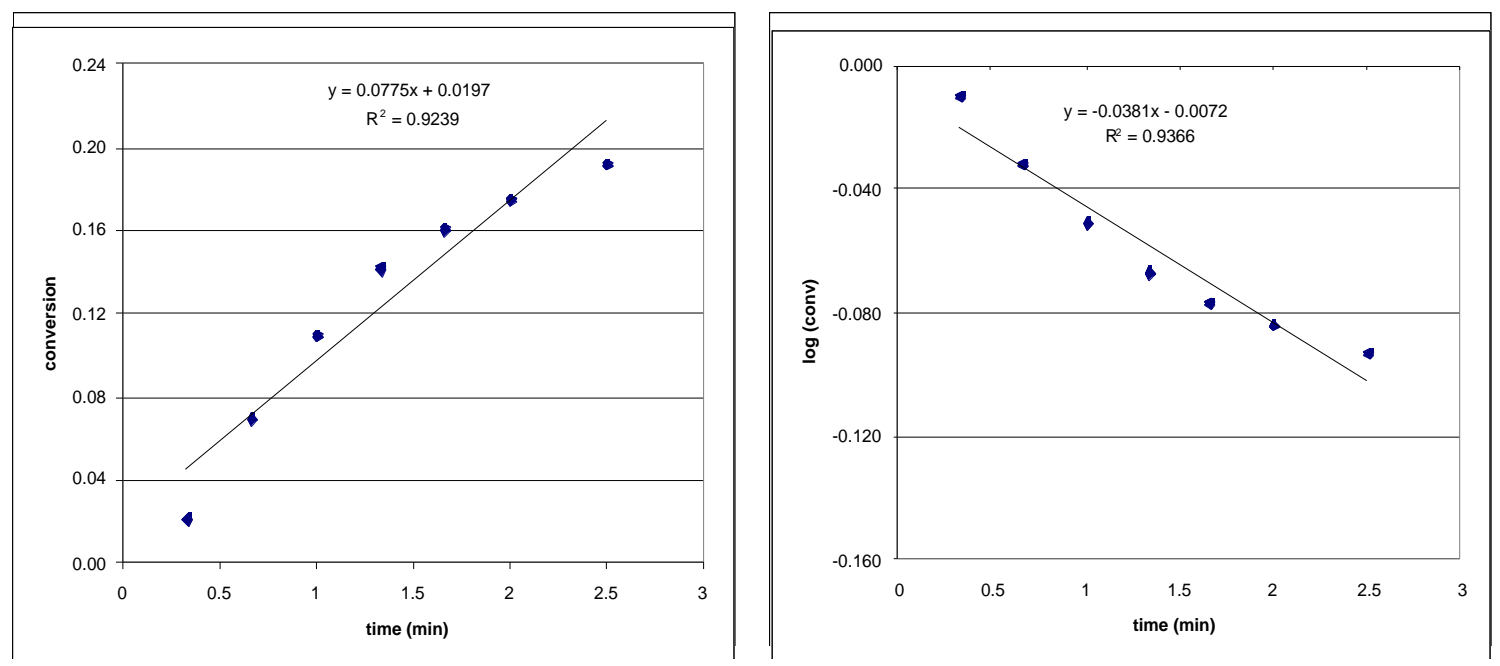


\begin{tabular}{c|c|c|c}
\hline time & area A & area 2 & conversion \\
\hline 0.33 & 7510 & 2322 & 0.082 \\
0.33 & 7693 & 2371 & 0.081 \\
0.33 & 7773 & 2413 & 0.082 \\
0.66 & 7068 & 4268 & 0.159 \\
0.66 & 6971 & 4202 & 0.159 \\
0.66 & 6981 & 4184 & 0.158 \\
1 & 7566 & 5497 & 0.192 \\
1 & 7530 & 5482 & 0.192 \\
1 & 7587 & 5504 & 0.192 \\
1.33 & 7121 & 5794 & 0.215 \\
1.33 & 7100 & 5766 & 0.214 \\
1.33 & 7145 & 5812 & 0.215 \\
1.66 & 8517 & 7448 & 0.231 \\
1.66 & 8507 & 7433 & 0.231 \\
1.66 & 8533 & 7738 & 0.230 \\
2 & 8377 & 7749 & 0.244 \\
2 & 8386 & 7746 & 0.244 \\
2 & 8369 & 8221 & 0.244 \\
2.5 & 8335 & 8227 & 0.260 \\
2.5 & 8305 & 8183 & 0.262 \\
2.5 & 8290 & 7935 & 0.261 \\
3 & 7549 & 7907 & 0.277 \\
3 & 7528 & 7946 & 0.277 \\
3 & 7560 & 8863 & 0.277 \\
5 & 7176 & 8926 & 0.326 \\
5 & 7189 & 8987 & 0.328 \\
5 & 7216 & 12808 & 0.329 \\
10 & 7784 & 12836 & 0.434 \\
10 & 7763 & & 0.436 \\
10 & 7764 & & 0.436 \\
& & &
\end{tabular}




\section{Order in $\mathrm{K}^{+}(E)-1^{-}$, 1.0 equiv.}

$\mathrm{K}^{+}(E)-\mathbf{1}^{-}$

2-Iodothiophene

Bis(dibenzylideneacetone)palladium $2.5 \mathrm{mM}$ (0.05 equiv)
$50 \mathrm{mM}$ (1.0 equiv)

$50 \mathrm{mM}$ (1.0 equiv)

Following the General Procedure, $\mathrm{K}^{+}(E)-\mathbf{1}^{-}(0.52 \mathrm{~mL}, 0.481 \mathrm{M})$ and biphenyl $(7.0 \mathrm{mg})$ were dissolved in DME $(3.48 \mathrm{~mL})$ in a flame-dried, 2-neck round-bottomed flask, equipped with a stir bar and a septum under argon. The 2-iodothiophene $(27.6 \mu \mathrm{L}, 0.25 \mathrm{mmol})$ was then added and the reaction was stirred for $1 \mathrm{~min}$. A suspension of $\mathrm{Pd}(\mathrm{dba})_{2}(7.2 \mathrm{mg}, 0.0125 \mathrm{mmol})$ in dry THF (1.0 mL) was added. The dark red solution slowly turned turbid over time as the precipitation of KI proceeded. Aliquots $(\sim 200 \mu \mathrm{L})$ were withdrawn after $0.33,0.66,1.0,1.33$, $1.66,2.0,2.5,3.0,4,5,7$, and $10 \mathrm{~min}$. To quench, these samples were added to $100 \mu \mathrm{L}$ of a $20 \%$ aqueous solution of 2-dimethylaminoethanethiol hydrochloride. The clear colorless to slightlyyellow solution was then filtered through a plug of silica gel, and the silica gel was washed with diethyl ether to give a total sample volume of $\sim 2 \mathrm{~mL}$. This sample was injected into the GC three times.

initial rate $=0.0739$

$\mathrm{k}_{\mathrm{obs}}=0.039$
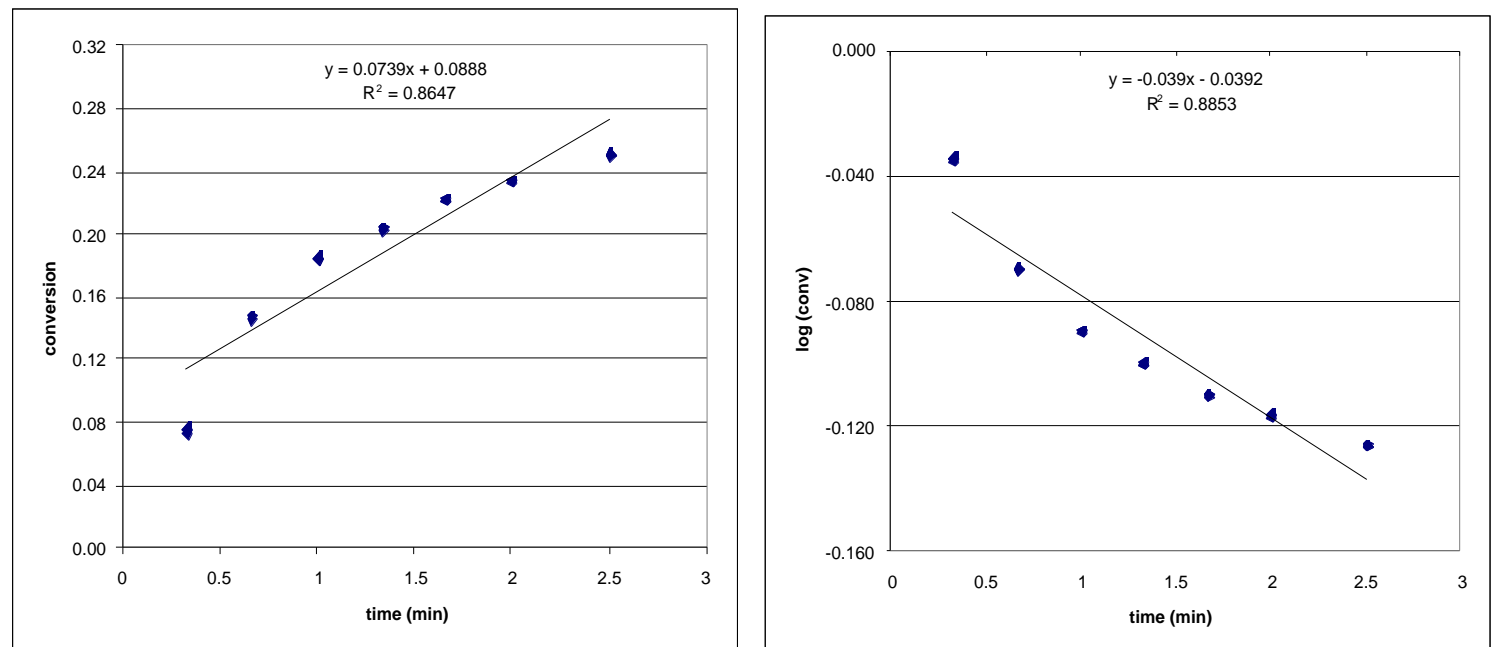


\begin{tabular}{c|c|c|c}
\hline time & area A & area 2 & Conversion \\
\hline 0.33 & 6011 & 1745 & 0.077 \\
0.33 & 6031 & 1726 & 0.076 \\
0.33 & 6027 & 1694 & 0.074 \\
0.66 & 7292 & 4096 & 0.148 \\
0.66 & 7270 & 4080 & 0.148 \\
0.66 & 7282 & 4049 & 0.147 \\
1 & 6462 & 4548 & 0.186 \\
1 & 6427 & 4510 & 0.185 \\
1 & 6416 & 4506 & 0.185 \\
1.33 & 5174 & 4015 & 0.205 \\
1.33 & 5172 & 4014 & 0.205 \\
1.33 & 5242 & 6040 & 0.203 \\
1.66 & 7337 & 6197 & 0.223 \\
1.66 & 7311 & 6177 & 0.224 \\
1.66 & 7323 & 6974 & 0.223 \\
2 & 7862 & 6994 & 0.234 \\
2 & 7848 & 6955 & 0.235 \\
2 & 7820 & 6363 & 0.235 \\
2.5 & 6706 & 6379 & 0.250 \\
2.5 & 6684 & 6428 & 0.252 \\
2.5 & 6737 & 7128 & 0.252 \\
3 & 7054 & 7059 & 0.267 \\
3 & 6972 & 7101 & 0.267 \\
3 & 7051 & 8764 & 0.266 \\
5 & 7313 & 8770 & 0.316 \\
5 & 7308 & 12397 & 0.317 \\
5 & 7279 & 12362 & 0.315 \\
10 & 8052 & 0.402 \\
10 & 8121 & 0.402 \\
10 & 8090 & &
\end{tabular}




\section{Order in $\mathrm{K}^{+}(E)-1^{-}, 1.5$ equiv.}

$\mathrm{K}^{+}(E)-\mathbf{1}^{-}$

2-Iodothiophene

Bis(dibenzylideneacetone)palladium $2.5 \mathrm{mM}$ (0.05 equiv)
$75 \mathrm{mM}$ (1.5 equiv)

$50 \mathrm{mM}$ (1.0 equiv)

Following the General Procedure, $\mathrm{K}^{+}(E)-\mathbf{1}^{-}(0.78 \mathrm{~mL}, 0.481 \mathrm{M})$ and biphenyl $(5.2 \mathrm{mg})$ were dissolved in DME (3.22 mL) in a flame-dried, 2-neck round-bottomed flask, equipped with a stir bar and a septum under argon. The 2-iodothiophene $(27.6 \mu \mathrm{L}, 0.25 \mathrm{mmol})$ was then added and the reaction was stirred for $1 \mathrm{~min}$. A suspension of $\mathrm{Pd}(\mathrm{dba})_{2}(7.2 \mathrm{mg}, 0.0125 \mathrm{mmol})$ in dry THF (1.0 mL) was added. The dark red solution slowly turned turbid over time as the precipitation of KI proceeded. Aliquots $(\sim 200 \mu \mathrm{L})$ were withdrawn after $0.33,0.66,1.0,1.33$, $1.66,2.0,2.5,3.0,4,5,7$, and $10 \mathrm{~min}$. To quench, these samples were added to $100 \mu \mathrm{L}$ of a $20 \%$ aqueous solution of 2-dimethylaminoethanethiol hydrochloride. The clear colorless to slightlyyellow solution was then filtered through a plug of silica gel, and the silica gel was washed with diethyl ether to give a total sample volume of $\sim 2 \mathrm{~mL}$. This sample was injected into the GC three times.

initial rate $=0.0855$

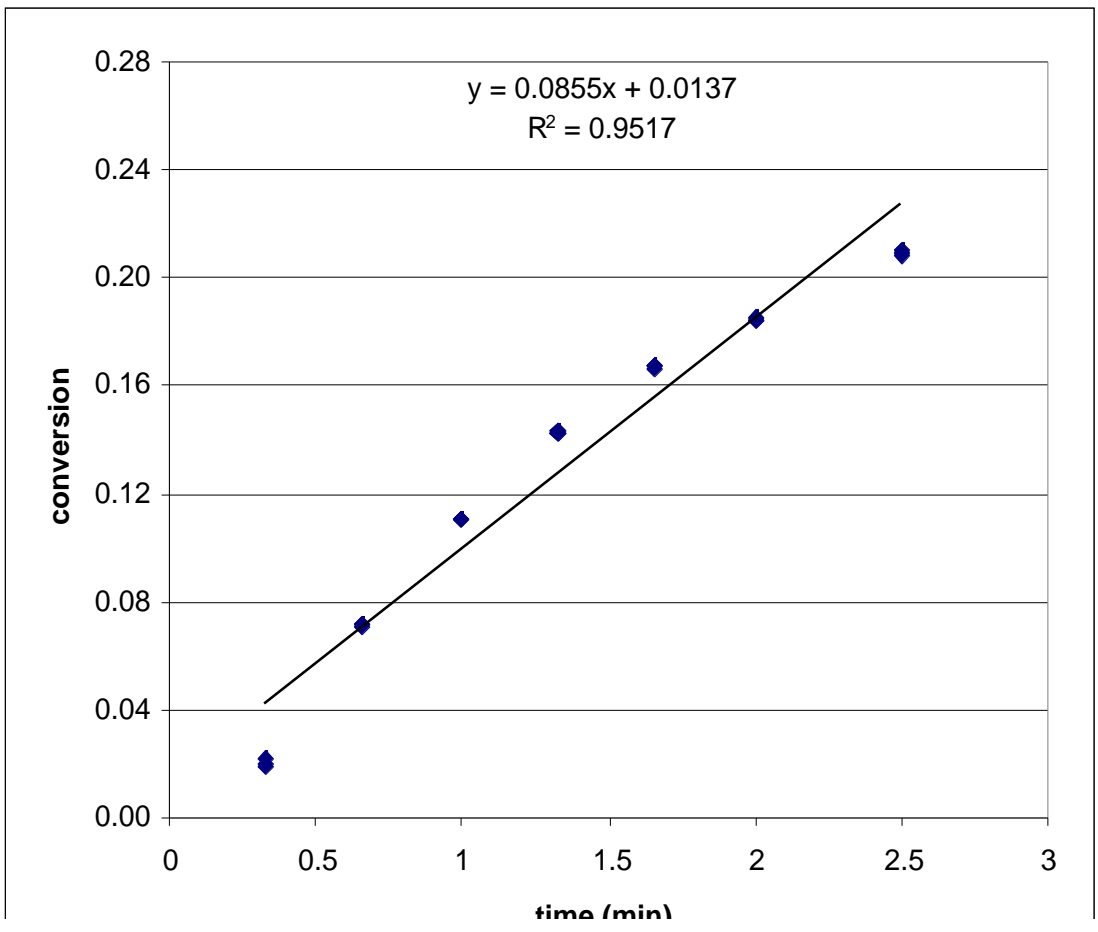




\begin{tabular}{|c|c|c|c|}
\hline time & area $\mathrm{A}$ & area 2 & Conversion \\
\hline 0.33 & 5031 & 508 & 0.020 \\
\hline 0.33 & 5035 & 496 & 0.019 \\
\hline 0.33 & 5026 & 550 & 0.021 \\
\hline 0.66 & 4546 & 1651 & 0.071 \\
\hline 0.66 & 4521 & 1649 & 0.072 \\
\hline 0.66 & 4500 & 1647 & 0.072 \\
\hline 1 & 4406 & 2476 & 0.110 \\
\hline 1 & 4378 & 2475 & 0.111 \\
\hline 1 & 4385 & 2467 & 0.110 \\
\hline 1.33 & 4762 & 3482 & 0.143 \\
\hline 1.33 & 4740 & 3451 & 0.143 \\
\hline 1.33 & 4739 & 3445 & 0.143 \\
\hline 1.66 & 4842 & 4126 & 0.167 \\
\hline 1.66 & 4848 & 4106 & 0.166 \\
\hline 1.66 & 4851 & 4137 & 0.167 \\
\hline 2 & 4349 & 4098 & 0.185 \\
\hline 2 & 4321 & 4069 & 0.185 \\
\hline 2 & 4300 & 4070 & 0.186 \\
\hline 2.5 & 5132 & 5462 & 0.209 \\
\hline 2.5 & 5128 & 5490 & 0.210 \\
\hline 2.5 & 5105 & 5460 & 0.210 \\
\hline 3 & 4466 & 5151 & 0.226 \\
\hline 3 & 4417 & 5129 & 0.228 \\
\hline 3 & 4434 & 5139 & 0.227 \\
\hline 5 & 4079 & 5941 & 0.286 \\
\hline 5 & 4085 & 5975 & 0.287 \\
\hline 5 & 4106 & 5991 & 0.286 \\
\hline 10 & 5629 & 11288 & 0.393 \\
\hline 10 & 5614 & 11295 & 0.395 \\
\hline 10 & 5621 & 11293 & 0.394 \\
\hline
\end{tabular}




\section{Order in $\mathrm{K}^{+}(E)-1^{-}, 1.5$ equiv.}

$\mathrm{K}^{+}(E)-\mathbf{1}^{-}$

2-Iodothiophene

Bis(dibenzylideneacetone)palladium $2.5 \mathrm{mM}$ (0.05 equiv)
$75 \mathrm{mM}$ (1.5 equiv)

$50 \mathrm{mM}$ (1.0 equiv)

Following the General Procedure, $\mathrm{K}^{+}(E)-\mathbf{1}^{-}(0.78 \mathrm{~mL}, 0.481 \mathrm{M})$ and biphenyl $(5.9 \mathrm{mg})$ were dissolved in DME (3.22 mL) in a flame-dried, 2-neck round-bottomed flask, equipped with a stir bar and a septum under argon. The 2-iodothiophene $(27.6 \mu \mathrm{L}, 0.25 \mathrm{mmol})$ was then added and the reaction was stirred for $1 \mathrm{~min}$. A suspension of $\mathrm{Pd}(\mathrm{dba})_{2}(7.2 \mathrm{mg}, 0.0125 \mathrm{mmol})$ in dry THF (1.0 mL) was added. The dark red solution slowly turned turbid over time as the precipitation of KI proceeded. Aliquots $(\sim 200 \mu \mathrm{L})$ were withdrawn after $0.33,0.66,1.0,1.33$, $1.66,2.0,2.5,3.0,4,5,7$, and $10 \mathrm{~min}$. To quench, these samples were added to $100 \mu \mathrm{L}$ of a $20 \%$ aqueous solution of 2-dimethylaminoethanethiol hydrochloride. The clear colorless to slightlyyellow solution was then filtered through a plug of silica gel, and the silica gel was washed with diethyl ether to give a total sample volume of $\sim 2 \mathrm{~mL}$. This sample was injected into the GC three times.

initial rate $=0.0832$

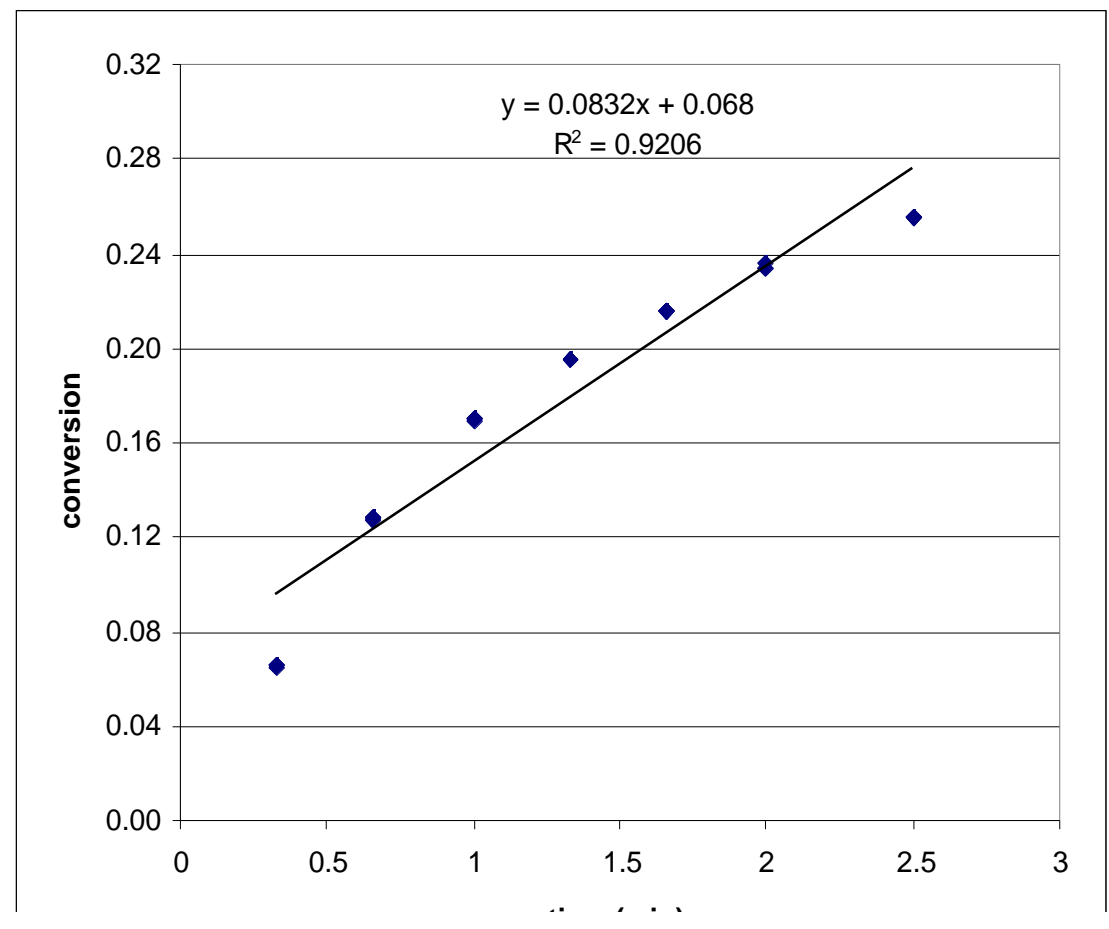




\begin{tabular}{|c|c|c|c|}
\hline time & $\operatorname{area} \mathrm{A}$ & area 2 & Conversion \\
\hline 0.33 & 7764 & 2250 & 0.064 \\
\hline 0.33 & 7714 & 2280 & 0.066 \\
\hline 0.33 & 7676 & 2274 & 0.066 \\
\hline 0.66 & 7019 & 4004 & 0.127 \\
\hline 0.66 & 7045 & 4071 & 0.129 \\
\hline 0.66 & 6993 & 4034 & 0.128 \\
\hline 1 & 6780 & 5174 & 0.170 \\
\hline 1 & 6756 & 5159 & 0.170 \\
\hline 1 & 6736 & 5133 & 0.170 \\
\hline 1.33 & 8259 & 7253 & 0.195 \\
\hline 1.33 & 8179 & 7182 & 0.195 \\
\hline 1.33 & 8310 & 7309 & 0.196 \\
\hline 1.66 & 8202 & 7967 & 0.216 \\
\hline 1.66 & 8256 & 7998 & 0.216 \\
\hline 1.66 & 8240 & 7992 & 0.216 \\
\hline 2 & 8100 & 8524 & 0.234 \\
\hline 2 & 8131 & 8551 & 0.234 \\
\hline 2 & 8201 & 8685 & 0.236 \\
\hline 2.5 & 7767 & 8908 & 0.255 \\
\hline 2.5 & 7705 & 8851 & 0.256 \\
\hline 2.5 & 7656 & 8791 & 0.255 \\
\hline 3 & 7505 & 9263 & 0.275 \\
\hline 3 & 7489 & 9211 & 0.274 \\
\hline 3 & 7456 & 9188 & 0.274 \\
\hline 5 & 7567 & 11235 & 0.330 \\
\hline 5 & 7548 & 11214 & 0.331 \\
\hline 5 & 7590 & 11283 & 0.331 \\
\hline 10 & 6018 & 11495 & 0.425 \\
\hline 10 & 6056 & 11523 & 0.423 \\
\hline 10 & 6035 & 11525 & 0.425 \\
\hline
\end{tabular}




\section{Order in $\mathrm{K}^{+}(E)-1^{-}, 1.5$ equiv.}

$\mathrm{K}^{+}(E)-\mathbf{1}^{-}$

2-Iodothiophene

Bis(dibenzylideneacetone)palladium $2.5 \mathrm{mM}$ (0.05 equiv)
$75 \mathrm{mM}$ (1.5 equiv)

$50 \mathrm{mM}$ (1.0 equiv)

Following the General Procedure, $\mathrm{K}^{+}(E) \mathbf{1}^{-}(0.78 \mathrm{~mL}, 0.481 \mathrm{M})$ and biphenyl $(7.0 \mathrm{mg})$ were dissolved in DME (3.22 mL) in a flame-dried, 2-neck round-bottomed flask, equipped with a stir bar and a septum under argon. The 2-iodothiophene $(27.6 \mu \mathrm{L}, 0.25 \mathrm{mmol})$ was then added and the reaction was stirred for $1 \mathrm{~min}$. A suspension of $\mathrm{Pd}(\mathrm{dba})_{2}(7.2 \mathrm{mg}, 0.0125 \mathrm{mmol})$ in dry THF (1.0 mL) was added. The dark red solution slowly turned turbid over time as the precipitation of KI proceeded. Aliquots $(\sim 200 \mu \mathrm{L})$ were withdrawn after $0.33,0.66,1.0,1.33$, $1.66,2.0,2.5,3.0,4,5,7$, and $10 \mathrm{~min}$. To quench, these samples were added to $100 \mu \mathrm{L}$ of a $20 \%$ aqueous solution of 2-dimethylaminoethanethiol hydrochloride. The clear colorless to slightlyyellow solution was then filtered through a plug of silica gel, and the silica gel was washed with diethyl ether to give a total sample volume of $\sim 2 \mathrm{~mL}$. This sample was injected into the GC three times.

initial rate $=0.0831$

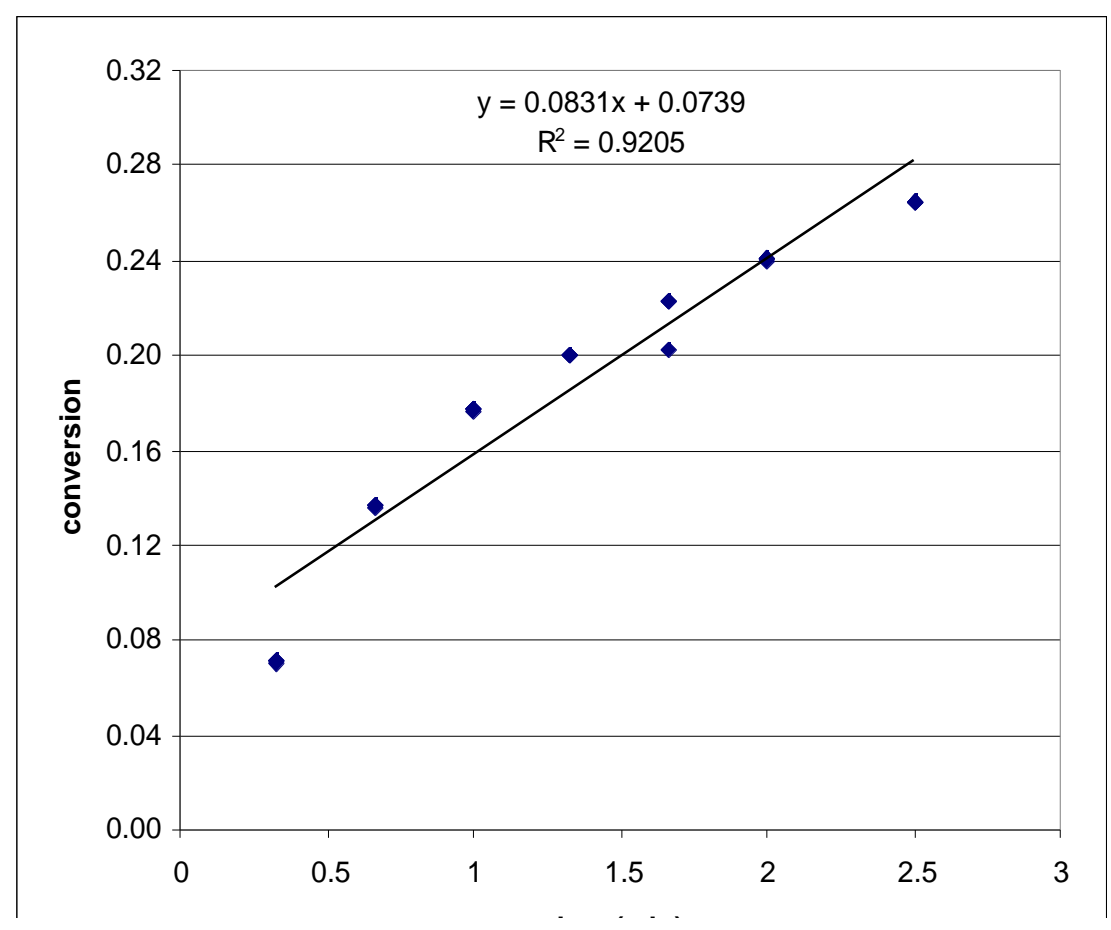




\begin{tabular}{|c|c|c|c|}
\hline time & $\operatorname{area} \mathrm{A}$ & area 2 & Conversion \\
\hline 0.33 & 9403 & 2495 & 0.070 \\
\hline 0.33 & 9738 & 2622 & 0.071 \\
\hline 0.33 & 9846 & 2639 & 0.071 \\
\hline 0.66 & 7938 & 4103 & 0.136 \\
\hline 0.66 & 7975 & 4141 & 0.137 \\
\hline 0.66 & 8042 & 4144 & 0.136 \\
\hline 1 & 8046 & 5419 & 0.178 \\
\hline 1 & 8055 & 5424 & 0.178 \\
\hline 1 & 8132 & 5450 & 0.177 \\
\hline 1.33 & 11298 & 8559 & 0.200 \\
\hline 1.33 & 11333 & 8597 & 0.200 \\
\hline 1.33 & 11351 & 8593 & 0.200 \\
\hline 1.66 & 9917 & 8383 & 0.223 \\
\hline 1.66 & 9958 & 8401 & 0.223 \\
\hline 1.66 & 11012 & 8441 & 0.202 \\
\hline 2 & 10970 & 10005 & 0.241 \\
\hline 2 & 10954 & 9983 & 0.241 \\
\hline 2 & 11018 & 10023 & 0.240 \\
\hline 2.5 & 10219 & 10239 & 0.265 \\
\hline 2.5 & 10242 & 10250 & 0.264 \\
\hline 2.5 & 10219 & 10236 & 0.264 \\
\hline 3 & 10273 & 10727 & 0.276 \\
\hline 3 & 10302 & 10753 & 0.276 \\
\hline 3 & 10297 & 10752 & 0.276 \\
\hline 5 & 7353 & 9600 & 0.345 \\
\hline 5 & 7356 & 9621 & 0.345 \\
\hline 5 & 7414 & 9664 & 0.344 \\
\hline 10 & 8829 & 14637 & 0.438 \\
\hline 10 & 8891 & 14761 & 0.438 \\
\hline 10 & 8907 & 14754 & 0.437 \\
\hline
\end{tabular}




\section{Order in $\mathrm{K}^{+}(E)-1^{-}, 2.0$ equiv.}

$\mathrm{K}^{+}(E)-1^{-}$

2-Iodothiophene

Bis(dibenzylideneacetone)palladium $2.5 \mathrm{mM}$ (0.05 equiv)
$100 \mathrm{mM}$ (2.0 equiv)

$50 \mathrm{mM}$ (1.0 equiv)

Following the General Procedure, $\mathrm{K}^{+}(E)-\mathbf{1}^{-}(1.16 \mathrm{~mL}, 0.430 \mathrm{M})$ and biphenyl $(6.6 \mathrm{mg})$ were dissolved in DME $(2.84 \mathrm{~mL})$ in a flame-dried, 2-neck round-bottomed flask, equipped with a stir bar and a septum under argon. The 2-iodothiophene $(27.6 \mu \mathrm{L}, 0.25 \mathrm{mmol})$ was then added and the reaction was stirred for $1 \mathrm{~min}$. A suspension of $\mathrm{Pd}(\mathrm{dba})_{2}(7.2 \mathrm{mg}, 0.0125 \mathrm{mmol})$ in dry THF (1.0 mL) was added. The dark red solution slowly turned turbid over time as the precipitation of KI proceeded. Aliquots $(\sim 200 \mu \mathrm{L})$ were withdrawn after $0.33,0.66,1.0,1.33$, $1.66,2.0,2.5,3.0,4,5,7$, and $10 \mathrm{~min}$. To quench, these samples were added to $100 \mu \mathrm{L}$ of a $20 \%$ aqueous solution of 2-dimethylaminoethanethiol hydrochloride. The clear colorless to slightlyyellow solution was then filtered through a plug of silica gel, and the silica gel was washed with diethyl ether to give a total sample volume of $\sim 2 \mathrm{~mL}$. This sample was injected into the GC three times.

initial rate $=0.0850$

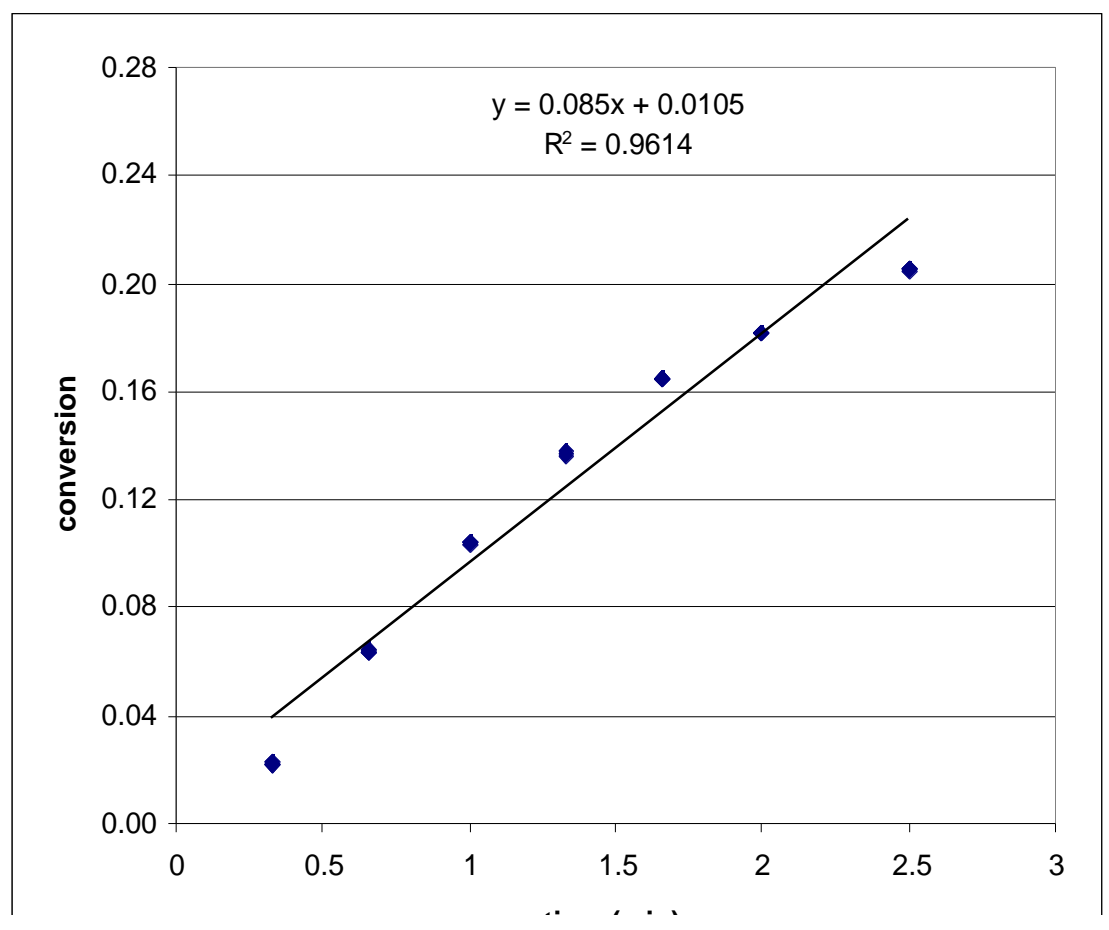




\begin{tabular}{|c|c|c|c|}
\hline time & area $\mathrm{A}$ & area 2 & Conversion \\
\hline 0.33 & 6354 & 561 & 0.022 \\
\hline 0.33 & 6342 & 581 & 0.023 \\
\hline 0.33 & 6345 & 567 & 0.022 \\
\hline 0.66 & 6767 & 1747 & 0.064 \\
\hline 0.66 & 6752 & 1725 & 0.064 \\
\hline 0.66 & 6748 & 1733 & 0.064 \\
\hline 1 & 6975 & 2912 & 0.104 \\
\hline 1 & 6950 & 2887 & 0.103 \\
\hline 1 & 6851 & 2869 & 0.104 \\
\hline 1.33 & 7353 & 4053 & 0.137 \\
\hline 1.33 & 7386 & 4082 & 0.138 \\
\hline 1.33 & 7396 & 4049 & 0.136 \\
\hline 1.66 & 8205 & 5440 & 0.165 \\
\hline 1.66 & 8202 & 5426 & 0.165 \\
\hline 1.66 & 8201 & 5439 & 0.165 \\
\hline 2 & 7497 & 5475 & 0.182 \\
\hline 2 & 7471 & 5460 & 0.182 \\
\hline 2 & 7504 & 5467 & 0.181 \\
\hline 2.5 & 8223 & 6773 & 0.205 \\
\hline 2.5 & 8194 & 6757 & 0.205 \\
\hline 2.5 & 8302 & 6871 & 0.206 \\
\hline 3 & 8076 & 7316 & 0.225 \\
\hline 3 & 8078 & 7329 & 0.226 \\
\hline 3 & 8115 & 7340 & 0.225 \\
\hline 5 & 6943 & 7978 & 0.286 \\
\hline 5 & 6962 & 7994 & 0.286 \\
\hline 5 & 6959 & 7992 & 0.286 \\
\hline 10 & 7256 & 11005 & 0.378 \\
\hline 10 & 7275 & 11019 & 0.377 \\
\hline 10 & 7249 & 10978 & 0.377 \\
\hline
\end{tabular}




\section{Order in $\mathrm{K}^{+}(E)-1^{-}, 2.0$ equiv.}

$\mathrm{K}^{+}(E)-\mathbf{1}^{-}$

2-Iodothiophene

Bis(dibenzylideneacetone)palladium $2.5 \mathrm{mM}$ (0.05 equiv)
$100 \mathrm{mM}$ (2.0 equiv)
$50 \mathrm{mM}$ (1.0 equiv)

Following the General Procedure, $\mathrm{K}^{+}(E)-\mathbf{1}^{-}(1.16 \mathrm{~mL}, 0.430 \mathrm{M})$ and biphenyl $(6.7 \mathrm{mg})$ were dissolved in DME (2.84 mL) in a flame-dried, 2-neck round-bottomed flask, equipped with a stir bar and a septum under argon. The 2-iodothiophene $(27.6 \mu \mathrm{L}, 0.25 \mathrm{mmol})$ was then added and the reaction was stirred for $1 \mathrm{~min}$. A suspension of $\mathrm{Pd}(\mathrm{dba})_{2}(7.2 \mathrm{mg}, 0.0125 \mathrm{mmol})$ in dry THF (1.0 mL) was added. The dark red solution slowly turned turbid over time as the precipitation of KI proceeded. Aliquots $(\sim 200 \mu \mathrm{L})$ were withdrawn after $0.33,0.66,1.0,1.33$, $1.66,2.0,2.5,3.0,4,5,7$, and $10 \mathrm{~min}$. To quench, these samples were added to $100 \mu \mathrm{L}$ of a $20 \%$ aqueous solution of 2-dimethylaminoethanethiol hydrochloride. The clear colorless to slightlyyellow solution was then filtered through a plug of silica gel, and the silica gel was washed with diethyl ether to give a total sample volume of $\sim 2 \mathrm{~mL}$. This sample was injected into the GC three times.

initial rate $=0.0831$

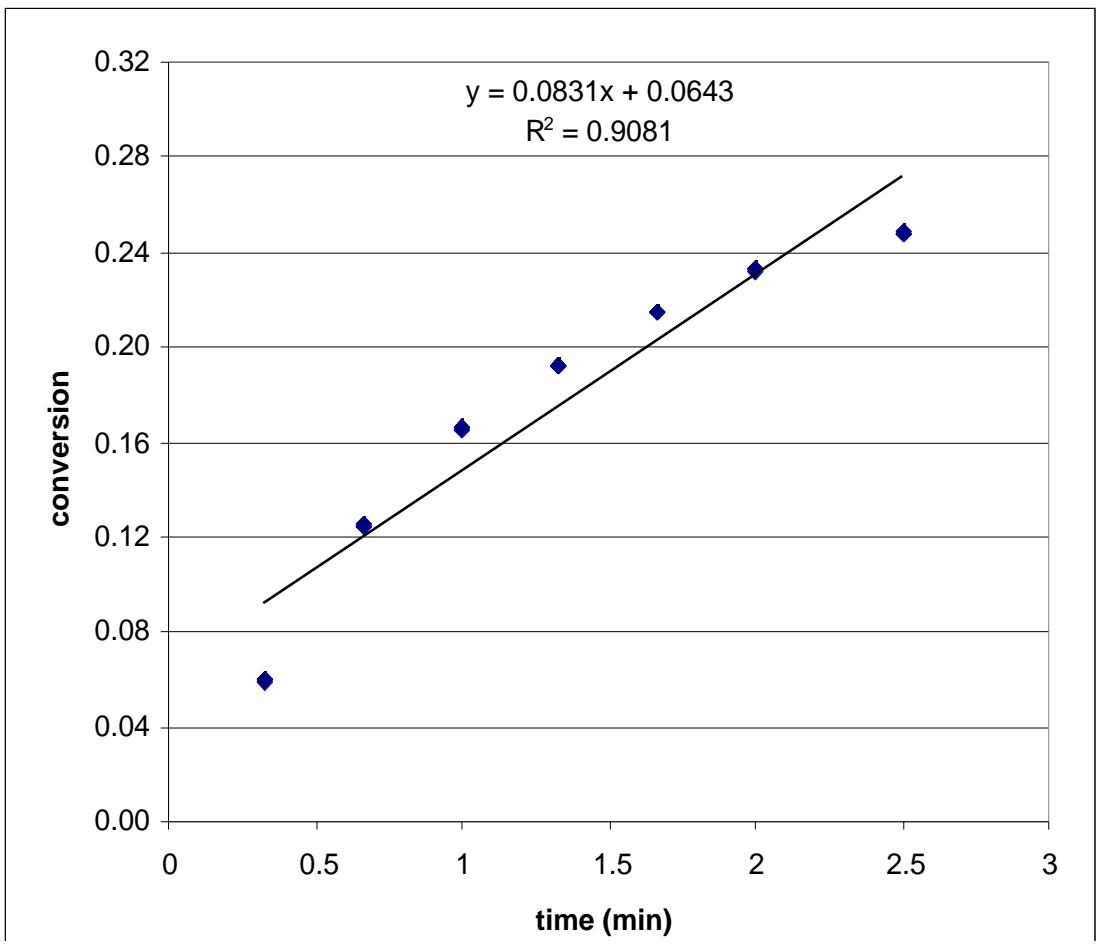




\begin{tabular}{|c|c|c|c|}
\hline time & $\operatorname{area} \mathrm{A}$ & area 2 & Conversion \\
\hline 0.33 & 11722 & 2757 & 0.059 \\
\hline 0.33 & 11749 & 2777 & 0.060 \\
\hline 0.33 & 11807 & 2773 & 0.059 \\
\hline 0.66 & 10438 & 5135 & 0.124 \\
\hline 0.66 & 10409 & 5126 & 0.124 \\
\hline 0.66 & 10411 & 5182 & 0.126 \\
\hline 1 & 9786 & 6400 & 0.165 \\
\hline 1 & 9802 & 6436 & 0.166 \\
\hline 1 & 9774 & 6408 & 0.166 \\
\hline 1.33 & 11417 & 8686 & 0.192 \\
\hline 1.33 & 11407 & 8675 & 0.192 \\
\hline 1.33 & 11492 & 8737 & 0.192 \\
\hline 1.66 & 8937 & 7590 & 0.215 \\
\hline 1.66 & 8998 & 7632 & 0.214 \\
\hline 1.66 & 8877 & 7539 & 0.215 \\
\hline 2 & 10263 & 9454 & 0.233 \\
\hline 2 & 10306 & 9468 & 0.232 \\
\hline 2 & 10274 & 9458 & 0.233 \\
\hline 2.5 & 9922 & 9734 & 0.248 \\
\hline 2.5 & 9914 & 9732 & 0.248 \\
\hline 2.5 & 9848 & 9685 & 0.248 \\
\hline 3 & 10614 & 11381 & 0.271 \\
\hline 3 & 10628 & 11372 & 0.270 \\
\hline 3 & 10619 & 11406 & 0.271 \\
\hline 5 & 10645 & 13998 & 0.332 \\
\hline 5 & 10680 & 14064 & 0.333 \\
\hline 5 & 10581 & 13915 & 0.332 \\
\hline 10 & 9802 & 16661 & 0.429 \\
\hline 10 & 9762 & 16619 & 0.430 \\
\hline 10 & 9681 & 16494 & 0.430 \\
\hline
\end{tabular}




\section{Order in $\mathrm{K}^{+}(E)-1^{-}, 2.0$ equiv.}

$\mathrm{K}^{+}(E)-1^{-}$

2-Iodothiophene

Bis(dibenzylideneacetone)palladium $2.5 \mathrm{mM}$ (0.05 equiv)
$100 \mathrm{mM}$ (2.0 equiv)

$50 \mathrm{mM}$ (1.0 equiv)

Following the General Procedure, $\mathrm{K}^{+}(E)-\mathbf{1}^{-}(1.16 \mathrm{~mL}, 0.430 \mathrm{M})$ and biphenyl $(5.5 \mathrm{mg})$ were dissolved in DME $(2.84 \mathrm{~mL})$ in a flame-dried, 2-neck round-bottomed flask, equipped with a stir bar and a septum under argon. The 2-iodothiophene $(27.6 \mu \mathrm{L}, 0.25 \mathrm{mmol})$ was then added and the reaction was stirred for $1 \mathrm{~min}$. A suspension of $\mathrm{Pd}(\mathrm{dba})_{2}(7.2 \mathrm{mg}, 0.0125 \mathrm{mmol})$ in dry THF (1.0 mL) was added. The dark red solution slowly turned turbid over time as the precipitation of KI proceeded. Aliquots $(\sim 200 \mu \mathrm{L})$ were withdrawn after $0.33,0.66,1.0,1.33$, $1.66,2.0,2.5,3.0,4,5,7$, and $10 \mathrm{~min}$. To quench, these samples were added to $100 \mu \mathrm{L}$ of a $20 \%$ aqueous solution of 2-dimethylaminoethanethiol hydrochloride. The clear colorless to slightlyyellow solution was then filtered through a plug of silica gel, and the silica gel was washed with diethyl ether to give a total sample volume of $\sim 2 \mathrm{~mL}$. This sample was injected into the GC three times.

initial rate $=0.0823$

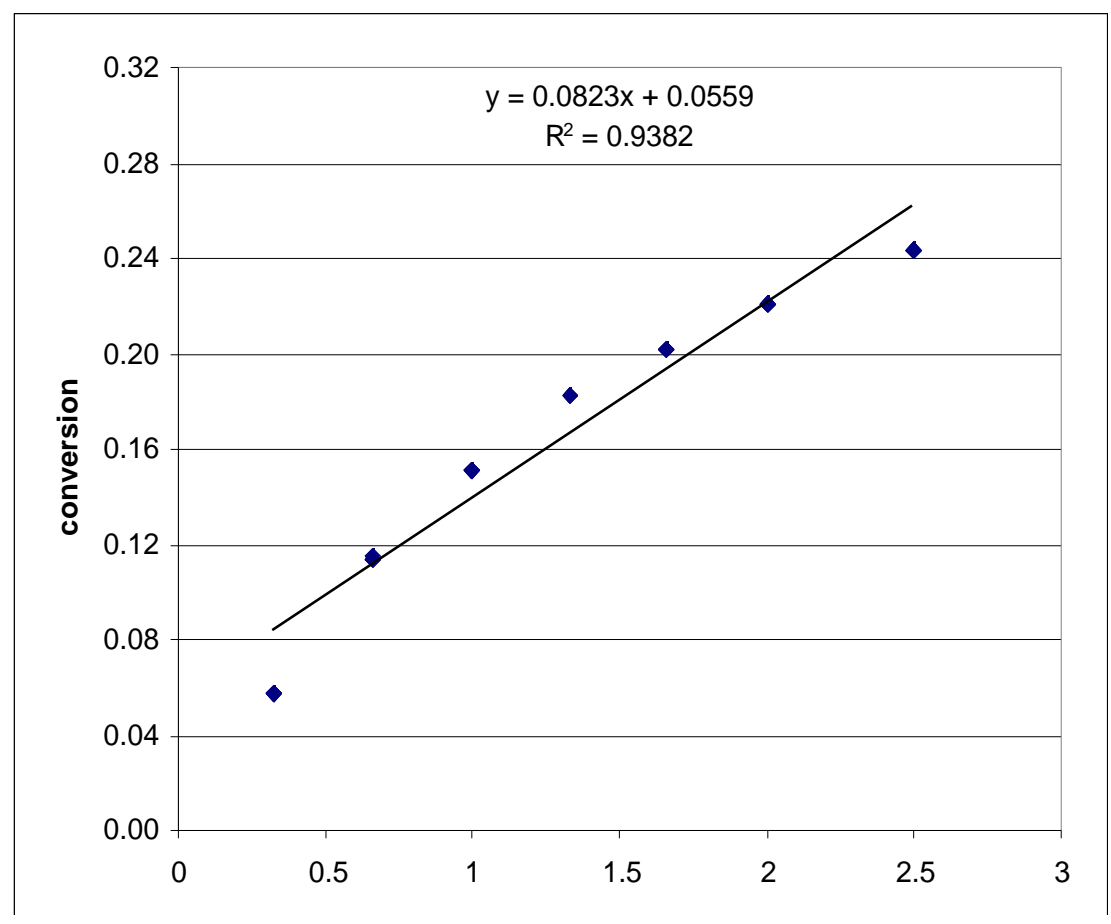




\begin{tabular}{|c|c|c|c|}
\hline time & $\operatorname{area} \mathrm{A}$ & area 2 & Conversion \\
\hline 0.33 & 20971 & 5832 & 0.058 \\
\hline 0.33 & 21286 & 5925 & 0.058 \\
\hline 0.33 & 21277 & 5925 & 0.058 \\
\hline 0.66 & 10277 & 5627 & 0.114 \\
\hline 0.66 & 10258 & 5653 & 0.114 \\
\hline 0.66 & 10352 & 5722 & 0.115 \\
\hline 1 & 9588 & 7001 & 0.151 \\
\hline 1 & 9612 & 7004 & 0.151 \\
\hline 1 & 9603 & 6978 & 0.151 \\
\hline 1.33 & 9913 & 8711 & 0.182 \\
\hline 1.33 & 9930 & 8753 & 0.183 \\
\hline 1.33 & 9966 & 8791 & 0.183 \\
\hline 1.66 & 10586 & 10299 & 0.202 \\
\hline 1.66 & 10575 & 10284 & 0.202 \\
\hline 1.66 & 10646 & 10358 & 0.202 \\
\hline 2 & 9733 & 10351 & 0.221 \\
\hline 2 & 9675 & 10295 & 0.221 \\
\hline 2 & 9717 & 10370 & 0.221 \\
\hline 2.5 & 15733 & 18438 & 0.243 \\
\hline 2.5 & 15593 & 18291 & 0.243 \\
\hline 2.5 & 15738 & 18434 & 0.243 \\
\hline 3 & 10623 & 13488 & 0.263 \\
\hline 3 & 10635 & 13488 & 0.263 \\
\hline 3 & 10649 & 13519 & 0.263 \\
\hline 5 & 20818 & 32431 & 0.323 \\
\hline 5 & 20893 & 32533 & 0.323 \\
\hline 5 & 20777 & 32336 & 0.323 \\
\hline 10 & 9463 & 19245 & 0.422 \\
\hline 10 & 9449 & 19178 & 0.421 \\
\hline 10 & 9451 & 19214 & 0.422 \\
\hline
\end{tabular}




\section{Order in $\mathrm{K}^{+}(E)-1^{-}, 3.0$ equiv.}

$\mathrm{K}^{+}(E)-1^{-}$

2-Iodothiophene

Bis(dibenzylideneacetone)palladium $2.5 \mathrm{mM}$ (0.05 equiv)
$150 \mathrm{mM}$ (3.0 equiv)

$50 \mathrm{mM}$ (1.0 equiv)

Following the General Procedure, $\mathrm{K}^{+}(E) \mathbf{1}^{-}(1.90 \mathrm{~mL}, 0.394 \mathrm{M})$ and biphenyl $(8.3 \mathrm{mg})$ were dissolved in DME $(2.10 \mathrm{~mL})$ in a flame-dried, 2-neck round-bottomed flask, equipped with a stir bar and a septum under argon. The 2-iodothiophene $(27.6 \mu \mathrm{L}, 0.25 \mathrm{mmol})$ was then added and the reaction was stirred for $1 \mathrm{~min}$. A suspension of $\mathrm{Pd}(\mathrm{dba})_{2}(7.2 \mathrm{mg}, 0.0125 \mathrm{mmol})$ in dry THF (1.0 mL) was added. The dark red solution slowly turned turbid over time as the precipitation of KI proceeded. Aliquots $(\sim 200 \mu \mathrm{L})$ were withdrawn after $0.33,0.66,1.0,1.33$, $1.66,2.0,2.5,3.0,4,5,7$, and $10 \mathrm{~min}$. To quench, these samples were added to $100 \mu \mathrm{L}$ of a $20 \%$ aqueous solution of 2-dimethylaminoethanethiol hydrochloride. The clear colorless to slightlyyellow solution was then filtered through a plug of silica gel, and the silica gel was washed with diethyl ether to give a total sample volume of $\sim 2 \mathrm{~mL}$. This sample was injected into the GC three times.

initial rate $=0.0833$

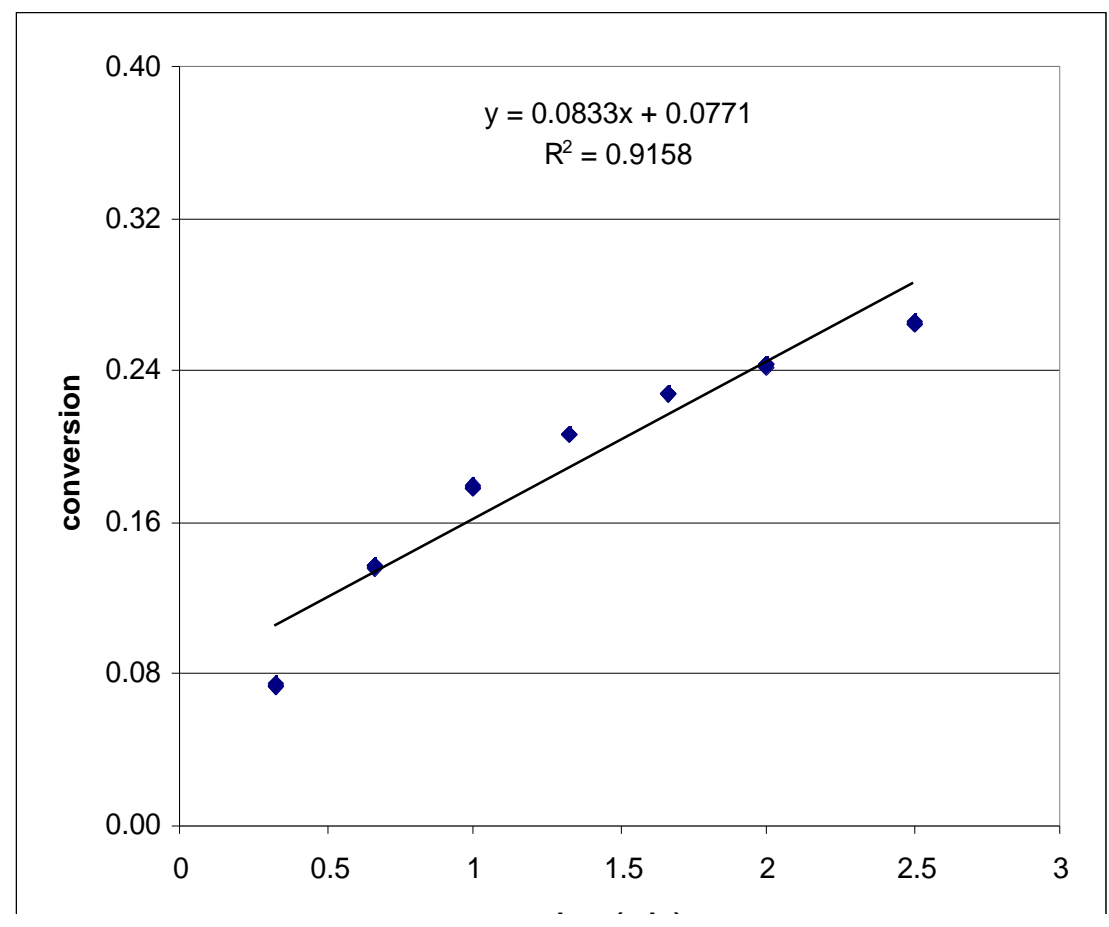




\begin{tabular}{|c|c|c|c|}
\hline time & area $\mathrm{A}$ & area 2 & Conversion \\
\hline 0.33 & 10312 & 2399 & 0.073 \\
\hline 0.33 & 10669 & 2575 & 0.076 \\
\hline 0.33 & 10498 & 2479 & 0.074 \\
\hline 0.66 & 10170 & 4436 & 0.137 \\
\hline 0.66 & 10218 & 4466 & 0.137 \\
\hline 0.66 & 10269 & 4458 & 0.136 \\
\hline 1 & 10426 & 5970 & 0.179 \\
\hline 1 & 10505 & 5989 & 0.178 \\
\hline 1 & 10514 & 5998 & 0.179 \\
\hline 1.33 & 13374 & 8802 & 0.206 \\
\hline 1.33 & 13497 & 8882 & 0.206 \\
\hline 1.33 & 13522 & 8944 & 0.207 \\
\hline 1.66 & 11715 & 8533 & 0.228 \\
\hline 1.66 & 11800 & 8561 & 0.227 \\
\hline 1.66 & 11827 & 8593 & 0.227 \\
\hline 2 & 12558 & 9763 & 0.243 \\
\hline 2 & 12465 & 9658 & 0.243 \\
\hline 2 & 12495 & 9660 & 0.242 \\
\hline 2.5 & 13435 & 11322 & 0.264 \\
\hline 2.5 & 13415 & 11306 & 0.264 \\
\hline 2.5 & 13348 & 11305 & 0.265 \\
\hline 3 & 12412 & 11171 & 0.282 \\
\hline 3 & 12579 & 11267 & 0.280 \\
\hline 3 & 12665 & 11418 & 0.282 \\
\hline 5 & 11928 & 12780 & 0.335 \\
\hline 5 & 11915 & 12780 & 0.336 \\
\hline 5 & 11902 & 12740 & 0.335 \\
\hline 10 & 11104 & 15111 & 0.426 \\
\hline 10 & 11209 & 15224 & 0.425 \\
\hline 10 & 11105 & 15098 & 0.426 \\
\hline
\end{tabular}




\section{Order in $\mathrm{K}^{+}(E)-1^{-}, 3.0$ equiv.}

$\mathrm{K}^{+}(E)-1^{-}$

2-Iodothiophene

Bis(dibenzylideneacetone)palladium $2.5 \mathrm{mM}$ (0.05 equiv)
$150 \mathrm{mM}$ (3.0 equiv)

$50 \mathrm{mM}$ (1.0 equiv)

Following the General Procedure, $\mathrm{K}^{+}(E)-\mathbf{1}^{-}(1.90 \mathrm{~mL}, 0.394 \mathrm{M})$ and biphenyl $(7.1 \mathrm{mg})$ were dissolved in DME $(2.10 \mathrm{~mL})$ in a flame-dried, 2-neck round-bottomed flask, equipped with a stir bar and a septum under argon. The 2-iodothiophene $(27.6 \mu \mathrm{L}, 0.25 \mathrm{mmol})$ was then added and the reaction was stirred for $1 \mathrm{~min}$. A suspension of $\mathrm{Pd}(\mathrm{dba})_{2}(7.2 \mathrm{mg}, 0.0125 \mathrm{mmol})$ in dry THF (1.0 mL) was added. The dark red solution slowly turned turbid over time as the precipitation of KI proceeded. Aliquots $(\sim 200 \mu \mathrm{L})$ were withdrawn after 0.33, 0.66, 1.0, 1.33, $1.66,2.0,2.5,3.0,4,5,7$, and $10 \mathrm{~min}$. To quench, these samples were added to $100 \mu \mathrm{L}$ of a $20 \%$ aqueous solution of 2-dimethylaminoethanethiol hydrochloride. The clear colorless to slightlyyellow solution was then filtered through a plug of silica gel, and the silica gel was washed with diethyl ether to give a total sample volume of $\sim 2 \mathrm{~mL}$. This sample was injected into the GC three times.

initial rate $=0.0808$

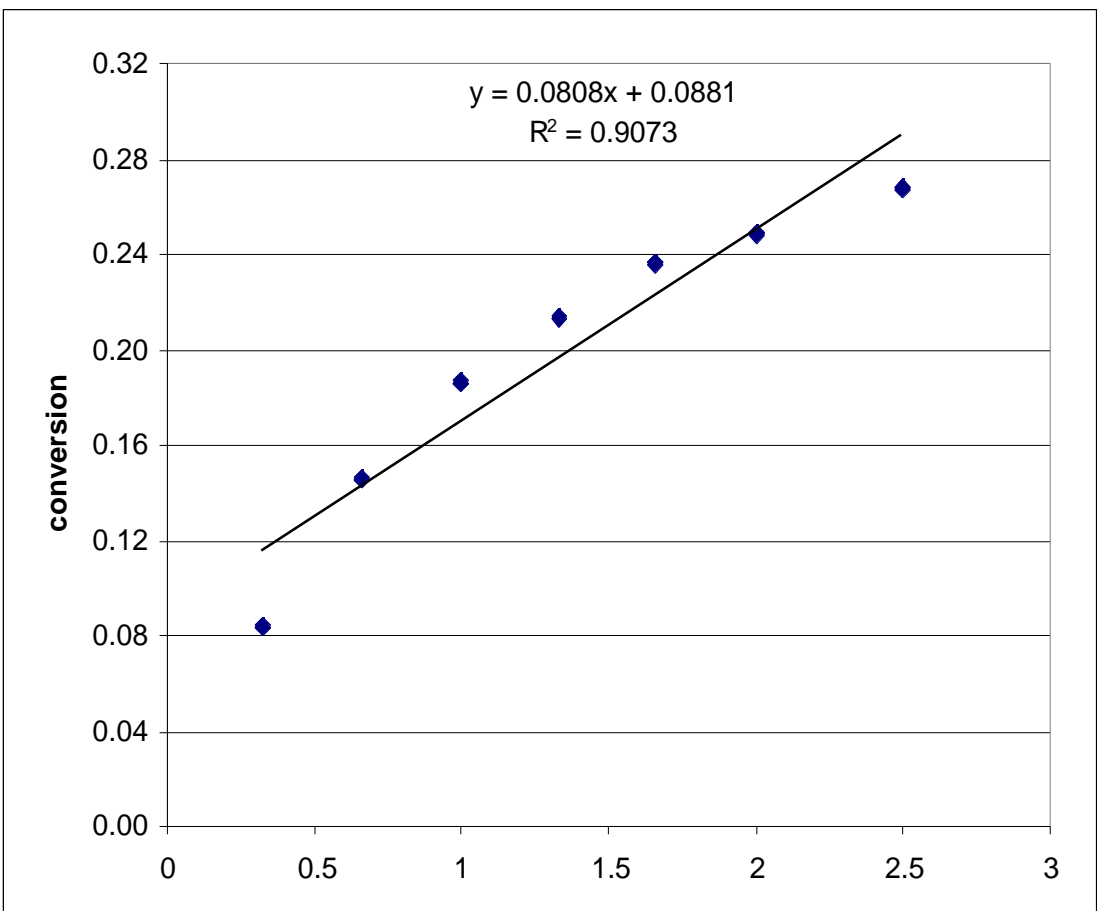




\begin{tabular}{|c|c|c|c|}
\hline time & area $\mathrm{A}$ & area 2 & Conversion \\
\hline 0.33 & 11816 & 3677 & 0.083 \\
\hline 0.33 & 11815 & 3747 & 0.085 \\
\hline 0.33 & 11806 & 3659 & 0.083 \\
\hline 0.66 & 9615 & 5264 & 0.147 \\
\hline 0.66 & 9668 & 5261 & 0.146 \\
\hline 0.66 & 9694 & 5253 & 0.145 \\
\hline 1 & 11917 & 8288 & 0.186 \\
\hline 1 & 11922 & 8352 & 0.188 \\
\hline 1 & 11927 & 8271 & 0.186 \\
\hline 1.33 & 12516 & 9969 & 0.213 \\
\hline 1.33 & 12432 & 9915 & 0.214 \\
\hline 1.33 & 12533 & 9993 & 0.213 \\
\hline 1.66 & 10208 & 8982 & 0.236 \\
\hline 1.66 & 10184 & 9009 & 0.237 \\
\hline 1.66 & 10188 & 8992 & 0.236 \\
\hline 2 & 12547 & 11673 & 0.249 \\
\hline 2 & 12546 & 11629 & 0.248 \\
\hline 2 & 12594 & 11696 & 0.249 \\
\hline 2.5 & 12801 & 12797 & 0.268 \\
\hline 2.5 & 12767 & 12765 & 0.268 \\
\hline 2.5 & 12830 & 12805 & 0.267 \\
\hline 3 & 13158 & 13951 & 0.284 \\
\hline 3 & 13178 & 14002 & 0.284 \\
\hline 3 & 13297 & 14201 & 0.286 \\
\hline 5 & 12415 & 15643 & 0.337 \\
\hline 5 & 12425 & 15614 & 0.336 \\
\hline 5 & 12406 & 15641 & 0.338 \\
\hline 10 & 10624 & 16785 & 0.423 \\
\hline 10 & 10580 & 16699 & 0.423 \\
\hline 10 & 10538 & 16606 & 0.422 \\
\hline
\end{tabular}




\section{Order in $\mathrm{K}^{+}(E)-1^{-}, 3.0$ equiv.}

$\mathrm{K}^{+}(E)-1^{-}$

2-Iodothiophene

Bis(dibenzylideneacetone)palladium $2.5 \mathrm{mM}$ (0.05 equiv)
$150 \mathrm{mM}$ (3.0 equiv)

$50 \mathrm{mM}$ (1.0 equiv)

Following the General Procedure, $\mathrm{K}^{+}(E) \mathbf{1}^{-}(1.90 \mathrm{~mL}, 0.394 \mathrm{M})$ and biphenyl $(8.7 \mathrm{mg})$ were dissolved in DME $(2.10 \mathrm{~mL})$ in a flame-dried, 2-neck round-bottomed flask, equipped with a stir bar and a septum under argon. The 2-iodothiophene $(27.6 \mu \mathrm{L}, 0.25 \mathrm{mmol})$ was then added and the reaction was stirred for $1 \mathrm{~min}$. A suspension of $\mathrm{Pd}(\mathrm{dba})_{2}(7.2 \mathrm{mg}, 0.0125 \mathrm{mmol})$ in dry THF (1.0 mL) was added. The dark red solution slowly turned turbid over time as the precipitation of KI proceeded. Aliquots $(\sim 200 \mu \mathrm{L})$ were withdrawn after $0.33,0.66,1.0,1.33$, $1.66,2.0,2.5,3.0,4,5,7$, and $10 \mathrm{~min}$. To quench, these samples were added to $100 \mu \mathrm{L}$ of a $20 \%$ aqueous solution of 2-dimethylaminoethanethiol hydrochloride. The clear colorless to slightlyyellow solution was then filtered through a plug of silica gel, and the silica gel was washed with diethyl ether to give a total sample volume of $\sim 2 \mathrm{~mL}$. This sample was injected into the GC three times.

initial rate $=0.0849$

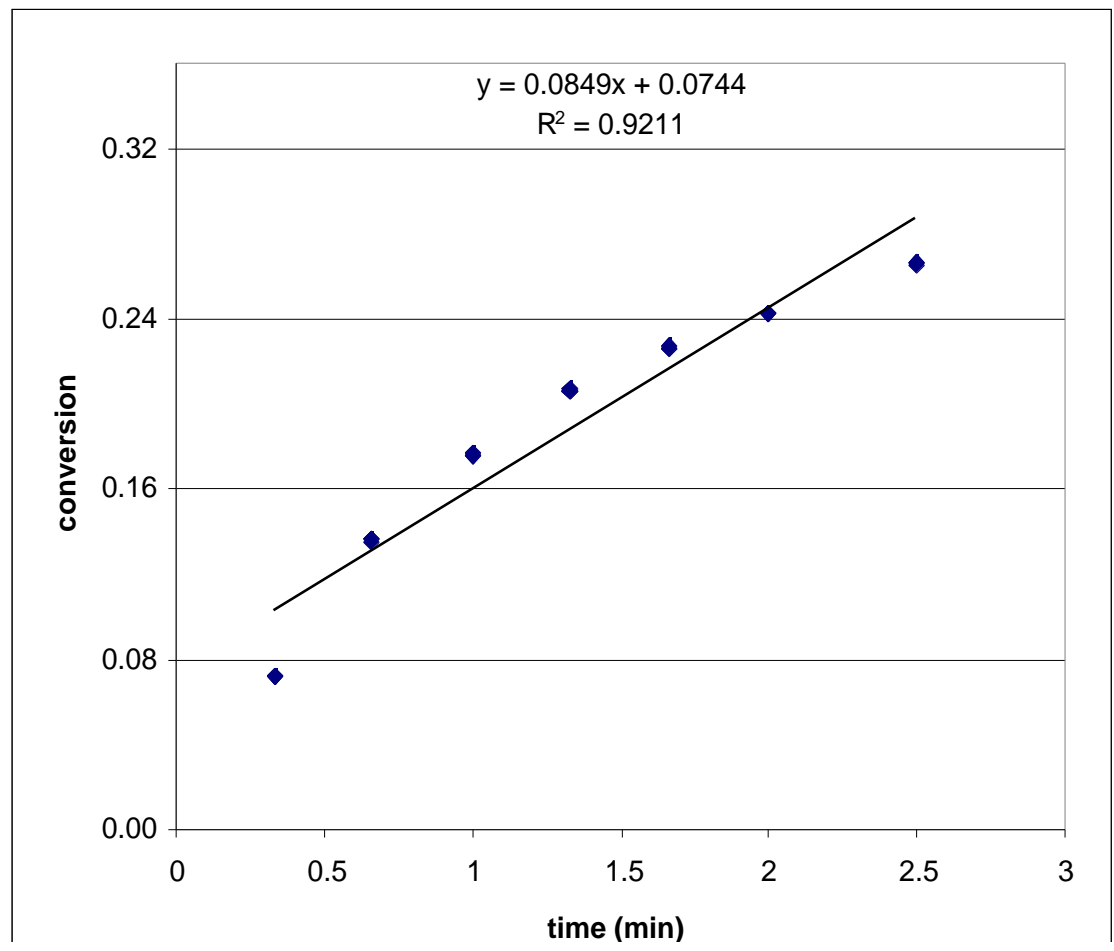




\begin{tabular}{c|c|c|c}
\hline time & area A & area 2 & Conversion \\
\hline 0.33 & 13374 & 2925 & 0.072 \\
0.33 & 13362 & 2921 & 0.072 \\
0.33 & 13330 & 2929 & 0.072 \\
0.66 & 11186 & 4648 & 0.136 \\
0.66 & 11229 & 4637 & 0.135 \\
0.66 & 11197 & 4649 & 0.136 \\
1 & 11645 & 6264 & 0.176 \\
1 & 11558 & 6196 & 0.176 \\
1 & 11583 & 6192 & 0.175 \\
1.33 & 11974 & 7550 & 0.207 \\
1.33 & 11987 & 7519 & 0.206 \\
1.33 & 11984 & 7515 & 0.206 \\
1.66 & 13519 & 9300 & 0.226 \\
1.66 & 13533 & 9325 & 0.226 \\
1.66 & 13528 & 9372 & 0.227 \\
2 & 13651 & 10099 & 0.243 \\
2 & 13680 & 10129 & 0.243 \\
2 & 13670 & 10114 & 0.243 \\
2.5 & 11534 & 9349 & 0.266 \\
2.5 & 11423 & 9269 & 0.266 \\
2.5 & 11494 & 9313 & 0.266 \\
3 & 11357 & 9837 & 0.284 \\
3 & 11482 & 9940 & 0.284 \\
3 & 11473 & 9945 & 0.284 \\
5 & 10671 & 11188 & 0.344 \\
5 & 10671 & 11121 & 0.342 \\
5 & 10664 & 11123 & 0.342 \\
10 & 10573 & 14061 & 0.436 \\
10 & 10593 & 14088 & 0.436 \\
10 & 10560 & & 0.437 \\
& & &
\end{tabular}




\section{Order in $\mathrm{K}^{+}(E)-1^{-}, 0.5$ equiv (with 1.0 equiv $\left.\mathrm{Pd}(\mathrm{dba})_{2}\right)$.}

$\mathrm{K}^{+}(E)-\mathbf{1}^{-}$

2-Iodothiophene

Bis(dibenzylideneacetone)palladium $25 \mathrm{mM}$ (1.0 equiv)
$12.5 \mathrm{mM}(0.5$ equiv $)$

$25 \mathrm{mM}$ (1.0 equiv)

Following the General Procedure, biphenyl $(2.0 \mathrm{mg})$ and $\operatorname{Pd}(\mathrm{dba})_{2}(71.9 \mathrm{mg}, 0.125$ mmol) were dissolved in DME $(4.85 \mathrm{~mL})$ in a flame-dried, 2-neck round-bottomed flask, equipped with a stir bar and a septum under argon. The 2-iodothiophene (13.8 $\mu \mathrm{L}, 0.125 \mathrm{mmol})$ was then added and the reaction was stirred for $1 \mathrm{~min}$. To this mixture was then added $\mathrm{K}^{+}(E)-\mathbf{1}^{-}$ $(134 \mu \mathrm{L}, 0.467 \mathrm{M})$. The dark red solution slowly turned turbid over time as the precipitation of KI proceeded. Aliquots $(\sim 200 \mu \mathrm{L})$ were withdrawn after 1, 3, 5, 7, 10, 15, 20, 30, 40, 50, and 65 min. To quench, these samples were added to $200 \mu \mathrm{L}$ of a $20 \%$ aqueous solution of 2dimethylaminoethanethiol hydrochloride. The clear colorless to slightly-yellow solution was then filtered through a plug of silica gel, and the silica gel was washed with diethyl ether to give a total sample volume of $\sim 2 \mathrm{~mL}$. This sample was injected into the GC three times.

initial rate $=0.0041$

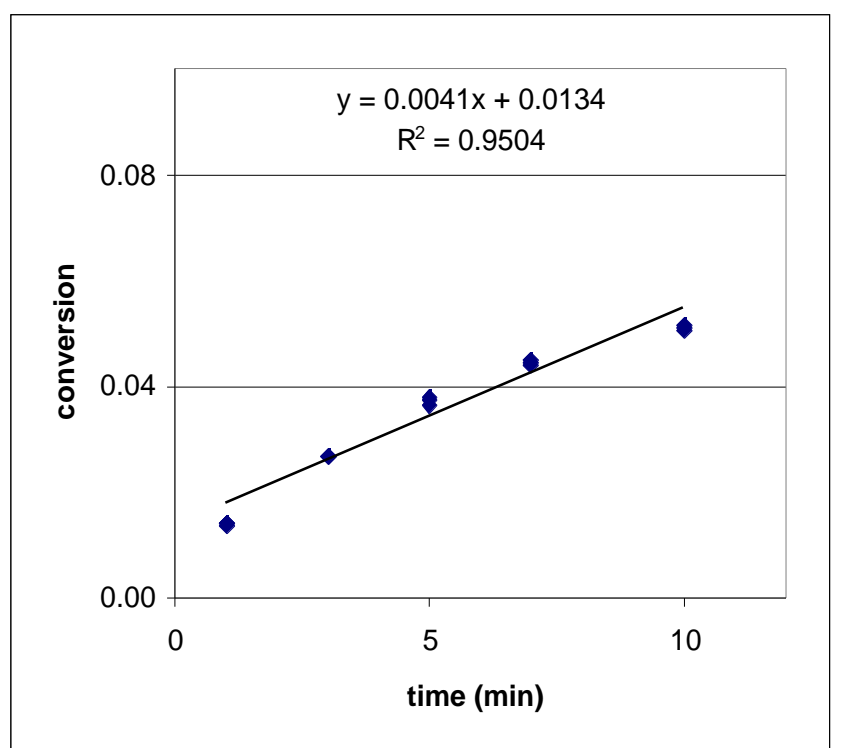




\begin{tabular}{|c|c|c|c|}
\hline Time & $\operatorname{area} \mathrm{A}$ & area 2 & Conversion \\
\hline 1 & 2798 & 252 & 0.014 \\
\hline 1 & 2797 & 260 & 0.014 \\
\hline 1 & 2807 & 259 & 0.014 \\
\hline 3 & 3082 & 552 & 0.027 \\
\hline 3 & 3120 & 558 & 0.027 \\
\hline 3 & 3097 & 554 & 0.027 \\
\hline 5 & 3280 & 813 & 0.037 \\
\hline 5 & 3236 & 809 & 0.038 \\
\hline 5 & 3258 & 785 & 0.036 \\
\hline 7 & 2525 & 752 & 0.045 \\
\hline 7 & 2533 & 750 & 0.045 \\
\hline 7 & 2539 & 737 & 0.044 \\
\hline 10 & 2976 & 1016 & 0.051 \\
\hline 10 & 3019 & 1013 & 0.051 \\
\hline 10 & 2967 & 1005 & 0.051 \\
\hline 15 & 3057 & 1153 & 0.057 \\
\hline 15 & 3054 & 1181 & 0.058 \\
\hline 15 & 3059 & 1164 & 0.057 \\
\hline 20 & 2456 & 986 & 0.061 \\
\hline 20 & 2519 & 1010 & 0.060 \\
\hline 20 & 2431 & 1000 & 0.062 \\
\hline 30 & 3595 & 1407 & 0.059 \\
\hline 30 & 3605 & 1515 & 0.063 \\
\hline 30 & 3616 & 1527 & 0.064 \\
\hline 40 & 2868 & 1373 & 0.072 \\
\hline 40 & 2651 & 1245 & 0.071 \\
\hline 40 & 2701 & 1266 & 0.071 \\
\hline 50 & 2953 & 1489 & 0.076 \\
\hline 50 & 2905 & 1427 & 0.074 \\
\hline 50 & 2820 & 1396 & 0.075 \\
\hline 65 & 2844 & 1539 & 0.082 \\
\hline 65 & 2833 & 1534 & 0.082 \\
\hline 65 & 2835 & 1544 & 0.082 \\
\hline
\end{tabular}




\section{Order in $\mathrm{K}^{+}(E)-1^{-}, 0.5$ equiv (with 1.0 equiv $\left.\mathrm{Pd}(\mathrm{dba})_{2}\right)$.}

$\mathrm{K}^{+}(E)-\mathbf{1}^{-}$

2-Iodothiophene

Bis(dibenzylideneacetone)palladium $25 \mathrm{mM}$ (1.0 equiv)
$12.5 \mathrm{mM}(0.5$ equiv $)$

$25 \mathrm{mM}$ (1.0 equiv)

Following the General Procedure, biphenyl $(2.0 \mathrm{mg})$ and $\operatorname{Pd}(\mathrm{dba})_{2}(71.9 \mathrm{mg}, 0.125$ mmol) were dissolved in DME $(4.85 \mathrm{~mL})$ in a flame-dried, 2-neck round-bottomed flask, equipped with a stir bar and a septum under argon. The 2-iodothiophene (13.8 $\mu \mathrm{L}, 0.125 \mathrm{mmol})$ was then added and the reaction was stirred for $1 \mathrm{~min}$. To this mixture was then added $\mathrm{K}^{+}(E)-\mathbf{1}^{-}$ $(134 \mu \mathrm{L}, 0.467 \mathrm{M})$. The dark red solution slowly turned turbid over time as the precipitation of KI proceeded. Aliquots $(\sim 200 \mu \mathrm{L})$ were withdrawn after 1, 3, 5, 7, 10, 15, 20, 30, 40, 50, and 65 min. To quench, these samples were added to $200 \mu \mathrm{L}$ of a $20 \%$ aqueous solution of 2dimethylaminoethanethiol hydrochloride. The clear colorless to slightly-yellow solution was then filtered through a plug of silica gel, and the silica gel was washed with diethyl ether to give a total sample volume of $\sim 2 \mathrm{~mL}$. This sample was injected into the GC three times.

initial rate $=0.0048$

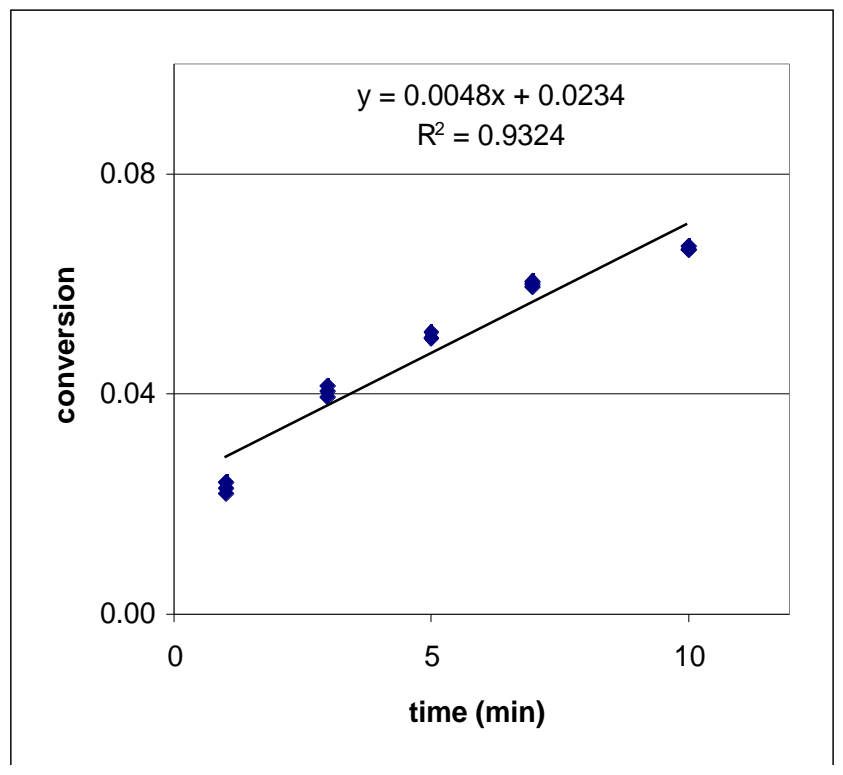




\begin{tabular}{|c|c|c|c|}
\hline Time & area $\mathrm{A}$ & area 2 & Conversion \\
\hline 1 & 2997 & 434 & 0.022 \\
\hline 1 & 2972 & 451 & 0.023 \\
\hline 1 & 3029 & 477 & 0.024 \\
\hline 3 & 3383 & 926 & 0.041 \\
\hline 3 & 3377 & 910 & 0.041 \\
\hline 3 & 3420 & 899 & 0.040 \\
\hline 5 & 2625 & 874 & 0.050 \\
\hline 5 & 2645 & 897 & 0.051 \\
\hline 5 & 2561 & 854 & 0.050 \\
\hline 7 & 2794 & 1102 & 0.059 \\
\hline 7 & 2797 & 1117 & 0.060 \\
\hline 7 & 2822 & 1128 & 0.060 \\
\hline 10 & 3073 & 1360 & 0.067 \\
\hline 10 & 3094 & 1361 & 0.066 \\
\hline 10 & 3085 & 1359 & 0.066 \\
\hline 15 & 2528 & 1273 & 0.076 \\
\hline 15 & 2483 & 1243 & 0.076 \\
\hline 15 & 2563 & 1289 & 0.076 \\
\hline 20 & 2808 & 1490 & 0.080 \\
\hline 20 & 2810 & 1489 & 0.080 \\
\hline 20 & 2809 & 1480 & 0.079 \\
\hline 30 & 2784 & 1593 & 0.086 \\
\hline 30 & 3588 & 1973 & 0.083 \\
\hline 30 & 3520 & 1949 & 0.084 \\
\hline 40 & 3602 & 2080 & 0.087 \\
\hline 40 & 3067 & 1893 & 0.093 \\
\hline 40 & 2942 & 1823 & 0.093 \\
\hline 50 & 3049 & 1905 & 0.094 \\
\hline 50 & 2673 & 1678 & 0.095 \\
\hline 50 & 2684 & 1679 & 0.094 \\
\hline 65 & 2725 & 1824 & 0.101 \\
\hline 65 & 2879 & 1906 & 0.100 \\
\hline 65 & 2803 & 1971 & 0.106 \\
\hline
\end{tabular}




\section{Order in $\mathrm{K}^{+}(E)-1^{-}, 0.5$ equiv (with 1.0 equiv $\left.\mathrm{Pd}(\mathrm{dba})_{2}\right)$.}

$\mathrm{K}^{+}(E)-\mathbf{1}^{-}$

2-Iodothiophene

Bis(dibenzylideneacetone)palladium $25 \mathrm{mM}$ (1.0 equiv)
$12.5 \mathrm{mM}(0.5$ equiv $)$

$25 \mathrm{mM}$ (1.0 equiv)

Following the General Procedure, biphenyl $(2.0 \mathrm{mg})$ and $\operatorname{Pd}(\mathrm{dba})_{2}(71.9 \mathrm{mg}, 0.125$ mmol) were dissolved in DME $(4.85 \mathrm{~mL})$ in a flame-dried, 2-neck round-bottomed flask, equipped with a stir bar and a septum under argon. The 2-iodothiophene (13.8 $\mu \mathrm{L}, 0.125 \mathrm{mmol})$ was then added and the reaction was stirred for $1 \mathrm{~min}$. To this mixture was then added $\mathrm{K}^{+}(E)-\mathbf{1}^{-}$ $(134 \mu \mathrm{L}, 0.467 \mathrm{M})$. The dark red solution slowly turned turbid over time as the precipitation of KI proceeded. Aliquots $(\sim 200 \mu \mathrm{L})$ were withdrawn after 1, 3, 5, 7, 10, 15, 20, 30, 40, 50, and 65 min. To quench, these samples were added to $200 \mu \mathrm{L}$ of a $20 \%$ aqueous solution of 2dimethylaminoethanethiol hydrochloride. The clear colorless to slightly-yellow solution was then filtered through a plug of silica gel, and the silica gel was washed with diethyl ether to give a total sample volume of $\sim 2 \mathrm{~mL}$. This sample was injected into the GC three times.

initial rate $=0.0056$

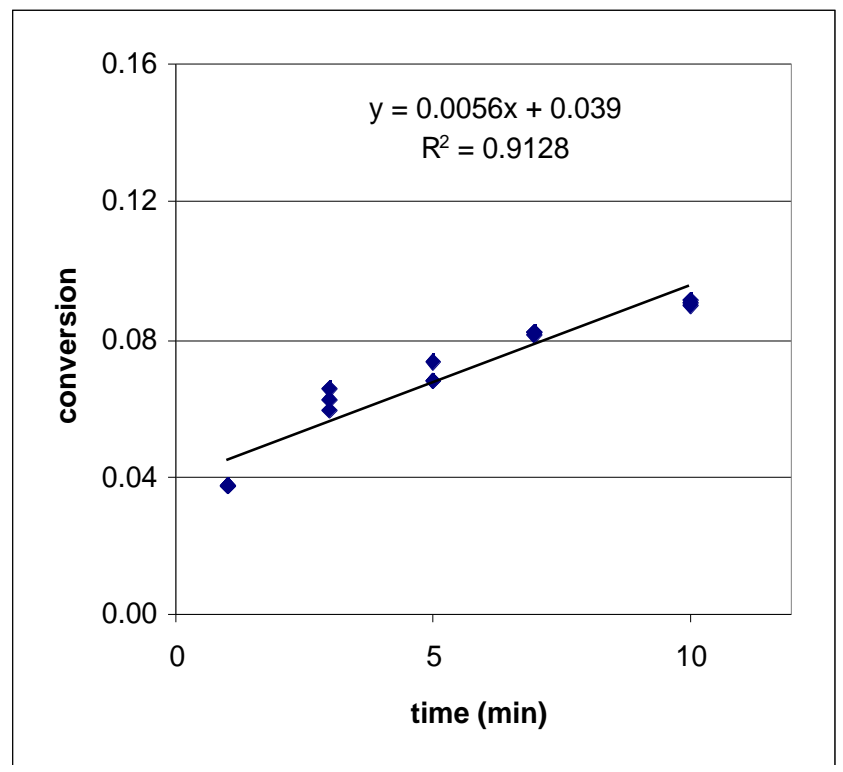




\begin{tabular}{c|c|c|c}
\hline Time & area A & area 2 & Conversion \\
\hline 1 & 965 & 238 & 0.037 \\
1 & 989 & 243 & 0.037 \\
1 & 977 & 242 & 0.037 \\
3 & 521 & 216 & 0.063 \\
3 & 497 & 215 & 0.065 \\
3 & 525 & 205 & 0.059 \\
5 & 497 & 223 & 0.068 \\
5 & 457 & 223 & 0.074 \\
5 & 484 & 217 & 0.068 \\
7 & 867 & 470 & 0.082 \\
7 & 867 & 465 & 0.081 \\
7 & 860 & 466 & 0.082 \\
10 & 898 & 540 & 0.091 \\
10 & 929 & 561 & 0.091 \\
10 & 923 & 551 & 0.090 \\
15 & 767 & 582 & 0.114 \\
15 & 779 & 588 & 0.114 \\
15 & 775 & 593 & 0.115 \\
20 & 816 & 686 & 0.127 \\
20 & 821 & 694 & 0.128 \\
20 & 803 & 669 & 0.126 \\
30 & 884 & 763 & 0.130 \\
30 & 2768 & 2401 & 0.131 \\
30 & 936 & 830 & 0.134 \\
40 & 970 & 866 & 0.135 \\
40 & 987 & 903 & 0.138 \\
40 & 945 & 590 & 0.136 \\
50 & 572 & 250 & 0.156 \\
50 & 602 & 0.156 \\
50 & 559 & 0.158 \\
65 & 204 & 0.161 \\
65 & 258 & 0.159 \\
65 & & 590 &
\end{tabular}




\section{Order in $\mathrm{K}^{+}(E)-1^{-}, 0.75$ equiv (with 1.0 equiv $\left.\mathrm{Pd}(\mathrm{dba})_{2}\right)$.}

$\mathrm{K}^{+}(E)-\mathbf{1}^{-}$

2-Iodothiophene

Bis(dibenzylideneacetone)palladium $25 \mathrm{mM}$ (1.0 equiv)
$18.75 \mathrm{mM}(0.75$ equiv)

$25 \mathrm{mM}$ (1.0 equiv)

Following the General Procedure, biphenyl $(2.0 \mathrm{mg})$ and $\operatorname{Pd}(\mathrm{dba})_{2}(71.9 \mathrm{mg}, 0.125$ mmol) were dissolved in DME $(4.79 \mathrm{~mL})$ in a flame-dried, 2-neck round-bottomed flask, equipped with a stir bar and a septum under argon. The 2-iodothiophene (13.8 $\mu \mathrm{L}, 0.125 \mathrm{mmol})$ was then added and the reaction was stirred for $1 \mathrm{~min}$. To this mixture was then added $\mathrm{K}^{+}(E)-\mathbf{1}^{-}$ $(201 \mu \mathrm{L}, 0.467 \mathrm{M})$. The dark red solution slowly turned turbid over time as the precipitation of KI proceeded. Aliquots $(\sim 200 \mu \mathrm{L})$ were withdrawn after 1, 3, 5, 7, 10, 15, 20, 30, 40, 50, and 65 min. To quench, these samples were added to $200 \mu \mathrm{L}$ of a $20 \%$ aqueous solution of 2dimethylaminoethanethiol hydrochloride. The clear colorless to slightly-yellow solution was then filtered through a plug of silica gel, and the silica gel was washed with diethyl ether to give a total sample volume of $\sim 2 \mathrm{~mL}$. This sample was injected into the GC three times.

initial rate $=0.0061$

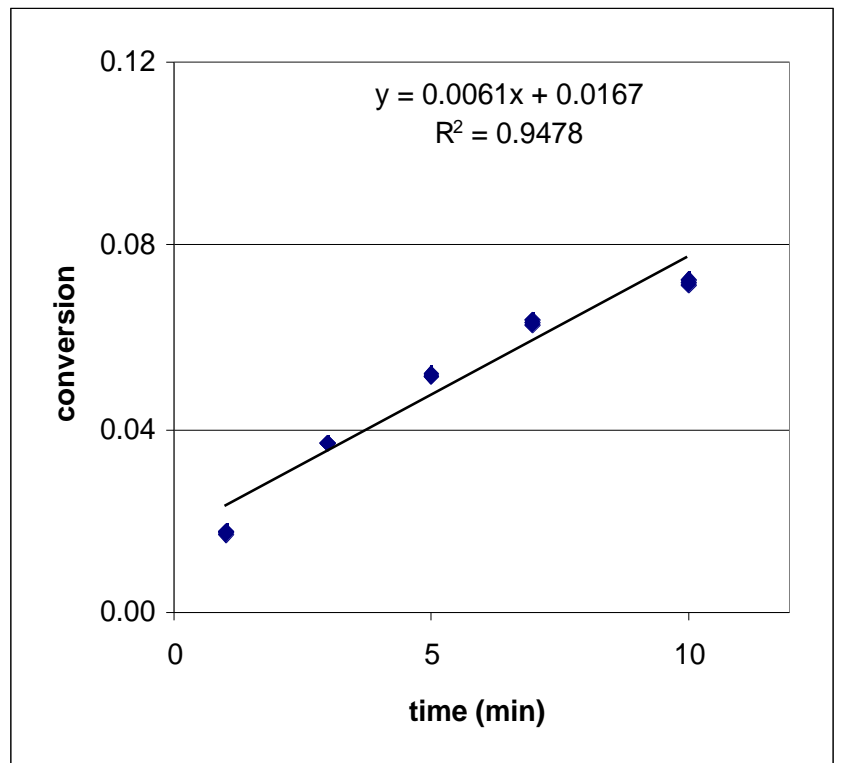




\begin{tabular}{|c|c|c|c|}
\hline Time & area $\mathrm{A}$ & area 2 & Conversion \\
\hline 1 & 2401 & 277 & 0.017 \\
\hline 1 & 2350 & 265 & 0.017 \\
\hline 1 & 2399 & 280 & 0.018 \\
\hline 3 & 2969 & 721 & 0.037 \\
\hline 3 & 3012 & 739 & 0.037 \\
\hline 3 & 3037 & 742 & 0.037 \\
\hline 5 & 2676 & 924 & 0.052 \\
\hline 5 & 2783 & 945 & 0.051 \\
\hline 5 & 2747 & 934 & 0.051 \\
\hline 7 & 3025 & 1256 & 0.063 \\
\hline 7 & 2934 & 1244 & 0.064 \\
\hline 7 & 3024 & 1268 & 0.063 \\
\hline 10 & 2823 & 1361 & 0.073 \\
\hline 10 & 2898 & 1374 & 0.072 \\
\hline 10 & 2882 & 1378 & 0.072 \\
\hline 15 & 2703 & 1412 & 0.079 \\
\hline 15 & 2692 & 1405 & 0.079 \\
\hline 15 & 2634 & 1399 & 0.080 \\
\hline 20 & 2475 & 1340 & 0.082 \\
\hline 20 & 2438 & 1317 & 0.082 \\
\hline 20 & 2429 & 1336 & 0.083 \\
\hline 30 & 3243 & 1839 & 0.086 \\
\hline 30 & 3262 & 1857 & 0.086 \\
\hline 30 & 3216 & 1823 & 0.085 \\
\hline 40 & 2732 & 1603 & 0.089 \\
\hline 40 & 2742 & 1609 & 0.089 \\
\hline 40 & 2737 & 1600 & 0.088 \\
\hline 50 & 3070 & 1832 & 0.090 \\
\hline 50 & 3084 & 1837 & 0.090 \\
\hline 50 & 3034 & 1792 & 0.089 \\
\hline 65 & 2437 & 1468 & 0.091 \\
\hline 65 & 2408 & 1453 & 0.091 \\
\hline 65 & 2397 & 1463 & 0.092 \\
\hline
\end{tabular}




\section{Order in $\mathrm{K}^{+}(E)-1^{-}, 0.75$ equiv (with 1.0 equiv $\left.\mathrm{Pd}(\mathrm{dba})_{2}\right)$.}

$\mathrm{K}^{+}(E)-\mathbf{1}^{-}$

2-Iodothiophene

Bis(dibenzylideneacetone)palladium $25 \mathrm{mM}$ (1.0 equiv)
$18.75 \mathrm{mM}(0.75$ equiv)

$25 \mathrm{mM}$ (1.0 equiv)

Following the General Procedure, biphenyl $(2.0 \mathrm{mg})$ and $\operatorname{Pd}(\mathrm{dba})_{2}(71.9 \mathrm{mg}, 0.125$ mmol) were dissolved in DME $(4.79 \mathrm{~mL})$ in a flame-dried, 2-neck round-bottomed flask, equipped with a stir bar and a septum under argon. The 2-iodothiophene (13.8 $\mu \mathrm{L}, 0.125 \mathrm{mmol})$ was then added and the reaction was stirred for $1 \mathrm{~min}$. To this mixture was then added $\mathrm{K}^{+}(E)-\mathbf{1}^{-}$ $(201 \mu \mathrm{L}, 0.467 \mathrm{M})$. The dark red solution slowly turned turbid over time as the precipitation of KI proceeded. Aliquots $(\sim 200 \mu \mathrm{L})$ were withdrawn after 1, 3, 5, 7, 10, 15, 20, 30, 40, 50, and 65 min. To quench, these samples were added to $200 \mu \mathrm{L}$ of a $20 \%$ aqueous solution of 2dimethylaminoethanethiol hydrochloride. The clear colorless to slightly-yellow solution was then filtered through a plug of silica gel, and the silica gel was washed with diethyl ether to give a total sample volume of $\sim 2 \mathrm{~mL}$. This sample was injected into the GC three times.

initial rate $=0.0072$

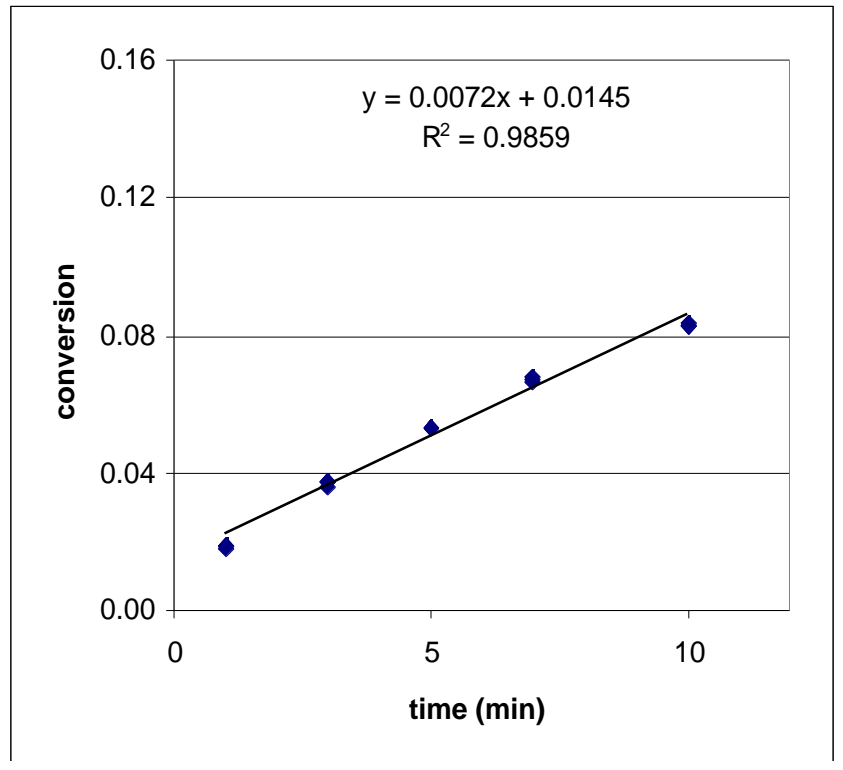




\begin{tabular}{|c|c|c|c|}
\hline Time & area $\mathrm{A}$ & area 2 & Conversion \\
\hline 1 & 2755 & 342 & 0.019 \\
\hline 1 & 2670 & 329 & 0.019 \\
\hline 1 & 2616 & 317 & 0.018 \\
\hline 3 & 2718 & 651 & 0.036 \\
\hline 3 & 2754 & 678 & 0.037 \\
\hline 3 & 2692 & 674 & 0.038 \\
\hline 5 & 2617 & 926 & 0.053 \\
\hline 5 & 2539 & 888 & 0.053 \\
\hline 5 & 2581 & 907 & 0.053 \\
\hline 7 & 2439 & 1094 & 0.068 \\
\hline 7 & 2419 & 1081 & 0.067 \\
\hline 7 & 2491 & 1097 & 0.066 \\
\hline 10 & 2868 & 1586 & 0.083 \\
\hline 10 & 2882 & 1581 & 0.083 \\
\hline 10 & 2211 & 1212 & 0.083 \\
\hline 15 & 552 & 328 & 0.090 \\
\hline 15 & 599 & 358 & 0.090 \\
\hline 15 & 631 & 377 & 0.090 \\
\hline 20 & 530 & 327 & 0.093 \\
\hline 20 & 481 & 296 & 0.093 \\
\hline 20 & 488 & 302 & 0.093 \\
\hline 30 & 541 & 339 & 0.094 \\
\hline 30 & 534 & 334 & 0.094 \\
\hline 30 & 553 & 349 & 0.095 \\
\hline 40 & 500 & 323 & 0.097 \\
\hline 40 & 488 & 315 & 0.097 \\
\hline 40 & 461 & 298 & 0.097 \\
\hline 50 & 565 & 373 & 0.100 \\
\hline 50 & 587 & 387 & 0.099 \\
\hline 50 & 574 & 379 & 0.099 \\
\hline 65 & 621 & 419 & 0.102 \\
\hline 65 & 623 & 418 & 0.101 \\
\hline 65 & 660 & 443 & 0.101 \\
\hline
\end{tabular}




\section{Order in $\mathrm{K}^{+}(E)-1^{-}, 0.75$ equiv (with 1.0 equiv $\left.\mathrm{Pd}(\mathrm{dba})_{2}\right)$.}

$\mathrm{K}^{+}(E)-\mathbf{1}^{-}$

2-Iodothiophene

Bis(dibenzylideneacetone)palladium $25 \mathrm{mM}$ (1.0 equiv)
$18.75 \mathrm{mM}(0.75$ equiv $)$

$25 \mathrm{mM}$ (1.0 equiv)

Following the General Procedure, biphenyl $(2.0 \mathrm{mg})$ and $\mathrm{Pd}(\mathrm{dba})_{2}(71.9 \mathrm{mg}, 0.125$ mmol) were dissolved in DME $(4.79 \mathrm{~mL})$ in a flame-dried, 2-neck round-bottomed flask, equipped with a stir bar and a septum under argon. The 2-iodothiophene (13.8 $\mu \mathrm{L}, 0.125 \mathrm{mmol})$ was then added and the reaction was stirred for $1 \mathrm{~min}$. To this mixture was then added $\mathrm{K}^{+}(E)-\mathbf{1}^{-}$ $(201 \mu \mathrm{L}, 0.467 \mathrm{M})$. The dark red solution slowly turned turbid over time as the precipitation of KI proceeded. Aliquots ( $200 \mu \mathrm{L})$ were withdrawn after 1, 3, 5, 7, 10, 15, 20, 30, 40, 50, and 65 min. To quench, these samples were added to $200 \mu \mathrm{L}$ of a $20 \%$ aqueous solution of 2 dimethylaminoethanethiol hydrochloride. The clear colorless to slightly-yellow solution was then filtered through a plug of silica gel, and the silica gel was washed with diethyl ether to give a total sample volume of $\sim 2 \mathrm{~mL}$. This sample was injected into the GC three times.

initial rate $=0.0067$

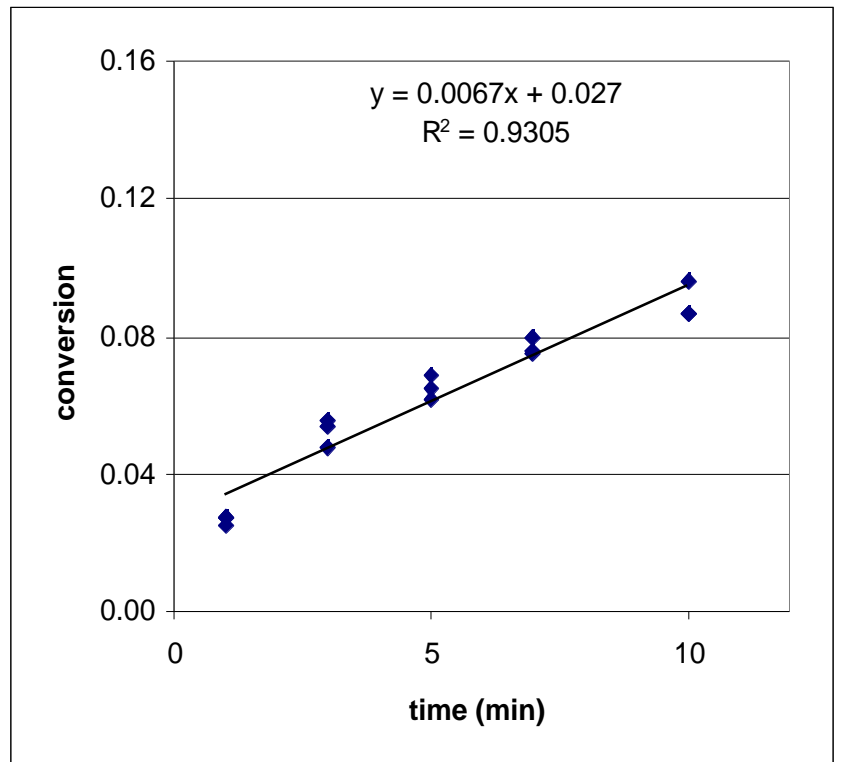




\begin{tabular}{|c|c|c|c|}
\hline Time & area $\mathrm{A}$ & area 2 & Conversion \\
\hline 1 & 587 & 106 & 0.027 \\
\hline 1 & 587 & 106 & 0.027 \\
\hline 1 & 587 & 98 & 0.025 \\
\hline 3 & 601 & 190 & 0.048 \\
\hline 3 & 634 & 226 & 0.054 \\
\hline 3 & 611 & 225 & 0.055 \\
\hline 5 & 631 & 270 & 0.065 \\
\hline 5 & 2318 & 945 & 0.061 \\
\hline 5 & 627 & 284 & 0.068 \\
\hline 7 & 507 & 267 & 0.079 \\
\hline 7 & 512 & 257 & 0.076 \\
\hline 7 & 475 & 237 & 0.075 \\
\hline 10 & 518 & 330 & 0.096 \\
\hline 10 & 534 & 308 & 0.087 \\
\hline 10 & 2539 & 1453 & 0.086 \\
\hline 15 & 563 & 399 & 0.107 \\
\hline 15 & 619 & 407 & 0.099 \\
\hline 15 & 586 & 373 & 0.096 \\
\hline 20 & 524 & 395 & 0.114 \\
\hline 20 & 508 & 395 & 0.117 \\
\hline 20 & 501 & 385 & 0.116 \\
\hline 30 & 622 & 502 & 0.122 \\
\hline 30 & 591 & 480 & 0.123 \\
\hline 30 & 570 & 461 & 0.122 \\
\hline 40 & 496 & 421 & 0.128 \\
\hline 40 & 577 & 510 & 0.133 \\
\hline 40 & 495 & 419 & 0.128 \\
\hline 50 & 474 & 428 & 0.136 \\
\hline 50 & 691 & 632 & 0.138 \\
\hline 50 & 668 & 600 & 0.135 \\
\hline 65 & 681 & 654 & 0.145 \\
\hline 65 & 634 & 610 & 0.145 \\
\hline 65 & 702 & 679 & 0.146 \\
\hline
\end{tabular}




\section{Order in $\mathrm{K}^{+}(E)-1^{-}$, 1.0 equiv (with 1.0 equiv $\left.\operatorname{Pd}(\mathrm{dba})_{2}\right)_{\text {. }}$}

$\mathrm{K}^{+}(E)-\mathbf{1}^{-}$

2-Iodothiophene

Bis(dibenzylideneacetone)palladium $25 \mathrm{mM}$ (1.0 equiv)
$25 \mathrm{mM}$ (1.0 equiv)

$25 \mathrm{mM}$ (1.0 equiv)

Following the General Procedure, biphenyl $(2.0 \mathrm{mg})$ and $\operatorname{Pd}(\mathrm{dba})_{2}(71.9 \mathrm{mg}, 0.125$ mmol) were dissolved in DME $(4.72 \mathrm{~mL})$ in a flame-dried, 2-neck round-bottomed flask, equipped with a stir bar and a septum under argon. The 2-iodothiophene (13.8 $\mu \mathrm{L}, 0.125 \mathrm{mmol})$ was then added and the reaction was stirred for $1 \mathrm{~min}$. To this mixture was then added $\mathrm{K}^{+}(E)-\mathbf{1}^{-}$ $(269 \mu \mathrm{L}, 0.464 \mathrm{M})$. The dark red solution slowly turned turbid over time as the precipitation of KI proceeded. Aliquots $(\sim 200 \mu \mathrm{L})$ were withdrawn after 1, 3, 5, 7, 10, 15, 20, 30, 40, 50, and 65 min. To quench, these samples were added to $200 \mu \mathrm{L}$ of a $20 \%$ aqueous solution of 2dimethylaminoethanethiol hydrochloride. The clear colorless to slightly-yellow solution was then filtered through a plug of silica gel, and the silica gel was washed with diethyl ether to give a total sample volume of $\sim 2 \mathrm{~mL}$. This sample was injected into the GC three times.

initial rate $=0.0097$

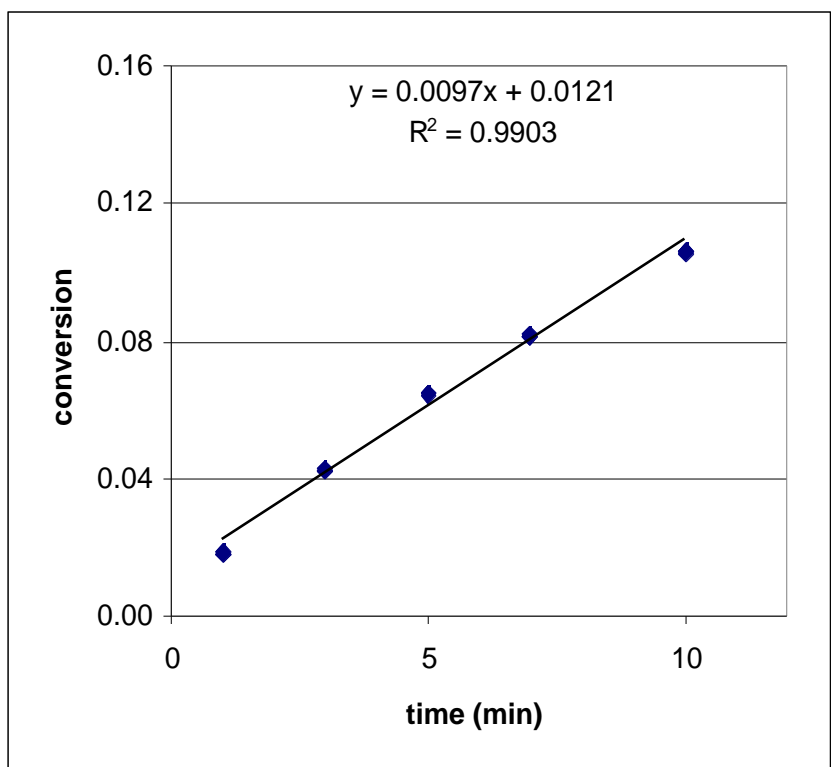




\begin{tabular}{|c|c|c|c|}
\hline Time & area $\mathrm{A}$ & area 2 & Conversion \\
\hline 1 & 3247 & 386 & 0.018 \\
\hline 1 & 3245 & 400 & 0.019 \\
\hline 1 & 3257 & 380 & 0.018 \\
\hline 3 & 2723 & 767 & 0.043 \\
\hline 3 & 2744 & 760 & 0.042 \\
\hline 3 & 2721 & 774 & 0.043 \\
\hline 5 & 2504 & 1070 & 0.064 \\
\hline 5 & 2524 & 1070 & 0.064 \\
\hline 5 & 2562 & 1105 & 0.065 \\
\hline 7 & 3412 & 1827 & 0.081 \\
\hline 7 & 3497 & 1886 & 0.081 \\
\hline 7 & 3499 & 1904 & 0.082 \\
\hline 10 & 3092 & 2160 & 0.105 \\
\hline 10 & 3102 & 2182 & 0.106 \\
\hline 10 & 3129 & 2194 & 0.106 \\
\hline 15 & 3744 & 3324 & 0.134 \\
\hline 15 & 3744 & 3299 & 0.133 \\
\hline 15 & 3763 & 3332 & 0.134 \\
\hline 20 & 2946 & 3103 & 0.159 \\
\hline 20 & 2981 & 3124 & 0.158 \\
\hline 20 & 3011 & 3127 & 0.157 \\
\hline 30 & 3626 & 4842 & 0.201 \\
\hline 30 & 3578 & 4877 & 0.206 \\
\hline 30 & 3713 & 4989 & 0.203 \\
\hline 40 & 3574 & 5060 & 0.214 \\
\hline 40 & 3489 & 4898 & 0.212 \\
\hline 40 & 3527 & 4964 & 0.212 \\
\hline 50 & 1535 & 2261 & 0.222 \\
\hline 50 & 1531 & 2226 & 0.219 \\
\hline 50 & 1555 & 2297 & 0.223 \\
\hline 65 & 3061 & 4686 & 0.231 \\
\hline 65 & 3085 & 4729 & 0.231 \\
\hline 65 & 3016 & 4633 & 0.232 \\
\hline
\end{tabular}




\section{Order in $\mathrm{K}^{+}(E)-1^{-}$, 1.0 equiv (with 1.0 equiv $\left.\operatorname{Pd}(\mathrm{dba})_{2}\right)_{\text {. }}$}

$\mathrm{K}^{+}(E)-\mathbf{1}^{-}$

2-Iodothiophene

Bis(dibenzylideneacetone)palladium $25 \mathrm{mM}$ (1.0 equiv)
$25 \mathrm{mM}$ (1.0 equiv)

$25 \mathrm{mM}$ (1.0 equiv)

Following the General Procedure, biphenyl $(2.0 \mathrm{mg})$ and $\operatorname{Pd}(\mathrm{dba})_{2}(71.9 \mathrm{mg}, 0.125$ mmol) were dissolved in DME $(4.72 \mathrm{~mL})$ in a flame-dried, 2-neck round-bottomed flask, equipped with a stir bar and a septum under argon. The 2-iodothiophene (13.8 $\mu \mathrm{L}, 0.125 \mathrm{mmol})$ was then added and the reaction was stirred for $1 \mathrm{~min}$. To this mixture was then added $\mathrm{K}^{+}(E)-\mathbf{1}^{-}$ $(269 \mu \mathrm{L}, 0.464 \mathrm{M})$. The dark red solution slowly turned turbid over time as the precipitation of KI proceeded. Aliquots $(\sim 200 \mu \mathrm{L})$ were withdrawn after 1, 3, 5, 7, 10, 15, 20, 30, 40, 50, and 65 min. To quench, these samples were added to $200 \mu \mathrm{L}$ of a $20 \%$ aqueous solution of 2dimethylaminoethanethiol hydrochloride. The clear colorless to slightly-yellow solution was then filtered through a plug of silica gel, and the silica gel was washed with diethyl ether to give a total sample volume of $\sim 2 \mathrm{~mL}$. This sample was injected into the GC three times.

initial rate $=0.0095$

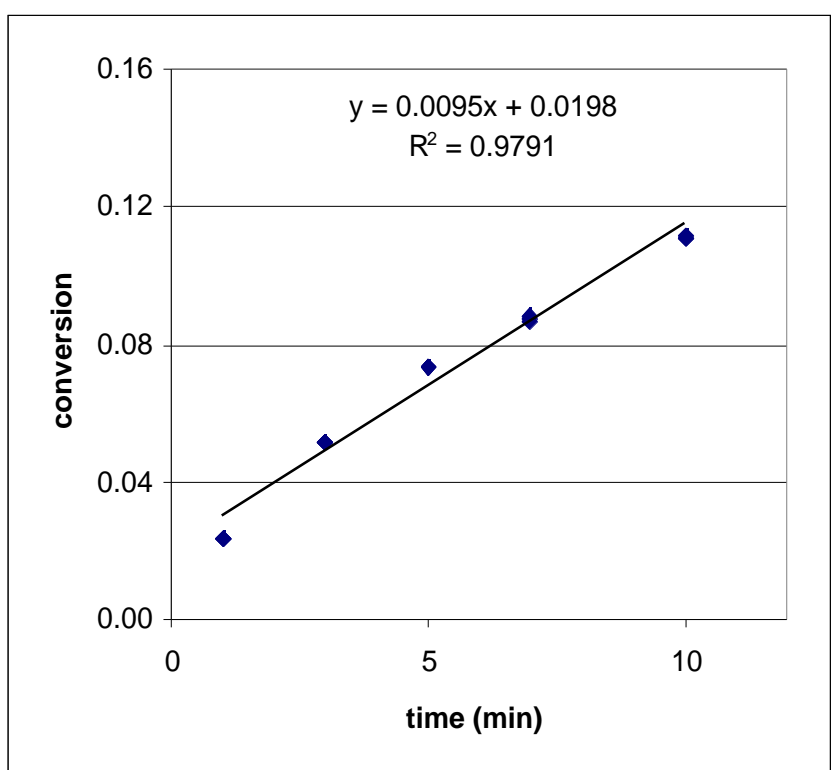




\begin{tabular}{|c|c|c|c|}
\hline Time & area $\mathrm{A}$ & area 2 & Conversion \\
\hline 1 & 2657 & 412 & 0.023 \\
\hline 1 & 2575 & 401 & 0.024 \\
\hline 1 & 2537 & 391 & 0.023 \\
\hline 3 & 2679 & 910 & 0.051 \\
\hline 3 & 2663 & 903 & 0.051 \\
\hline 3 & 2765 & 951 & 0.052 \\
\hline 5 & 2111 & 1025 & 0.073 \\
\hline 5 & 2139 & 1035 & 0.073 \\
\hline 5 & 2105 & 1022 & 0.073 \\
\hline 7 & 2477 & 1442 & 0.088 \\
\hline 7 & 2533 & 1448 & 0.086 \\
\hline 7 & 2496 & 1447 & 0.087 \\
\hline 10 & 2932 & 2167 & 0.111 \\
\hline 10 & 2954 & 2174 & 0.111 \\
\hline 10 & 3002 & 2202 & 0.111 \\
\hline 15 & 2524 & 2243 & 0.134 \\
\hline 15 & 2583 & 2288 & 0.134 \\
\hline 15 & 2576 & 2245 & 0.131 \\
\hline 20 & 2556 & 2624 & 0.155 \\
\hline 20 & 2576 & 2653 & 0.155 \\
\hline 20 & 2613 & 2673 & 0.154 \\
\hline 30 & 2979 & 3271 & 0.166 \\
\hline 30 & 2994 & 3297 & 0.166 \\
\hline 30 & 3043 & 3324 & 0.165 \\
\hline 40 & 2680 & 3104 & 0.175 \\
\hline 40 & 2650 & 3071 & 0.175 \\
\hline 40 & 2636 & 3078 & 0.176 \\
\hline 50 & 2329 & 2826 & 0.183 \\
\hline 50 & 2317 & 2771 & 0.180 \\
\hline 50 & 2332 & 2798 & 0.181 \\
\hline 65 & 2335 & 2903 & 0.188 \\
\hline 65 & 2336 & 2924 & 0.189 \\
\hline 65 & 2328 & 2927 & 0.190 \\
\hline
\end{tabular}




\section{Order in $\mathrm{K}^{+}(E)-1 ;$, 1.0 equiv (with 1.0 equiv $\left.\mathrm{Pd}(\mathrm{dba})_{2}\right)$.}

$\mathrm{K}^{+}(E)-\mathbf{1}^{-}$

2-Iodothiophene

Bis(dibenzylideneacetone)palladium $25 \mathrm{mM}$ (1.0 equiv)
$25 \mathrm{mM}$ (1.0 equiv)

$25 \mathrm{mM}$ (1.0 equiv)

Following the General Procedure, biphenyl $(2.0 \mathrm{mg})$ and $\mathrm{Pd}(\mathrm{dba})_{2}(71.9 \mathrm{mg}, 0.125$ mmol) were dissolved in DME $(4.72 \mathrm{~mL})$ in a flame-dried, 2-neck round-bottomed flask, equipped with a stir bar and a septum under argon. The 2-iodothiophene (13.8 $\mu \mathrm{L}, 0.125 \mathrm{mmol})$ was then added and the reaction was stirred for $1 \mathrm{~min}$. To this mixture was then added $\mathrm{K}^{+}(E)-\mathbf{1}^{-}$ $(269 \mu \mathrm{L}, 0.464 \mathrm{M})$. The dark red solution slowly turned turbid over time as the precipitation of KI proceeded. Aliquots $(\sim 200 \mu \mathrm{L})$ were withdrawn after 1, 3, 5, 7, 10, 15, 20, 30, 40, 50, and 65 min. To quench, these samples were added to $200 \mu \mathrm{L}$ of a $20 \%$ aqueous solution of 2 dimethylaminoethanethiol hydrochloride. The clear colorless to slightly-yellow solution was then filtered through a plug of silica gel, and the silica gel was washed with diethyl ether to give a total sample volume of $\sim 2 \mathrm{~mL}$. This sample was injected into the GC three times.

initial rate $=0.0089$

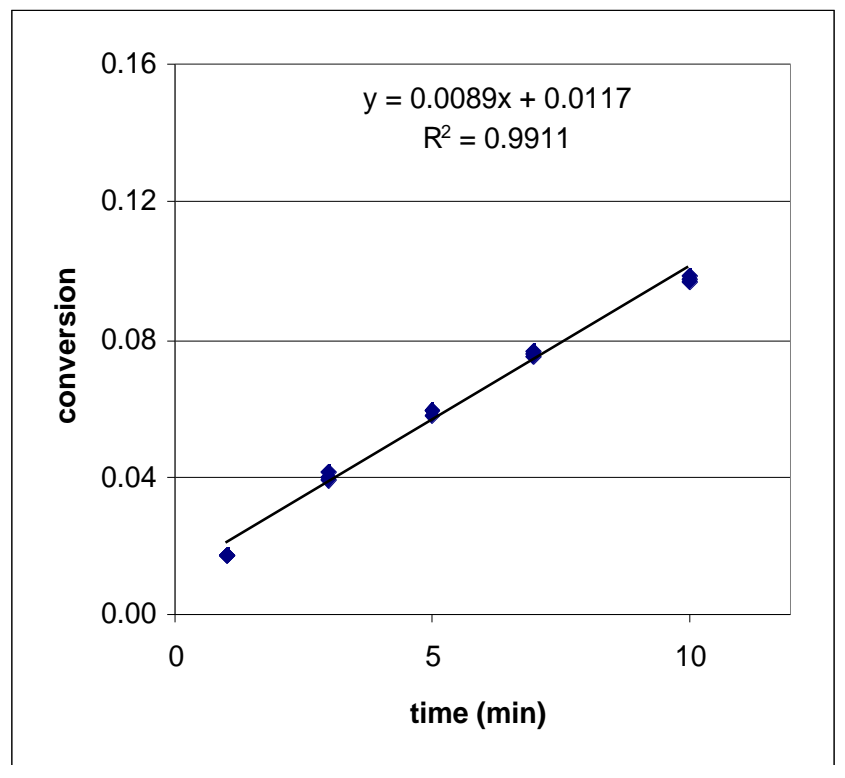




\begin{tabular}{|c|c|c|c|}
\hline Time & area $\mathrm{A}$ & area 2 & Conversion \\
\hline 1 & 2659 & 309 & 0.018 \\
\hline 1 & 2684 & 300 & 0.017 \\
\hline 1 & 2754 & 311 & 0.017 \\
\hline 3 & 2276 & 586 & 0.039 \\
\hline 3 & 2297 & 608 & 0.040 \\
\hline 3 & 2243 & 618 & 0.042 \\
\hline 5 & 2303 & 901 & 0.059 \\
\hline 5 & 2272 & 889 & 0.059 \\
\hline 5 & 2354 & 900 & 0.058 \\
\hline 7 & 2918 & 1474 & 0.076 \\
\hline 7 & 2900 & 1463 & 0.076 \\
\hline 7 & 2943 & 1468 & 0.075 \\
\hline 10 & 2568 & 1665 & 0.098 \\
\hline 10 & 2577 & 1684 & 0.099 \\
\hline 10 & 2560 & 1643 & 0.097 \\
\hline 15 & 2247 & 1886 & 0.127 \\
\hline 15 & 2215 & 1828 & 0.124 \\
\hline 15 & 2243 & 1817 & 0.122 \\
\hline 20 & 2498 & 2551 & 0.154 \\
\hline 20 & 2576 & 2610 & 0.153 \\
\hline 20 & 2566 & 2642 & 0.155 \\
\hline 30 & 2816 & 3305 & 0.177 \\
\hline 30 & 2823 & 3306 & 0.177 \\
\hline 30 & 2827 & 3293 & 0.176 \\
\hline 40 & 2963 & 3769 & 0.192 \\
\hline 40 & 2959 & 3711 & 0.189 \\
\hline 40 & 2926 & 3710 & 0.191 \\
\hline 50 & 2922 & 3834 & 0.198 \\
\hline 50 & 2993 & 3881 & 0.196 \\
\hline 50 & 2993 & 3893 & 0.196 \\
\hline 65 & 2946 & 4003 & 0.205 \\
\hline 65 & 2912 & 3988 & 0.207 \\
\hline 65 & 2949 & 4030 & 0.206 \\
\hline
\end{tabular}




\section{Order in $\mathrm{K}^{+}(E)-1^{-}, 1.25$ equiv (with 1.0 equiv $\left.\mathrm{Pd}(\mathrm{dba})_{2}\right)$.}

$\mathrm{K}^{+}(E)-\mathbf{1}^{-}$

2-Iodothiophene

Bis(dibenzylideneacetone)palladium $25 \mathrm{mM}$ (1.0 equiv)
$31.25 \mathrm{mM}$ (1.25 equiv)

$25 \mathrm{mM}$ (1.0 equiv)

Following the General Procedure, biphenyl $(2.0 \mathrm{mg})$ and $\mathrm{Pd}(\mathrm{dba})_{2}(71.9 \mathrm{mg}, 0.125$ mmol) were dissolved in DME $(4.65 \mathrm{~mL})$ in a flame-dried, 2-neck round-bottomed flask, equipped with a stir bar and a septum under argon. The 2-iodothiophene (13.8 $\mu \mathrm{L}, 0.125 \mathrm{mmol})$ was then added and the reaction was stirred for $1 \mathrm{~min}$. To this mixture was then added $\mathrm{K}^{+}(E)-\mathbf{1}^{-}$ (337 $\mu \mathrm{L}, 0.464 \mathrm{M})$. The dark red solution slowly turned turbid over time as the precipitation of KI proceeded. Aliquots ( $200 \mu \mathrm{L})$ were withdrawn after 1, 3, 5, 7, 10, 15, 20, 30, 40, 50, and 65 min. To quench, these samples were added to $200 \mu \mathrm{L}$ of a $20 \%$ aqueous solution of 2 dimethylaminoethanethiol hydrochloride. The clear colorless to slightly-yellow solution was then filtered through a plug of silica gel, and the silica gel was washed with diethyl ether to give a total sample volume of $\sim 2 \mathrm{~mL}$. This sample was injected into the GC three times.

initial rate $=0.0109$

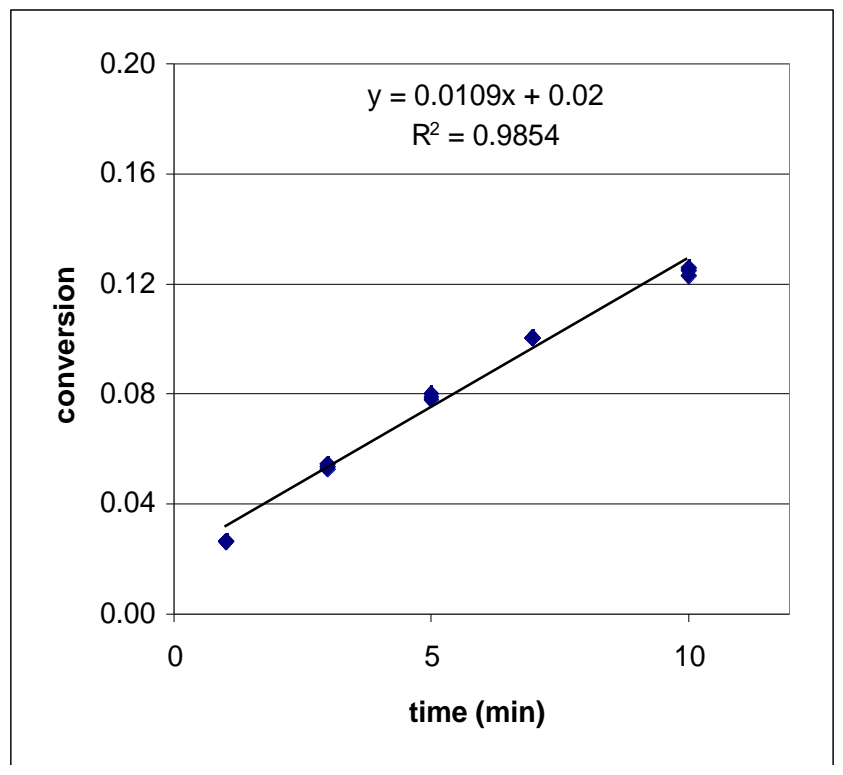




\begin{tabular}{|c|c|c|c|}
\hline Time & area $\mathrm{A}$ & area 2 & Conversion \\
\hline 1 & 2589 & 459 & 0.027 \\
\hline 1 & 2639 & 458 & 0.026 \\
\hline 1 & 2633 & 452 & 0.026 \\
\hline 3 & 1970 & 715 & 0.055 \\
\hline 3 & 1952 & 689 & 0.053 \\
\hline 3 & 1964 & 690 & 0.053 \\
\hline 5 & 2403 & 1260 & 0.079 \\
\hline 5 & 2421 & 1259 & 0.078 \\
\hline 5 & 2413 & 1280 & 0.080 \\
\hline 7 & 2440 & 1619 & 0.100 \\
\hline 7 & 2413 & 1601 & 0.100 \\
\hline 7 & 2428 & 1623 & 0.101 \\
\hline 10 & 2303 & 1915 & 0.125 \\
\hline 10 & 2301 & 1903 & 0.125 \\
\hline 10 & 2344 & 1904 & 0.123 \\
\hline 15 & 2423 & 2700 & 0.168 \\
\hline 15 & 2438 & 2740 & 0.170 \\
\hline 15 & 2521 & 2751 & 0.165 \\
\hline 20 & 2365 & 2960 & 0.189 \\
\hline 20 & 2292 & 2960 & 0.195 \\
\hline 20 & 2248 & 2878 & 0.193 \\
\hline 30 & 2407 & 3806 & 0.239 \\
\hline 30 & 2429 & 3817 & 0.237 \\
\hline 30 & 2370 & 3818 & 0.243 \\
\hline 40 & 2410 & 4227 & 0.265 \\
\hline 40 & 2391 & 4199 & 0.265 \\
\hline 40 & 2422 & 4230 & 0.263 \\
\hline 50 & 2350 & 4822 & 0.310 \\
\hline 50 & 2363 & 4799 & 0.306 \\
\hline 50 & 2357 & 4808 & 0.308 \\
\hline 65 & 2559 & 5921 & 0.349 \\
\hline 65 & 2557 & 5897 & 0.348 \\
\hline 65 & 2560 & 5881 & 0.347 \\
\hline
\end{tabular}




\section{Order in $\mathrm{K}^{+}(E)-1^{-}, 1.25$ equiv (with 1.0 equiv $\left.\mathrm{Pd}(\mathrm{dba})_{2}\right)$.}

$\mathrm{K}^{+}(E)-\mathbf{1}^{-}$

2-Iodothiophene

Bis(dibenzylideneacetone)palladium $25 \mathrm{mM}$ (1.0 equiv)
$31.25 \mathrm{mM}$ (1.25 equiv)

$25 \mathrm{mM}$ (1.0 equiv)

Following the General Procedure, biphenyl $(2.0 \mathrm{mg})$ and $\mathrm{Pd}(\mathrm{dba})_{2}(71.9 \mathrm{mg}, 0.125$ mmol) were dissolved in DME $(4.65 \mathrm{~mL})$ in a flame-dried, 2-neck round-bottomed flask, equipped with a stir bar and a septum under argon. The 2-iodothiophene (13.8 $\mu \mathrm{L}, 0.125 \mathrm{mmol})$ was then added and the reaction was stirred for $1 \mathrm{~min}$. To this mixture was then added $\mathrm{K}^{+}(E)-\mathbf{1}^{-}$ (337 $\mu \mathrm{L}, 0.464 \mathrm{M})$. The dark red solution slowly turned turbid over time as the precipitation of KI proceeded. Aliquots ( $200 \mu \mathrm{L})$ were withdrawn after 1, 3, 5, 7, 10, 15, 20, 30, 40, 50, and 65 min. To quench, these samples were added to $200 \mu \mathrm{L}$ of a $20 \%$ aqueous solution of 2 dimethylaminoethanethiol hydrochloride. The clear colorless to slightly-yellow solution was then filtered through a plug of silica gel, and the silica gel was washed with diethyl ether to give a total sample volume of $\sim 2 \mathrm{~mL}$. This sample was injected into the GC three times.

initial rate $=0.0118$

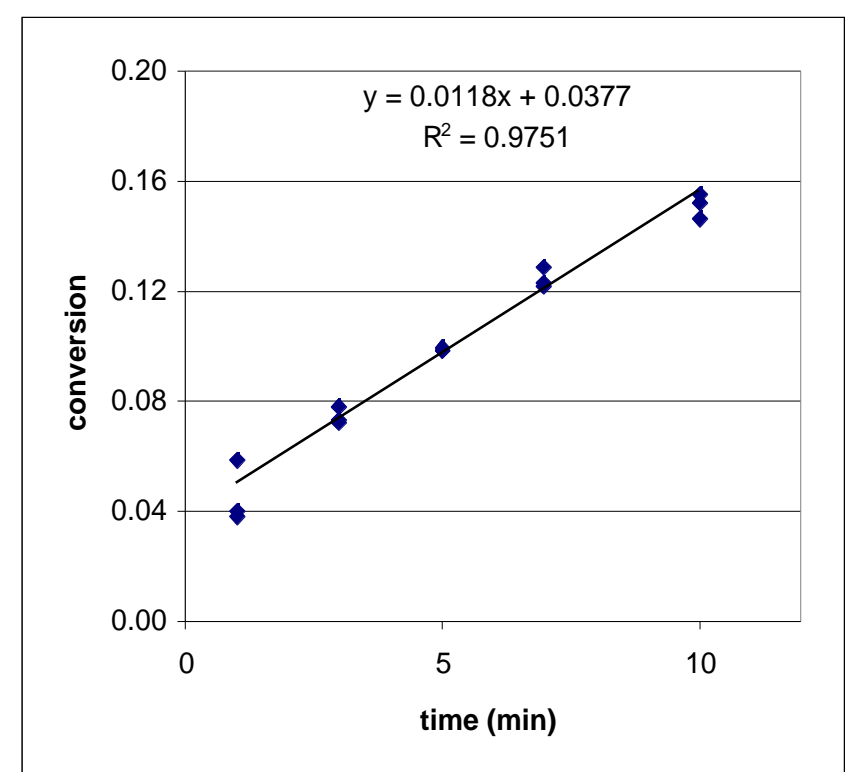




\begin{tabular}{|c|c|c|c|}
\hline Time & area $\mathrm{A}$ & area 2 & Conversion \\
\hline 1 & 431 & 108 & 0.038 \\
\hline 1 & 451 & 120 & 0.040 \\
\hline 1 & 436 & 170 & 0.059 \\
\hline 3 & 663 & 344 & 0.078 \\
\hline 3 & 682 & 328 & 0.073 \\
\hline 3 & 695 & 336 & 0.073 \\
\hline 5 & 522 & 342 & 0.099 \\
\hline 5 & 517 & 338 & 0.099 \\
\hline 5 & 538 & 356 & 0.100 \\
\hline 7 & 394 & 320 & 0.123 \\
\hline 7 & 423 & 360 & 0.128 \\
\hline 7 & 443 & 358 & 0.122 \\
\hline 10 & 537 & 522 & 0.147 \\
\hline 10 & 512 & 518 & 0.153 \\
\hline 10 & 511 & 526 & 0.155 \\
\hline 15 & 491 & 594 & 0.182 \\
\hline 15 & 492 & 588 & 0.180 \\
\hline 15 & 498 & 584 & 0.177 \\
\hline 20 & 575 & 778 & 0.204 \\
\hline 20 & 583 & 774 & 0.200 \\
\hline 20 & 549 & 766 & 0.210 \\
\hline 30 & 551 & 802 & 0.220 \\
\hline 30 & 532 & 762 & 0.216 \\
\hline 30 & 507 & 732 & 0.218 \\
\hline 40 & 623 & 960 & 0.232 \\
\hline 40 & 1186 & 1812 & 0.230 \\
\hline 40 & 618 & 948 & 0.231 \\
\hline 50 & 630 & 992 & 0.238 \\
\hline 50 & 537 & 844 & 0.237 \\
\hline 50 & 578 & 914 & 0.239 \\
\hline 65 & 445 & 737 & 0.250 \\
\hline 65 & 2059 & 3389 & 0.248 \\
\hline 65 & 2088 & 3422 & 0.247 \\
\hline
\end{tabular}




\section{Order in $\mathrm{K}^{+}(E)-1^{-}, 1.25$ equiv (with 1.0 equiv $\left.\mathrm{Pd}(\mathrm{dba})_{2}\right)$.}

$\mathrm{K}^{+}(E)-\mathbf{1}^{-}$

2-Iodothiophene

Bis(dibenzylideneacetone)palladium $25 \mathrm{mM}$ (1.0 equiv)
$31.25 \mathrm{mM}$ (1.25 equiv)

$25 \mathrm{mM}$ (1.0 equiv)

Following the General Procedure, biphenyl $(2.0 \mathrm{mg})$ and $\mathrm{Pd}(\mathrm{dba})_{2}(71.9 \mathrm{mg}, 0.125$ mmol) were dissolved in DME $(4.65 \mathrm{~mL})$ in a flame-dried, 2-neck round-bottomed flask, equipped with a stir bar and a septum under argon. The 2-iodothiophene (13.8 $\mu \mathrm{L}, 0.125 \mathrm{mmol})$ was then added and the reaction was stirred for $1 \mathrm{~min}$. To this mixture was then added $\mathrm{K}^{+}(E)-\mathbf{1}^{-}$ (337 $\mu \mathrm{L}, 0.464 \mathrm{M})$. The dark red solution slowly turned turbid over time as the precipitation of KI proceeded. Aliquots ( $200 \mu \mathrm{L})$ were withdrawn after 1, 3, 5, 7, 10, 15, 20, 30, 40, 50, and 65 min. To quench, these samples were added to $200 \mu \mathrm{L}$ of a $20 \%$ aqueous solution of 2 dimethylaminoethanethiol hydrochloride. The clear colorless to slightly-yellow solution was then filtered through a plug of silica gel, and the silica gel was washed with diethyl ether to give a total sample volume of $\sim 2 \mathrm{~mL}$. This sample was injected into the GC three times.

initial rate $=0.0104$

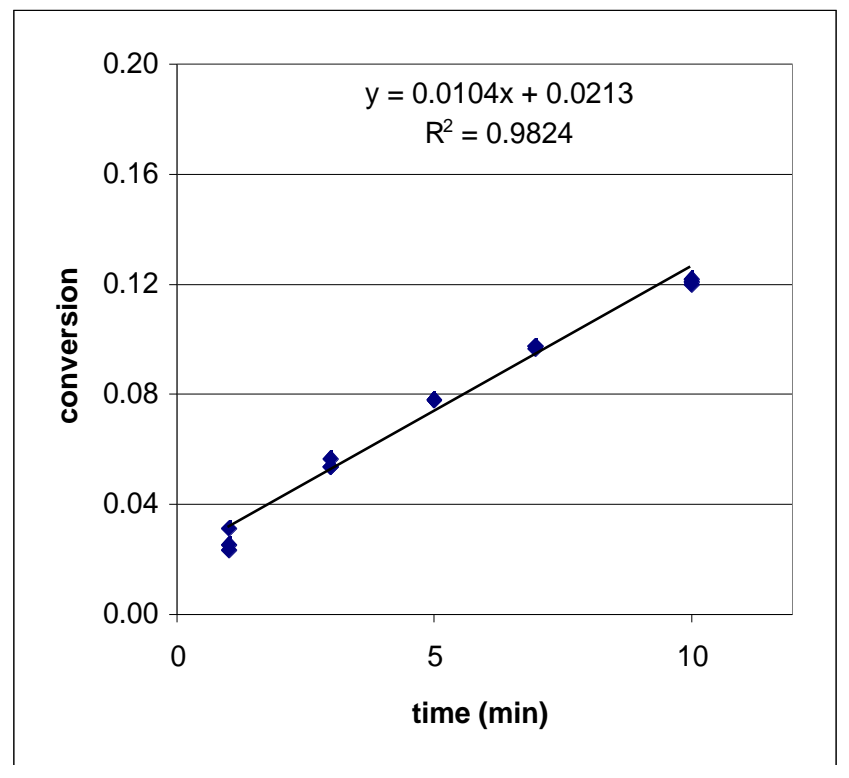




\begin{tabular}{|c|c|c|c|}
\hline Time & area $\mathrm{A}$ & area 2 & Conversion \\
\hline 1 & 327 & 50 & 0.023 \\
\hline 1 & 317 & 53 & 0.025 \\
\hline 1 & 323 & 66 & 0.031 \\
\hline 3 & 637 & 239 & 0.056 \\
\hline 3 & 3103 & 1105 & 0.054 \\
\hline 3 & 2977 & 1067 & 0.054 \\
\hline 5 & 784 & 404 & 0.078 \\
\hline 5 & 3189 & 1651 & 0.078 \\
\hline 5 & 815 & 420 & 0.078 \\
\hline 7 & 864 & 558 & 0.097 \\
\hline 7 & 875 & 565 & 0.097 \\
\hline 7 & 899 & 574 & 0.096 \\
\hline 10 & 821 & 662 & 0.122 \\
\hline 10 & 840 & 676 & 0.121 \\
\hline 10 & 831 & 660 & 0.120 \\
\hline 15 & 726 & 741 & 0.154 \\
\hline 15 & 754 & 737 & 0.147 \\
\hline 15 & 782 & 751 & 0.145 \\
\hline 20 & 576 & 622 & 0.163 \\
\hline 20 & 603 & 643 & 0.161 \\
\hline 20 & 590 & 640 & 0.164 \\
\hline 30 & 802 & 917 & 0.172 \\
\hline 30 & 808 & 937 & 0.175 \\
\hline 30 & 852 & 974 & 0.172 \\
\hline 40 & 852 & 1053 & 0.186 \\
\hline 40 & 827 & 1020 & 0.186 \\
\hline 40 & 848 & 1047 & 0.186 \\
\hline 50 & 747 & 963 & 0.194 \\
\hline 50 & 724 & 944 & 0.197 \\
\hline 50 & 725 & 949 & 0.197 \\
\hline 65 & 718 & 993 & 0.209 \\
\hline 65 & 704 & 955 & 0.205 \\
\hline 65 & 696 & 957 & 0.207 \\
\hline
\end{tabular}




\section{Effect of $\mathrm{K}^{+} \mathrm{I}^{-}$and $n-B \mathrm{u}_{4} \mathrm{~N}^{+} \mathrm{I}^{-}$Addition.}
$\mathrm{K}^{+}(E)-\mathbf{1}^{-}$
$50 \mathrm{mM}$ (1.0 equiv)
2-Iodothiophene
$50 \mathrm{mM}$ (1.0 equiv)
Bis(dibenzylideneacetone)palladium $2.5 \mathrm{mM}$ (0.05 equiv)
$\mathrm{KI}$ or $n-\mathrm{Bu}_{4} \mathrm{NI}$
$50 \mathrm{mM}$ (1.0 equiv)

Following the General Procedure, $\mathrm{K}^{+}(E)-\mathbf{1}^{-}(0.52 \mathrm{~mL}, 0.481 \mathrm{M})$ and biphenyl $(5.3 \mathrm{mg})$ were dissolved in DME (3.48 mL) in a flame-dried, 2-neck round-bottomed flask, equipped with a stir bar and a septum under argon. The 2-iodothiophene $(27.6 \mu \mathrm{L}, 0.25 \mathrm{mmol})$ was then added followed by either $\mathrm{KI}(41.5 \mathrm{mg}, 0.25 \mathrm{mmol})$ or $n-\mathrm{Bu}_{4} \mathrm{NI}(92.5 \mathrm{mg}, 0.25 \mathrm{mmol})$ and the reaction was stirred for $1 \mathrm{~min}$. A suspension of $\mathrm{Pd}(\mathrm{dba})_{2}(7.2 \mathrm{mg}, 0.0125 \mathrm{mmol})$ in dry THF $(1.0 \mathrm{~mL})$ was added. The dark red solution slowly turned turbid over time as the precipitation of KI proceeded. Aliquots $(\sim 200 \mu \mathrm{L})$ were withdrawn after $0.33,0.66,1.0,1.33,1.66,2.0,2.5,3.0,4$, 5,7 , and $10 \mathrm{~min}$. To quench, these samples were added to $100 \mu \mathrm{L}$ of a $20 \%$ aqueous solution of 2-dimethylaminoethanethiol hydrochloride. The clear colorless to slightly-yellow solution was then filtered through a plug of silica gel, and the silica gel was washed with diethyl ether to give a total sample volume of $\sim 2 \mathrm{~mL}$. This sample was injected into the GC three times.

\begin{tabular}{cc} 
standard & \\
\hline $\begin{array}{c}\text { time } \\
(\min )\end{array}$ & conversion \\
\hline 0.33 & 0.094 \\
0.66 & 0.134 \\
1 & 0.173 \\
1.33 & 0.192 \\
1.66 & 0.217 \\
2 & 0.238 \\
2.5 & 0.250 \\
3 & 0.270 \\
5 & 0.354 \\
10 & 0.441 \\
\hline
\end{tabular}

\begin{tabular}{cc}
\multicolumn{2}{c}{ with 1 equiv KI } \\
\hline $\begin{array}{c}\text { time } \\
\text { (min) }\end{array}$ & conversion \\
\hline 0.33 & 0.105 \\
0.66 & 0.150 \\
1 & 0.189 \\
1.33 & 0.217 \\
1.66 & 0.227 \\
2 & 0.250 \\
2.5 & 0.273 \\
3 & 0.295 \\
5 & 0.328 \\
10 & 0.420 \\
\hline
\end{tabular}

\begin{tabular}{cc}
\multicolumn{2}{c}{ with 1 equiv TBAI } \\
\hline $\begin{array}{c}\text { time } \\
(\mathrm{min})\end{array}$ & conversion \\
\hline 0.33 & 0.095 \\
0.66 & 0.135 \\
1 & 0.167 \\
1.33 & 0.188 \\
1.66 & 0.211 \\
2 & 0.243 \\
2.5 & 0.276 \\
3 & 0.301 \\
5 & 0.348 \\
10 & 0.428 \\
\hline
\end{tabular}




\section{References}

(1) Denmark, S. E.; Wehrli, D. Org. Lett. 2000, 2, 565.

(2) Ukai, T.; Kawazura, H.; Ishii, Y.; Bonnett, J. J.; Ibers, J. A. J. Organomet. Chem. 1974, 65, 253. 